\title{
Seismic Retrofit and Strengthening of Deficient Reinforced Concrete Shear Walls Using Externally Bonded Fibre Reinforced Polymer Sheets
}

\author{
By
}

\author{
Ibrahim Shaheen
}

A thesis submitted to the Faculty of Graduate and Postdoctoral Affairs in partial fulfillment of the requirements for the degree of

Master of Applied Science

Department of Civil and Environmental Engineering

Carleton University

Ottawa, Ontario, Canada

March 2014

C2014, Ibrahim Shaheen 


\begin{abstract}
Seismically deficient reinforced concrete structures are widely present in many regions of the world. Structural deficiencies commonly found in old reinforced concrete structures are poor confinement, poor detailing and the presence of non ductile details (lap splices) at the plastic hinge region. The adverse effects of these deficiencies often translate to poor seismic performance due to poor energy dissipation capabilities, poor ductility behaviour, and the association of these effects with brittle failure mechanisms.

The Seismic response of old deficient shear wall structures built in the 1960's and 1970's is investigated. The wall specimens investigated contain poor confinement, insufficient shear reinforcement, and lap splices of the longitudinal reinforcement located at the plastic hinge region. As a result of these deficiencies, the wall specimens have non-ductile response behaviour and require retrofit to enhance their seismic performance. Nine shear wall specimens with aspect ratio ranging from 0.65 to 1.20 subjected to quasi-static reverse cyclic loading are investigated as part of a comprehensive research program. Analytical simulations utilizing the finite element method are conducted to predict the response of the wall specimens. The use of carbon fibre reinforced polymers (CFRP) tow sheets in both the transverse and longitudinal directions to mitigate the structural deficiencies of the wall specimens is evaluated. Analytical results show that the numerical models can accurately predict the elastic and inelastic behaviour, peak load, maximum displacement, energy dissipation and the failure mechanisms of shear walls strengthened and repaired with FRP tow sheets. The fibre reinforced polymer material is effective in eliminating the brittle shear failure mode in walls with insufficient shear reinforcement.
\end{abstract}


Lap spliced reinforcing steel bars are used in older construction practises, and are present at potential plastic hinge regions of structural members in many old reinforced concrete structures in the world. The behaviour of these non ductile details is complex and is known to lead to poor seismic performance. There has been many experimental tests in previous studies but relatively few analytical studies have been conducted on the modelling of lap splice behaviour in reinforced concrete structures. While most of the existing research in structures with lap spliced reinforcing steel bars have focused on beams and columns, considerably less number of studies has are found in investigating structural shear wall elements. In this paper an analytical finite element model that can capture the behaviour of lap spliced reinforcing steel bars in seismically deficient reinforced concrete shear wall structures is presented. In the proposed analytical model, bond stress-slip models are used to model the bond behaviour between concrete and steel in reinforced concrete structural elements. The proposed models are correlated with experimental beam and shear wall test data obtained from the literature. Numerical results obtained from the analytical models show a good correlation with experimental data of both the load-displacement responses and observed overall failure behaviour. 


\section{Acknowledgements}

I would like to thank God for helping me in completing this research. Without him this research would not be possible. I would like to express my sincere gratitude to my supervisor Dr. David T. Lau for providing me with guidance, support, knowledge, wisdom and patience throughout the course of my study. The endless support and knowledge provided by Dr. David T. Lau motivated me to improve as a researcher and to pursue a higher academic learning experience. My sincere gratitude is also due to Dr. Carlos A. Cruz-Noguez for his patience, knowledge, and fruitful discussions on various topics regarding this research. Words alone cannot describe what I have learned from Dr. David T. Lau and Dr. Carlos A. Cruz-Noguez, and for that I am truly grateful. I would like to dedicate this Thesis to my dear father (Mr. Khalil Shaheen), my beloved

mother (Mrs. Wafaa Rizkallah) and to my dear brother and future aspiring Engineer (Mr. Karim Shaheen). Without their support and encouragement throughout this research, it truly wouldn't have been possible. 


\section{Table of Contents}

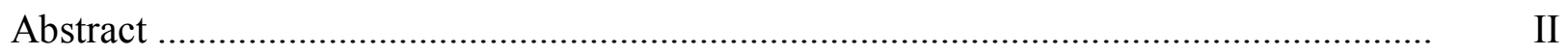

Acknowledgements ............................................................................................ IV

Table of Contents ....................................................................................................

List of Tables ............................................................................................... VII

List of Figures ................................................................................................... VIII

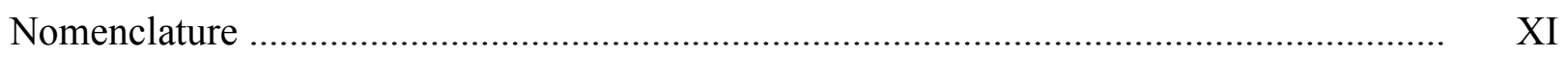

Chapter 1: Introduction .............................................................................................

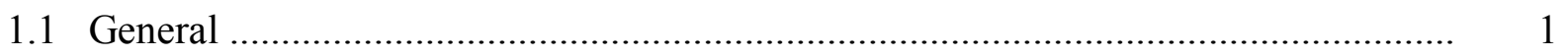

1.2 Layout of Thesis ..........................................................................................

Chapter 2: Shear Wall Design Methodology and Strength Calculations ............................... 4

Chapter 3: Modelling of Shear Walls ........................................................................ 13

3.1 Modelling Overview ................................................................................... 13

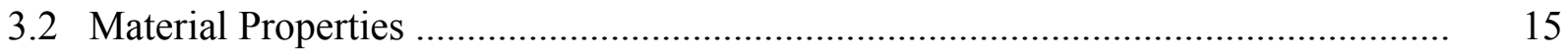

3.3 Finite Element Formulations ............................................................................. 16

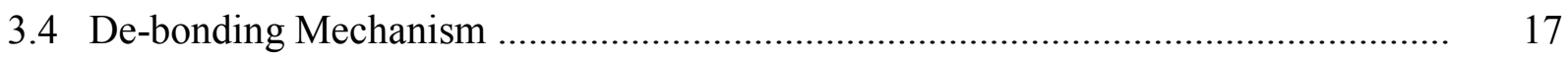

3.5 Lap Splice Modelling Background ……………............................................... 20

3.6 Lap Splice Behavioural Mechanisms ……………..................................................... 23

3.7 Lap Splice Modelling Methodology ………………….......................................... 25

Chapter 4: Analysis of Reinforced Concrete Structures ....................................................... 36

4.1 Modelling of Unconfined Reinforced Concrete Beams .............................................. 36

4.1.1 Modelling Approach and Material Properties ..................................................... 36

4.1.2 Material Models and Finite Element Simulations ……........................................... 37 
4.1.3 Finite Element Analysis and Discussion of Results .................................... 38

4.2 Modelling of Unconfined Reinforced Concrete Shear Wall I ................................ 39

4.2.1 Material and Element Formulations ........................................................... 39

4.2.2 Finite Element Analysis and Discussion of Results .................................... 40

4.3 Modelling of Unconfined Reinforced Concrete Shear Wall II ................................ 41

4.3.1 Finite Element Analysis and Discussion of Results ...................................... 42

Chapter 5: Analysis of Seismically Deficient Reinforced Concrete Shear Walls ................ 48

5.1 Finite Element Results and Discussions of Seismically Deficient Walls ................... 48

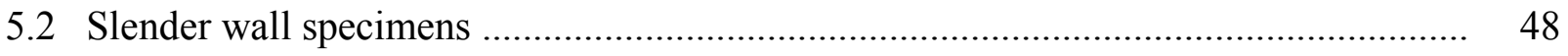

5.3 Intermediate wall specimens ................................................................... 49

5.4 Squat wall specimens without Lap Splices .................................................. 50

5.5 Squat wall specimens with Lap Splices ...................................................... 51

5.6 Ductility and Drift Ratio ................................................................... 53

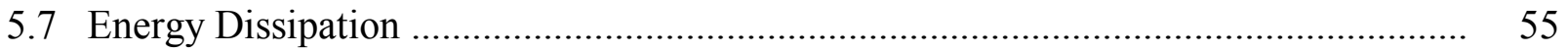

5.8 Comparison with experimental results ........................................................ 57

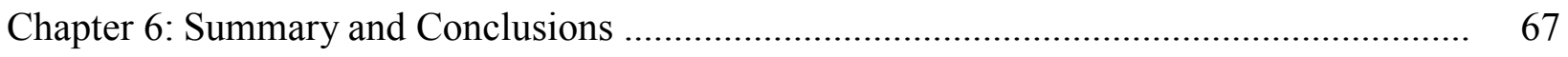

6.1 Conclusions and Recommendations ............................................................... 67

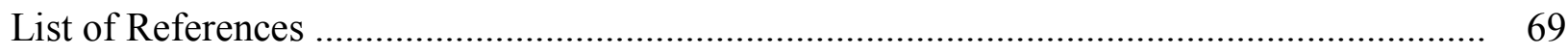




\section{List of Tables}

Table 2.1: Repair/Strengthening Scheme …………….............................................. 10

Table 4.1: Reinforcement Properties in Various Concrete Regions .................................. 43

Table 4.2: Reinforcement Properties in Various Concrete Regions .................................. 43

Table 4.3: Reinforcement Properties in Various Concrete Regions ................................ 44

Table 5.1: Finite element analysis results for Control vs. Strengthened with FRP .......... $\quad 60$

Table 5.2: Finite element analysis results for Control vs. Repair with FRP ...................... 61

Table 5.3: Comparison between FRP reinforced/unreinforced specimens ....................... 61

Table 5.4: Drift Ratio and Ductility ............................................................ 61

Table 5.5: Experimental Slender Wall Results ................................................................ 61 


\section{List of Figures}

Figure 2.1: Comparison of shear and flexure computations ............................... 10

Figure 2.2: Wall specimen detailing .................................................................. 11

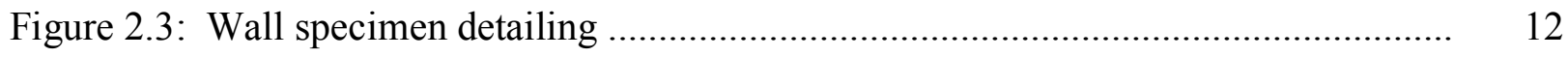

Figure 3.1: Finite element model of slender FRP wall and components ......................... 32

Figure 3.2: Harajli bond stress-slip relationship (Harajli et al. 2004) used to model lap spliced

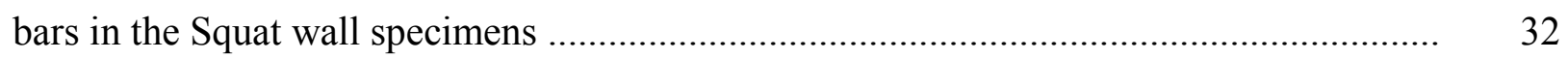

Figure 3.3: Bond stress-slip relationships derived from meso-scale finite element models

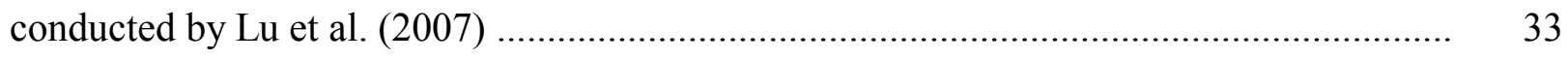

Figure 3.4: Tri-linear approximation of Bond-Slip Model I ( $\mathrm{Lu}$ et al. 2005) ..................... 33

Figure 3.5: Schematic of lap splice behaviour and bond stresses zones ......................... 34

Figure 3.6: Bond stresses generated on a deformed bar (ACI 408R-03) ........................ 34

Figure 3.7: Lap splice behavioural mechanisms ................................................... 35

Figure 3.8: Local bond stress-slip relationship for different concrete confinement criteria (Harajli

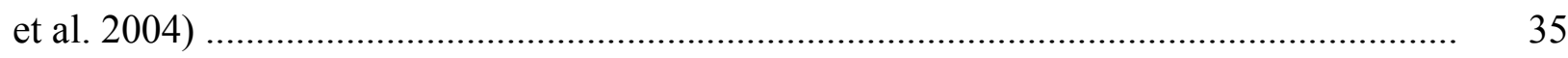

Figure 4.1: Beam specimen specifications (Harajli 2006) .......................................... 44

Figure 4.2: Finite element model of beam specimen ................................................

Figure 4.3: Bond stress-slip relationship for lap spliced bars in beam specimen ................ 45

Figure 4.4: Hysteretic curve comparison of analytical modelling with original beam specimen B25 (Harajli 2006) and associated failure mode ....................................................... 45

Figure 4.5: W1 wall specimen details and lap splice locations (Paterson and Mitchell 2003) 
Figure 4.6: Bond stress-slip curves for lap spliced bars in the Paterson and Mitchell (2003) wall

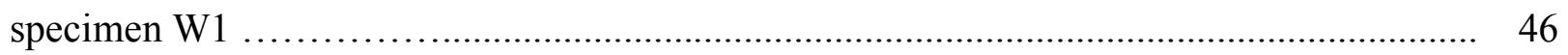

Figure 4.7: Finite element model of wall specimen $\mathrm{W} 1$........................................... 46

Figure 4.8: Hysteresis curve of wall specimen W1 along with failure modes and original failure mode from experiment (Paterson and Mitchell 2003) 46

Figure 4.9: W1 and W2 wall specimen details and lap splice locations (Layssi and Mitchell 2012) 47

Figure 4.10: Bond stress-slip curves for lap spliced bars in the W1 and W2 wall specimens in the Layssi and Mitchell (2012) study 47

Figure 4.11: Hysteresis plots for both W1 and W2 specimens .................................... 47

Figure 5.1: Hysteresis curve for slender wall specimen (scenario (a)) ............................... 62

Figure 5.2: Hysteresis curve for slender wall specimen (scenario (b)) ............................. 62

Figure 5.3: Hysteresis curve for intermediate wall specimen (scenario (a)) ....................... 62

Figure 5.4: Hysteresis curve for intermediate wall specimen (scenario (b)) ....................... 63

Figure 5.5: Hysteresis curve for squat wall specimen (scenario (a)) .............................. 63

Figure 5.6: Hysteresis curve for squat wall specimen (scenario (b)) .................................. 63

Figure 5.7: Hysteresis curve for squat wall specimen with $36 \mathrm{~d}_{\mathrm{b}}$ lap splice length (scenario (a))

Figure 5.8: Hysteresis curve for squat wall specimen with $36 \mathrm{~d}_{\mathrm{b}}$ lap splice length (scenario (b))

Figure 5.9: Hysteresis curve for squat wall specimen with $21 \mathrm{~d}_{\mathrm{b}}$ lap splice length (scenario (a)) 
Figure 5.10: Hysteresis curve for squat wall specimen with $21 \mathrm{~d}_{\mathrm{b}}$ lap splice length (scenario (b))

Figure 5.11: Energy dissipation curves for (Slender, Intermediate and Squat wall specimens) with and without FRP

Figure 5.12: Comparison between analytical and experimental control slender wall specimens

Figure 5.13: Comparison between analytical and experimental strengthened slender wall specimens 66

Figure 5.14: Comparison between analytical and experimental repaired slender wall specimens 


\section{Nomenclature}

$A_{e} \quad$ Effective area

$A_{h} \quad$ Area of one leg of transverse reinforcement

$A_{s} \quad$ Area of longitudinal reinforcement

$A_{v} \quad$ Area of horizontal shear reinforcement

$A_{w} \quad$ Gross area of the web section

$A_{t r} \quad$ Area of transverse reinforcement in Harajli model computation

$b_{c} \quad$ Width of concrete member in IC de-bonding computation

$b_{f} \quad$ Width of FRP plate in IC de-bonding computation

c Cohesion parameter

$c_{0} \quad$ Clear distance between bar ribs of the reinforcing bar

C Concrete cover

d Effective depth

$D^{\prime} \quad$ Effective depth

$d_{b} \quad$ Bar diameter

$E_{S} \quad$ Steel modulus of elasticity

$E_{s h} \quad$ Strain hardening modulus of elasticity

$E_{F R P} \quad$ Elastic tensile modulus of carbon fibre sheets

$\varepsilon_{y} \quad$ Yielding strain of steel reinforcement

$\varepsilon_{u} \quad$ Ultimate strain of steel reinforcement

$\varepsilon_{s} \quad$ Steel reinforcement strain

$\varepsilon_{\text {sh }} \quad$ Strain hardening strain of steel reinforcement 
$f_{c}^{\prime} \quad$ Compressive strength of concrete

$f_{F R P U}$ Ultimate strength of FRP sheets

$F_{S} \quad$ Steel reinforcement stress

$f_{t} \quad$ Tensile strength of concrete

$f_{y} \quad$ Yield stress of vertical reinforcement

$f_{y h} \quad$ Yield stress of horizontal web reinforcement

$f_{u} \quad$ Ultimate strength of steel reinforcement

$G_{f} \quad$ Interfacial fracture energy between FRP plate and concrete substrate

$h_{w} \quad$ Height of wall specimen

$K_{c} \quad$ Concrete confinement parameter used in Harajli model computation

$K_{c s} \quad$ Concrete confinement parameter used in Harajli model computation

$L_{s} \quad$ Lap splice length

$l_{w} \quad$ Length of wall specimen

$M_{u} \quad$ Ultimate bending moment

$N_{u} \quad$ Ultimate axial force

$n \quad$ Number of reinforcement bars per layer

$n_{s} \quad$ Number of spliced bars

$\rho_{h} \quad$ Horizontal web reinforcement ratio

$\rho_{l} \quad$ Longitudinal reinforcement ratio

$S \quad$ Spacing of transverse reinforcement

$s \quad$ Bond slip

$S_{0} \quad$ Confinement factor based in Harajli model computation

$s_{0} \quad$ Allowable slip limit before initiation of IC de-bonding 
$S_{1} \quad$ Parameter related to the rib pattern of reinforcement bar

$S_{s p} \quad$ Splitting failure slip

$s_{t} \quad$ Spacing of transverse reinforcement in Harajli model computation

$t_{F R P} \quad$ Thickness of the dry carbon fibre tow-sheets

$t_{w} \quad$ Thickness of the wall specimen

$\tau \quad$ Bond stress

$\tau_{\max }$ Maximum shear bond stress

$u \quad$ Local bond stress

$u_{m} \quad$ Maximum bond strength reached for a fully confined specimen

$u_{s p} \quad$ Maximum splitting bond strength

$u_{p} \quad$ Post splitting bond strength

$\mu \quad$ Friction parameter

$V_{c}, V_{c 1}, V_{c 2} \quad$ Concrete contribution to shear capacity

$v_{c} \quad$ Concrete shear stress

$V_{r 1}, V_{r 2}, V_{r 3}, V_{r 4} \quad$ Diagonal shear strength

$V_{S} \quad$ Steel reinforcement contribution to shear capacity

$V_{s l} \quad$ Sliding shear strength

$V \quad$ Ultimate shear strength

$\alpha \quad$ Force reduction factor used in Harajli model computation

$\alpha \quad$ Factor which controls descending branch after IC de-bonding

$\alpha_{c} \quad$ Empirical factor which is a function of the wall aspect ratio

$\beta_{w} \quad$ FRP to concrete width modification factor

$\beta \quad$ Force reduction factor used in Harajli model computation

$\theta \quad$ Angle of the critical inclined shear/flexural crack to the member longitudinal axis 


\section{Chapter 1}

\section{Introduction}

\subsection{General}

Many structures constructed in seismically active regions incorporate shear wall elements to resist lateral loads. Although recent design code advancements (ACI 318-08, CSA A23.3 04) have led to improvement in the design of shear wall structures from the basic strength design approach to the incorporation of design requirements for both strength and ductility, there are still a large number of old shear wall structures at risk of suffering damage during earthquakes. This is generally attributed to two broad reasons. First, the seismic hazards in many parts of Canada as well as in other parts of the world have increased due to more extensive earthquake information and data accumulated over the past decades and better seismic hazard modelling techniques. Thus, the seismic demands in current design standards for earthquake resistant design of structures have been significantly increased over the years. Consequently, old structures designed using obsolete design codes decades ago are often found not to have sufficient seismic resisting capacities to withstand demands from the design earthquakes required in current design standards. The second reason for the poor seismic performance of older structures is that many old structures have inadequate design detailing, which includes inadequate shear design, insufficient concrete confinement, and lap splice of reinforcing bars at moment critical locations of structural members. In order to improve the performance of existing reinforced concrete shear wall structures with these design deficiencies to better withstand seismic events, techniques to retrofit and strengthen old deficient reinforced concrete shear wall 
structures are needed. Conventional retrofit and rehabilitation techniques include: (a) the addition of shear walls or bracings to increase lateral load resisting stiffness and capacity, (b) the use of special devices, such as headed bars or addition of concrete collars to strengthen lap splice regions. Although these techniques are effective in improving the seismic response of deficient shear wall structures, they are labour intensive and can be quite disruptive to the occupants and the functioning of the facilities. They may also alter the distribution of lateral loads on the building by adding more weight to the structure (Lombard et al. 2000). An effective minimally disruptive alternative approach for repair and strengthening of reinforced concrete structural members is the use of externally bonded fibre reinforced polymer (FRP) tow sheets. In recent years, the use of FRP advanced composite materials in structural design has gained increasing acceptance as an alternative form of reinforcement to conventional steel reinforcement in design of reinforced concrete structures because of its advantage of high strength to weight ratio, resistance to corrosion, and its ease of handling (Meier et al. 1992). Of previous research reported in the literature, most studies on seismic retrofit of reinforced concrete shear walls focus on increasing the shear strength and energy dissipation capabilities (Antoniades et al. 2003; Paterson and Mitchell 2003; Khalil and Ghobarah 2005; Elnady 2008; Layssi and Mitchell 2012). Relative few studies investigate the increase in flexural strength in addition to the effect of the addition of FRP reinforcement on shear strength and energy dissipation (Lombard et al. 1999; Hiotakis 2004; Shaheen et al. 2013). In this study the effectiveness of using transverse and longitudinal externally bonded carbon fibre reinforced polymer (CFRP) sheets is evaluated in the repair and strengthening of shear wall specimens detailed to old code provisions (ACI 1968, CSA 1977). Finite element simulations are conducted to evaluate the seismic response behaviour 
of the wall specimens, including examination of the ultimate strength and failure mode mechanism of the analyzed walls. The increases in stiffness, strength, and ultimate displacement capacities are presented. The experimental setup for testing of the wall specimens is briefly discussed. The primary focus of the study here is on the analytical modelling of the wall specimens by the finite element method and the prediction of the seismic response of the wall specimens.

\subsection{Layout of Thesis}

This thesis is presented in six chapters. The first chapter is the introductory chapter to the thesis and states the primary objectives and scope of the study. Chapter 2 addresses the shear strength

design calculations and comparison of various shear strength determination methods, flexural strength and sliding shear strength. Chapter 3 discusses the modelling of seismically deficient shear wall specimens, the intermediate crack de-bonding mechanism between the FRP plate and the concrete substrate, and the modelling methodology to capture the behaviour of lap spliced reinforcing bars present at potential plastic hinge regions in reinforced concrete shear wall specimens. Chapter 4 presents analytical simulations and results of an unconfined beam specimen with lap splices at mid-span tested by Harajli (2006) to validate the lap splice bond stress-slip relationship used for modelling lap spliced bars in shear wall specimens, along with the application of the lap splice model in analysis of shear wall specimens tested by Paterson and Mitchell (2003) and Layssi and Mitchell (2012). Chapter 5 presents the analytical results and discussion of the seismically deficient shear walls. Chapter 6 presents a summary of the findings and conclusions of the study. 


\section{Chapter 2}

\section{Shear Wall Design Methodology and Strength Calculations}

The determination of the flexural and shear strength of the walls with no FRP reinforcement, and the strength against sliding shear failure by the design code provisions is presented in this section. Currently, one approach for the design of structural wall elements against sliding shear failure is based on the design provisions of CSA A23.3-04. The objective of the design approach is to ensure the sliding shear capacity exceeds the flexural capacity of the wall, which may be determined by conventional section analysis. To calculate the strength against diagonal tension failure $V_{r}$ in plain reinforced concrete walls with no FRP reinforcement, four different approaches can be followed. The first approach is the semi-empirical equation for seismic design of shear walls by ACI 318-05 as given in Equation [1], which is based on the modified truss analogy approach.

$[1] V_{r 1}=\left(\alpha_{c} \sqrt{f_{c}^{\prime}}+\rho_{h} f_{y h}\right) A_{w} \leq 0.83 \sqrt{f_{c}^{\prime}} A_{w}$

where $f_{c}^{\prime}$ is the compressive strength of the concrete, $\rho_{h}$ is the horizontal web reinforcement ratio, and $f_{y h}$ is the yield stress of the horizontal web reinforcement, $A_{w}$ is the gross area of the web section of the wall bounded by the web thickness and length of the section in the direction of shear force considered. In Equation [1], $\alpha_{c}$ is an empirical factor that is a function of the wall aspect ratio, which accounts for the contribution of concrete strength to the nominal shear strength of a wall. The parameter $\alpha_{c}$ is taken as 0.25 for walls with an aspect ratio of height over

length $\frac{h_{w}}{l_{w}}<1.5$ in this study. In Equation [1], the term $0.83 \sqrt{f_{c}^{\prime}}(\mathrm{MPa})$ is a limit intended to 
prevent diagonal compression failure. If $V_{r 1}$ in Equation [1] is larger than the diagonal compression failure limit, then the diagonal compression failure limit is taken as $V_{r 1}$. This limit in the calculation of shear strength of wall elements is considered to recognize the shear strength of low-rise walls with high shear to moment ratio is likely governed by diagonal compression failure instead of diagonal tension failure. It is typically considered low rise walls are wall elements with an aspect ratio less than 2 . The second method adopted in this study to calculate the shear strength of walls against diagonal tension failure is a semi-empirical equation based on the general design method of the modified truss analogy approach. In this approach, the shear wall strength against diagonal tension failure is calculated from separate expressions of contributions from steel and concrete. The contribution from the concrete is taken as the lesser of Equations [2] and [3] presented as follows. The differences in the computation of Equations [2] and [3] arise from different cracking conditions of the concrete, and the minimum of the results from the two equations is taken to be the concrete contribution.

[2] $V_{c 1}=\left(0.27\left(\sqrt{f_{c}^{\prime}}\right) t_{w} d\right)+\frac{N_{u} d}{4 l_{w}}$

where $t_{w}$ is the thickness of the section, $\mathrm{d}$ is the distance from the extreme compression fibre to the centroid of longitudinal tension reinforcement. For the wall specimens in this study, it is determined to be equal to $0.46 l_{w}$ for the slender wall, $0.54 l_{w}$ for the intermediate wall and $0.5 l_{w}$ for the squat wall specimen, where $l_{w}$ is the overall length of the wall. In design purposes the value of $d$ is taken to be equal to $0.8 l_{w}$ as a conservative assumption as indicated by the code specifications. The factored axial force $N_{u}$ in the equation is taken as negative in tension and positive in compression. 
$[3] V_{c 2}=\left(0.05\left(\sqrt{f_{c}^{\prime}}\right)+\frac{l_{w}\left(0.1 \sqrt{f_{c}^{\prime}}+0.2 \frac{N_{u}}{l_{w} t_{w}}\right)}{\frac{M_{u}}{V_{u}}-\frac{-}{2}}\left(t_{w} d\right)\right.$

where $\mathrm{M}_{\mathrm{u}}$ is the factored moment at the section, and $V_{u}$ is the factored shear force at the section, and the collective term $\left(\frac{M_{u}}{V_{u}}-\frac{l_{w}}{2}\right)$ must not be negative. If the term is negative, then Equation [3] is not to be used and the concrete contribution to the wall strength is determined by Equation [2]. The contribution from the steel reinforcement is computed by Equation [4] as follows.

$[4] V_{s}=\frac{A_{v} f_{y h} d}{S}$

where $A_{v}$ is the area of horizontal shear reinforcement within the spacing $S$. The diagonal shear capacity is computed by summing up the contributions obtained from both the concrete and steel reinforcement as shown in Equation [5].

$[5] V_{r 2}=\operatorname{Min}\left(V_{c 1}, V_{c 2}\right)+V_{s}$

The third approach in determining the diagonal shear strength is by the method proposed by Wiradinata (1985) which takes into account the increase in shear capacity due to a reduction in the aspect ratio of the wall. In this method, the diagonal tension shear strength is obtained from the contributions of both the diagonal concrete struts $V_{c}$ and the transverse shear reinforcement $V_{s}$, given in Equation [6] and Equation [7], respectively.

$[6] V_{c}=\left(0.5-\frac{h_{w}}{6 l_{w}}\right) A_{e} \sqrt{f_{c}^{\prime}}$

where $A_{e}$ is the effective area of the wall (taken to be $90 \%$ of the cross-sectional wall area), and $f_{c}^{\prime}$ is the 28 day compressive strength of concrete. 
The ratio $\left(\frac{h_{w}}{l_{w}}\right)$ is the ratio of the height to length of the wall specimen. As for the contribution from the transverse steel reinforcement, the contribution is given by Equation [7].

[7] $V_{s}=\left(\frac{n A_{h} f_{y h} D^{\prime}}{S}\right) \cot \theta$

where $A_{h}$ is the area of one leg of transverse reinforcement, the number $n$ denotes the number of reinforcing bars per layer, and $S$ is the spacing between the transverse reinforcing bars. The angle $\theta$ of the critical inclined flexural/shear crack with the longitudinal axis of the wall is taken to be equal to $45^{\circ}$ as suggested by Wiradinata (1985), as a conservative assumption of the failure plane. The effective depth $D^{\prime}$ of the wall is taken to be equal to the values listed previously for each of the wall specimens in Equation [2]. The nominal diagonal shear strength is given by Equation [8].

[8] $V_{r 3}=V_{c}+V_{s} \leq 0.83 \sqrt{f_{c}^{\prime}} A_{w} \leq V_{s l}$

Similar to Equation [1], the nominal shear strength from the contributions of concrete struts and transverse reinforcement given in Equation [8] is also limited at the upper bound, instead of the yielding of the steel reinforcing bars in a diagonal tension failure, by the diagonal compression failure of crushing of the concrete struts. As noted in Equation [8], the shear wall specimens are also designed to prevent sliding shear failure as the nominal shear strength from the concrete and steel contributions is less than the sliding shear strength $V_{s l}$ of the wall. Sliding shear failure is a direct shear transfer failure due to opening of cracks in unfavourable areas of the wall specimen, usually at the base which weakens the horizontal plane to an extent that the plane starts to slip after the concrete crushes. The sliding shear strength $V_{s l}$ is calculated in accordance to CSA A23.3-04 design specification. 
It is assumed that crack occurs along the shear plane of the element. The relative displacement is resisted by cohesion, aggregate interlock and friction of concrete and the dowel action of the steel reinforcement across the crack plane. The sliding shear resistance at a plane is computed according to Equations [9] and [10].

[9] $V_{s l}=\left(c+\mu\left(\frac{A_{s} f_{y}}{t_{w} d}+\frac{N_{u}}{t_{w} l_{w}}\right) A_{w}\right.$

where $c$ and $\mu$ are the cohesion and friction parameters taken as $c=0.5 \mathrm{MPa}$ and $\mu=1.00, f_{y}$ is the yield stress of the vertical reinforcement, and $A_{s}$ is the area of longitudinal reinforcement. An upper limit of the sliding shear strength computation is given by Equation [10] and the lesser of the two values given by Equations [9] and [10] is taken as the sliding shear strength of the wall. $[10] V_{s l}=0.25 f_{c}^{\prime} A_{w}$

For comparison, a fourth approach in determining the diagonal shear strength considered in this study is the ultimate strength design methodology implemented in ACI 318-1968 design standard. The diagonal shear strength determined according to the ACI 318-1968 code follows the general method of combining contribution from the concrete and the stirrups to resist the ultimate shear force imposed on the section. The concrete contribution is first determined by calculating the concrete shear stress $\left(v_{c}\right)$ given in Equation [11], and then computing the concrete shear force by Equation [12]. The contribution from the stirrups is given previously in Equation [4]. The diagonal shear capacity $V_{r 4}$ is computed by summing up the shear force contributions obtained from both the concrete and steel reinforcement as shown in Equation [5]. $[11] v_{c}=\left(0.93 \sqrt{f_{c}^{\prime}}+176 \frac{\rho_{l} V_{u} d}{M_{u}}\right)$

where $\rho_{l}$ is the longitudinal reinforcement ratio, and $v_{c}$ is the shear stress associated with the 
concrete section. The other factors of Equation [11] are previously defined.

$[12] V_{c}=\left(v_{c}\right)\left(t_{w} \mathrm{~d}\right)$

The use of externally bonded CFRP sheets in repair/strengthening applications for reinforced concrete shear walls with structural deficiencies typical of older construction are currently being investigated in a comprehensive study at Carleton University. Nine deficient shear wall specimens are tested under quasi-static reverse cyclic loading up to failure. The wall specimens are classified based on their aspect ratio. These include two slender wall specimens with an aspect ratio of 1.20 , three intermediate walls with an aspect ratio of 0.85 , and four squat wall specimens, two of which include lap splices of lap splice length $36 d_{b}$ and $21 d_{b}$ at the plastic hinge location of the walls. The other two squat wall specimens do not have lap splice. The aspect ratio of the four squat wall specimens is 0.65 . It is noted that the wall specimens labelled under the slender wall category do not imply that these walls are expected to behave in a flexural dominated manner. In accordance to common design practice such as CSA A23.3-04 design standard, a shear wall component with an aspect ratio $\frac{h_{w}}{l_{w}}<2$ is expected to resist lateral load predominantly by shear mechanisms. Therefore the labelling of the "slender" wall specimens in this study here is only for classification purposes to distinguish them from the other two categories of "intermediate" and "squat" wall specimens. All wall specimens have a longitudinal reinforcement ratio of $3 \%$ and a transverse reinforcement ratio of $0.25 \%$ prior to repair or strengthening. The wall specimens are expected to have brittle shear failure response before their ultimate flexural capacity is reached. A comparison between the different diagonal shear determination methods in determining the flexure and sliding shear of the wall specimens are shown in Figure 2.1. In the experimental program, the wall specimens are first tested in their 
control state. Control state denotes the as-built state of the wall specimens. Externally bonded CFRP sheets directed in both vertical and horizontal directions are used to repair the damaged control wall before retesting to evaluate the effectiveness of the FRP repair scheme. In other specimens, CFRP sheets are used in strengthening applications to increase the resistant capacities of the wall specimens. The CFRP retrofitting scheme adopted here aims to promote a more ductile flexural behaviour and prevent the walls from a premature brittle shear failure. In this study, the fibre reinforced polymer tow sheets are also used to enhance the confinement effect of the wall specimens. The repair/strengthening scheme is summarized in Table 2.1. The detailing of the wall specimens are shown in Figures 2.2 and 2.3.

Table 2.1: Repair/Strengthening Scheme

\begin{tabular}{ccccc}
\hline Wall Type & $\begin{array}{c}\text { Aspect } \\
\text { Ratio } \\
\left(\mathrm{A}_{s}\right)\end{array}$ & $\begin{array}{c}\text { Vertical } \\
\text { sheets }\end{array}$ & $\begin{array}{c}\text { Horizontal } \\
\text { sheets }^{*}\end{array}$ & $\begin{array}{c}\text { Total sheets } \\
\text { per side }\end{array}$ \\
\hline Slender wall & 1.2 & $1 \mathrm{~V}$ & $3 \mathrm{H}$ & $1 \mathrm{~V}+3 \mathrm{H}$ \\
\hline Slender wall & 1.2 & $1 \mathrm{~V}$ & $3 \mathrm{H}$ & $1 \mathrm{~V}+3 \mathrm{H}$ \\
\hline Intermediate wall & 0.85 & $1 \mathrm{~V}$ & $3 \mathrm{H}$ & $1 \mathrm{~V}+3 \mathrm{H}$ \\
\hline Intermediate wall & 0.85 & $1 \mathrm{~V}$ & $3 \mathrm{H}$ & $1 \mathrm{~V}+3 \mathrm{H}$ \\
\hline Intermediate wall & 0.85 & $1 \mathrm{~V}$ & $3 \mathrm{H}$ & $1 \mathrm{~V}+3 \mathrm{H}$ \\
\hline Squat wall & 0.65 & - & $4 \mathrm{H}$ & $4 \mathrm{H}$ \\
\hline Squat wall & 0.65 & - & $4 \mathrm{H}$ & $4 \mathrm{H}$ \\
\hline Squat wall-36 db lap splice & 0.65 & - & $4 \mathrm{H}$ & $4 \mathrm{H}$ \\
\hline
\end{tabular}

${ }^{*} \mathrm{nV}=$ wall reinforced with $\mathrm{n}$ number of layers in the vertical direction per one side of the wall specimen. ${ }^{*} \mathrm{nH}=$ wall reinforced with $\mathrm{n}$ number of layers in the horizontal direction per one side of the wall specimen.

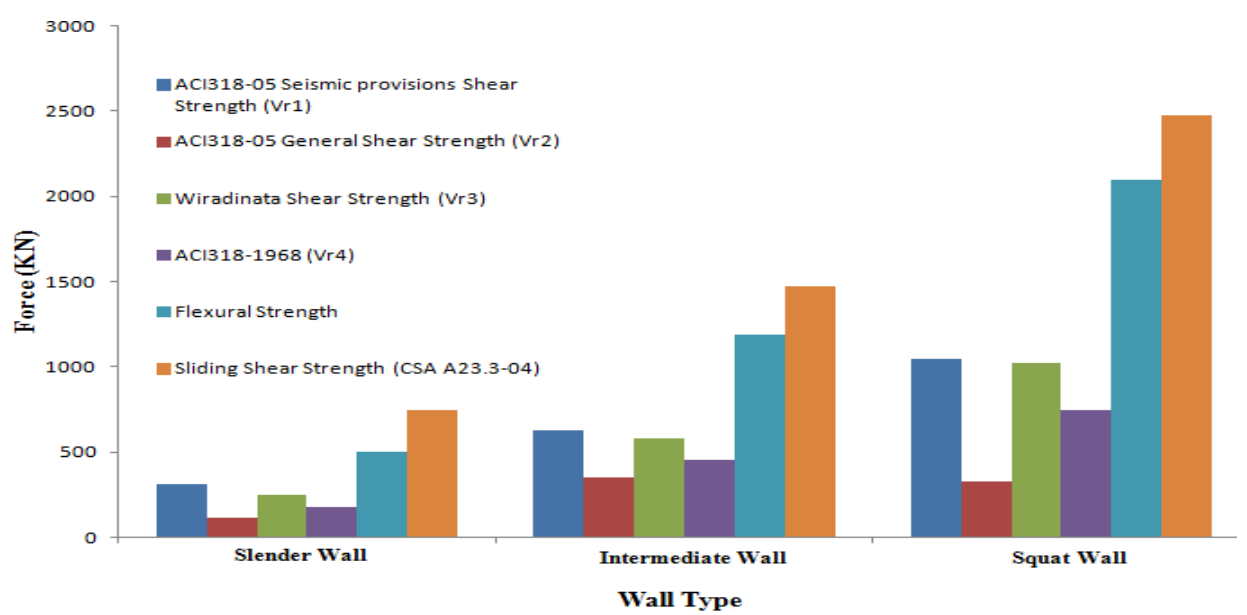

Figure 2.1: Comparison of shear and flexure computations. 

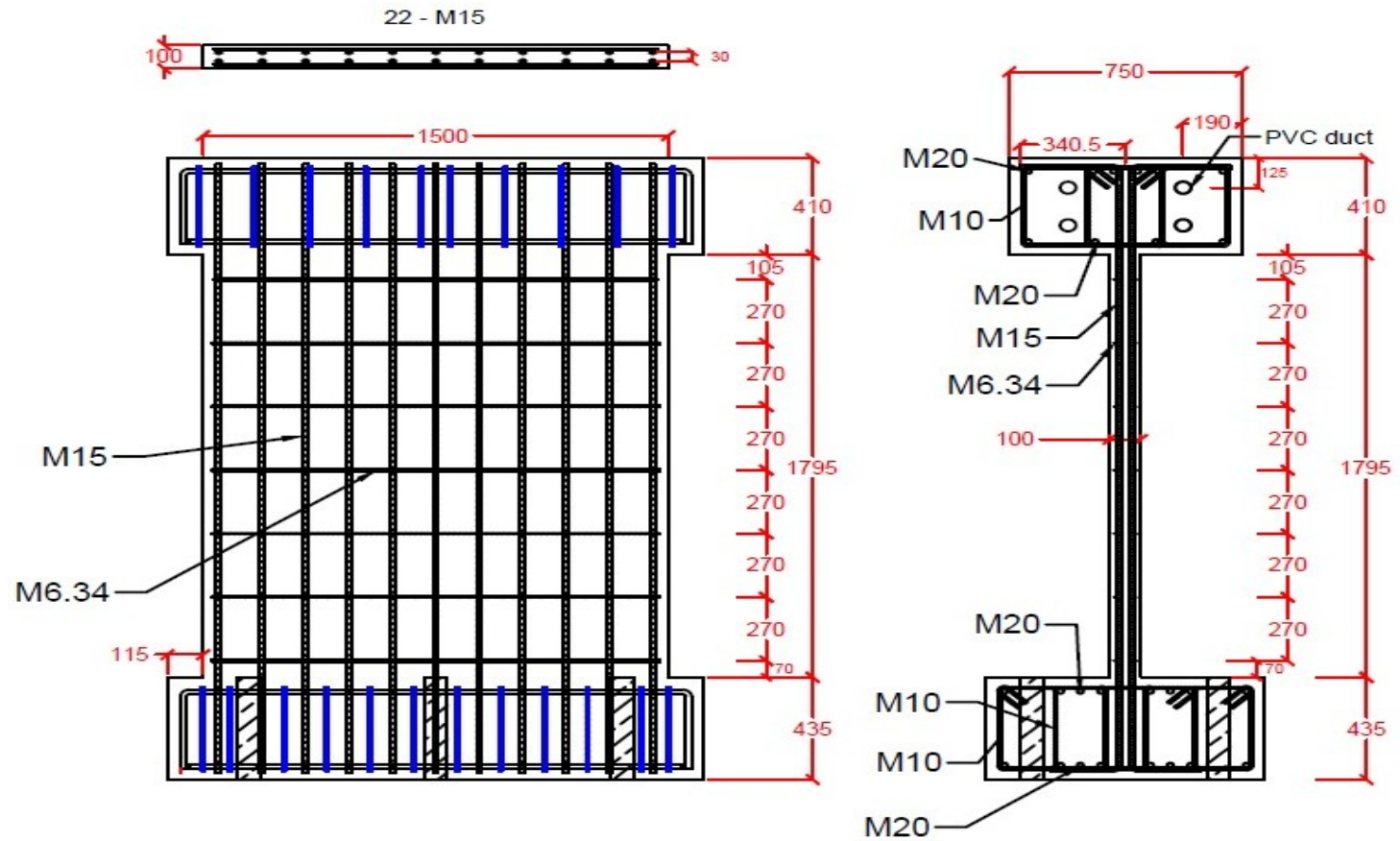

Slender Wall (Aspect ratio $=1.2)$
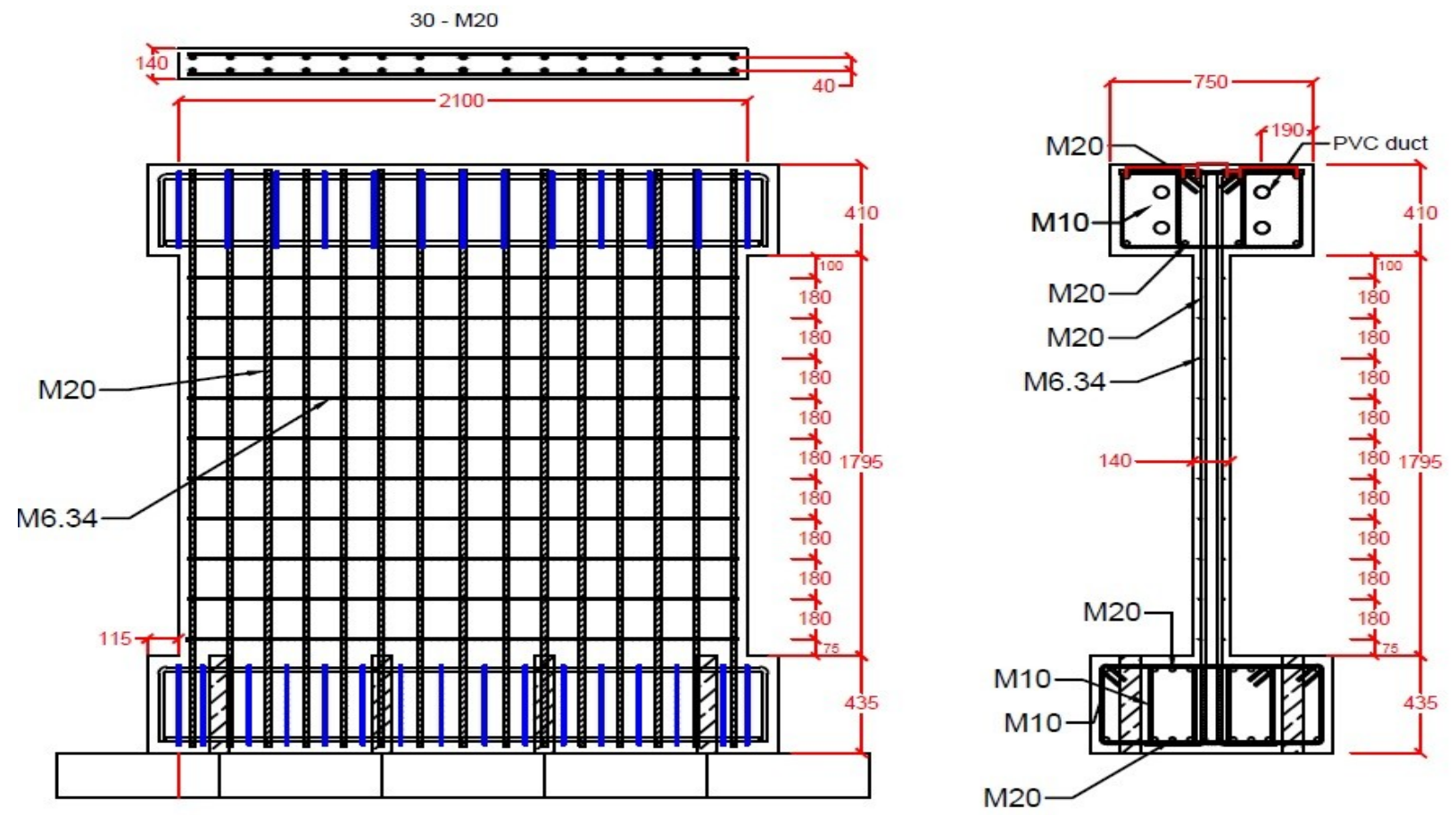

Intermediate Wall (Aspect ratio $=0.85$ )

Figure 2.2: Wall specimen detailing (all dimensions are in mm), (Cruz-Noguez et al. 2012). 

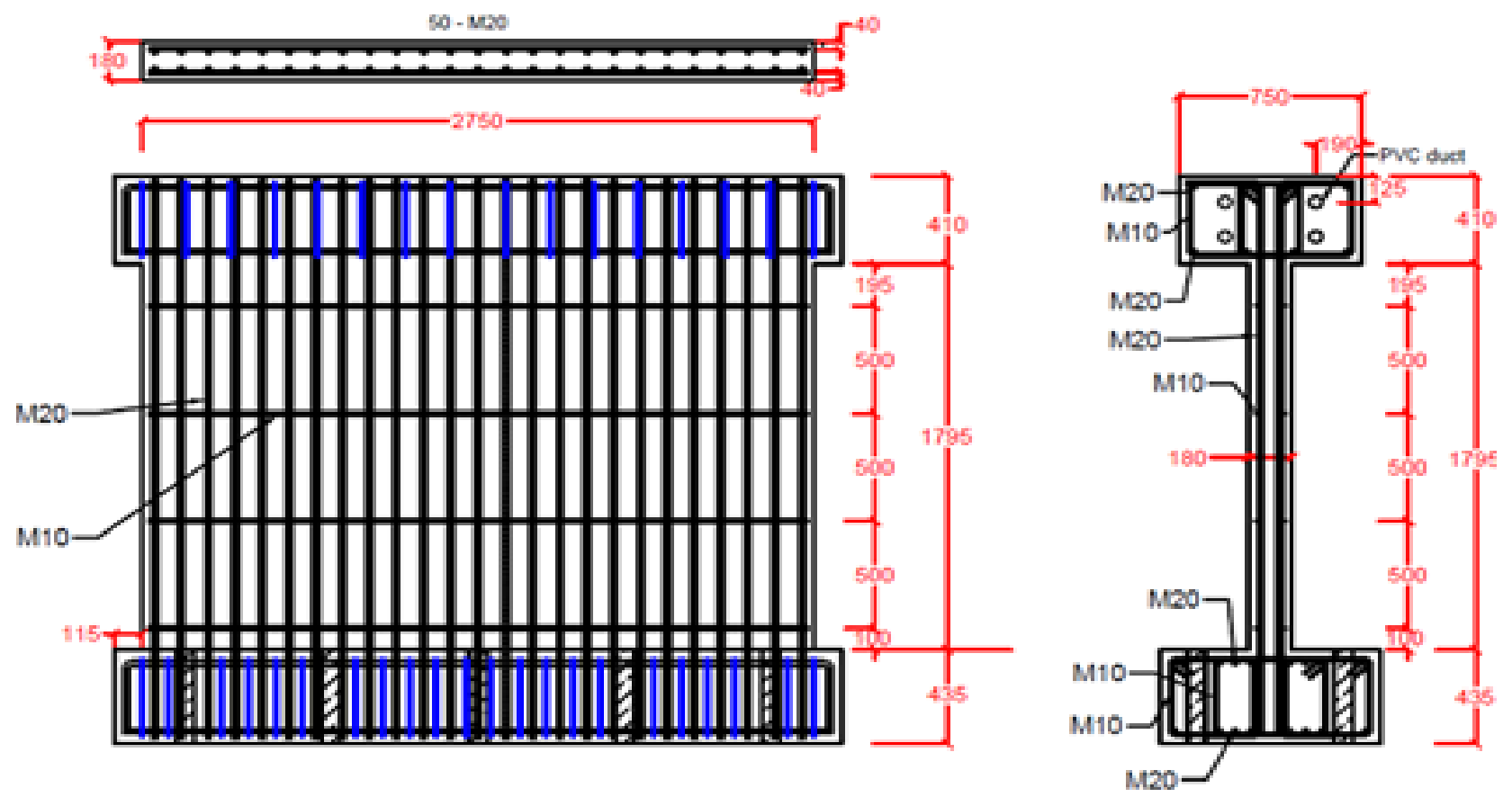

Squat Wall (Aspect ratio $=0.65$ )
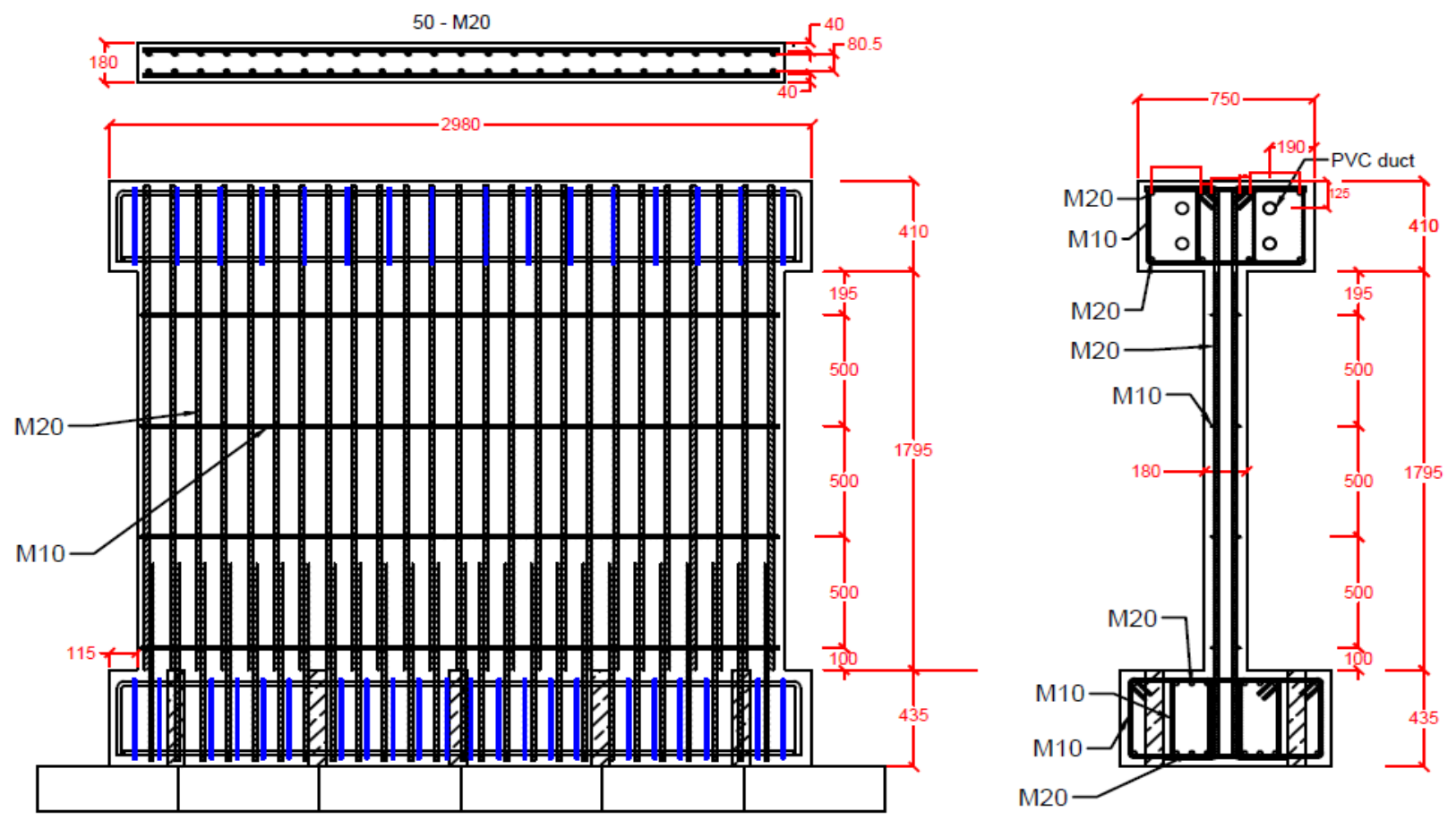

Squat Wall with Lap Splices (Aspect ratio $=0.65$ )

Figure 2.3: Wall specimen detailing (all dimensions are in mm), (Cruz-Noguez et al. 2012). 


\section{Chapter 3}

\section{Modelling of Shear Walls}

\subsection{Modelling Overview}

There are extensive experimental studies reported in the literature on the behaviour and seismic performance of reinforced concrete structures repaired or strengthened with FRP. In comparison, studies reported in the literature on analytical or numerical modelling and simulations on the seismic response of these structures are fewer in number. Li, Balendra, and Kong (2005) have developed a three dimensional non-linear finite element model to predict the response of an Ishaped flanged squat shear wall element strengthened with glass fibre reinforced polymers subjected to reverse cyclic loading by using the non linear finite element program ABAQUS. The model accounts for the increase in strength and ductility due to the confinement effect of the FRP on the concrete medium, and the strength degradation behaviour in the post peak response. Vecchio and Bucci (1999) have conducted analytical modelling of reinforced concrete beams and slabs retrofitted by externally bonded FRP laminate using the finite element program Vector2. They have introduced a method that can reproduce the effects of strengthening and repair by engaging and disengaging concrete elements in the structure. Good predictions have been obtained with the method on the load bearing capacity of reinforced concrete members strengthened with FRP. Wong and Vecchio (2003) have investigated the de-bonding phenomenon between FRP sheets and the concrete substrate utilizing a finite element model of reinforced concrete beams and slabs strengthened by bonded FRP sheets. They compare two different link elements in capturing the contact behaviour and de-bonding behaviour at the interface between the FRP and concrete. They conclude that the link elements and contact 
elements yield the same result and the accuracy of the predictions depends on the bond stressslip relationship used. Two bond relations are considered in the study. A linear-elastic bond relation is found to be appropriate when the failure mode is dominated by the delamination of the FRP sheet from the concrete surface, whereas an elastic-plastic bond relation is used when the failure is dominated by the peeling of the concrete. Cortés Puentes (2009) conducts a parametric study on shear wall structures using the finite element program Vector2. Analytical results are are obtained for six slender wall specimens tested by Fiorato et al. (1983) and Oesterle et al. (1976). In addition, two squat wall specimens tested by Palermo and Vecchio (2002) have also been modelled. In addition to the parametric study, Cortés Puentes (2009) has conducted finite element modelling of shear walls repaired by various repair proceedures ranging from concrete replacement to the addition of externally bonded FRP sheets to enhance the seismic reponse of the wall specimens. The specimens that included the FRP repair scheme simulations are shear walls tested by Antonaides et al. $(2003,2005)$. The results of the analytical study help to provide guidance on selection of benchmark parameters for concrete models and other parameters that affect the seismic response of structures including stiffness, ductility, energy dissipation, load bearing capacity, maximum lateral displacement and failure modes. The finite element simulations of the walls undergoing repair with FRP are found to be in good correlation with the experimental results.

Analysis of the nine shear wall specimens by the finite element method is presented in this section. Analytical modelling of all wall specimens is carried out using the finite element program Vector2 (Wong and Vecchio 2002). The control walls in their undamaged states are modelled and analyzed first. Following the discussion of the control walls, strengthened walls 
with FRP sheets included from the beginning of the analysis are considered. Next, the effectiveness of the FRP reinforcing scheme in repair applications is investigated with the FRP sheets applied to repair the damage sustained by walls tested previously.

\subsection{Material Properties}

The concrete material of the wall specimens has a compressive strength $f_{c}^{\prime}=20 \mathrm{MPa}$. In the analysis, the concrete tensile strength is taken as $f_{t}=1.5 \mathrm{MPa}$. The steel reinforcement has a yielding stress of $f_{y}=412 \mathrm{MPa}$ and an associated yielding strain $\varepsilon_{y}=0.00206$. The ultimate strength of the steel is $f_{u}=654 \mathrm{MPa}$ and the associated ultimate strain $\varepsilon_{u}=0.1126$. The onset of the strain hardening is $\varepsilon_{s h}=0.0126$ and the strain hardening modulus $E_{s h}=2420 \mathrm{MPa}$. The CFRP material has a linear elastic behaviour until failure. It has a tensile strength $f_{F R P u}$ of 3480 MPa, tensile modulus $E_{F R P}$ of $230 \mathrm{GPa}$, and thickness $t_{F R P}$ of $0.11 \mathrm{~mm}$. The concrete material is modelled as an orthotropic material with smeared rotating cracks (Wong and Vecchio 2003). The steel reinforcement material is modelled as an elasto-plastic material with strain hardening effects. The smeared crack approach is used to model the cracking of the concrete. In the smeared crack approach an infinite number of parallel cracks with infinitely small width are considered to be evenly distributed or "smeared" over the element, and crack propagation is simulated by reducing the stiffness and strength of the concrete. This approach is implemented in this study due to its simplicity while at the same time being accurate as reported previously by Cortés Puentes (2009); and Cruz-Noguez et al. (2012). The CFRP material is modelled as a brittle material with tensile capacity and zero compressive strength. 


\subsection{Finite Element Formulations}

The wall specimens are modelled using four node quadrilateral elements as shown in Figure 3.1. The steel reinforcement is smeared in the concrete region of the wall element except in the walls with lap splices. The steel reinforcement representing the lap spliced bars is modelled as discrete truss elements overlapped on top of each other. The discrete truss elements are linked to the concrete region through link elements with the Harajli bond stress-slip model (Harajli et al. 2004), as shown in Figure 3.2, to relate the interaction mechanism between the steel reinforcing bars and the concrete medium. In the analysis, the FRP material is modelled using discrete truss elements. The discrete CFRP truss elements are attached to the concrete medium through the utilization of link elements. Link elements are composed of two orthogonal springs that connect the nodes of the reinforcement (CFRP trusses, Lap splice bars) with the concrete medium at the same coordinates. Link elements in general establish contact between two materials through a defined bond stress-slip relationship which governs the behaviour between the CFRP trusses or lap splice bars with the underlying or surrounding concrete. The material models used in the analysis are the Popovics concrete model (Popovics 1973) for the pre-peak response, and the Popovics/Mander model (Mander et al. 1988) for the post-peak response. Slip distortions between the steel reinforcement (smeared and discrete reinforcement truss elements) and concrete medium are considered by using the Vecchio-Lai slip distortion model (Vecchio and Lai 2004). The hysteretic response model adopted in the finite element modelling of the walls considers cyclic decay (Palermo and Vecchio 2002), as it extends the plastic offsets to simulate the effect of sustained damage in repaired walls during reloading (Cortés Puentes 2009). 
The cap-beam and the foundation block are modelled by rigid elements in the analysis. Connection between the CFRP truss elements and the concrete at the base of the wall follows the common node approach as mechanical anchorage is provided at the base of the wall specimens.

\subsection{De-bonding Mechanism}

During previous experimental tests conducted on flexural wall specimens reinforced with externally-bonded CFRP sheets (Lombard et al. 1999; and Hiotakis 2004), significant debonding between the FRP and the concrete substrate is observed. De-bonding in flexural elements occurs due to opening up of flexural cracks in concrete and the interfacial stresses exceeding the bond strength between the CFRP sheets and the concrete surface. The mechanism of the opening up of flexural cracks in the concrete leading to the de-bonding of the FRP sheets from the concrete substrate is referred to as intermediate crack de-bonding also called IC debonding (Teng et al. 2003). In most reinforced concrete structures repaired or strengthened with externally bonded FRP sheets, the controlling factor in the overall response and failure mechanism of the structural member is the de-bonding of the FRP sheets from the concrete prior to the FRP reaching its ultimate strength (Lu et al. 2005). Few studies in the literature investigate the effect of IC de-bonding on the response of reinforced concrete elements experimentally and analytically (Teng et al. 2003, Lu et al. 2005, Lu et al. 2007, and Cruz-Noguez et al. 2012). Typically, the bond stress-slip relationships between FRP and concrete used in previous studies (Wong and Vecchio 2003) are obtained from experimental pullout tests of FRP on concrete prisms. However, this type of pull out test cannot duplicate the intermediate crack de-bonding behaviour as the pull out tests do not take into account the effect of flexural cracks on the 
development of the de-bonding mechanism (Sato 2003). To overcome this shortcoming, mesoscale finite element models are conducted by $\mathrm{Lu}$ et al. (2007) to capture the interaction between the FRP material and the concrete substrate. The finite element analysis results of the bond stress-slip relationships between FRP and concrete substrates are shown in Figure 3.3. In Figure 3.3, the bond stress-slip behaviour between FRP and concrete interface areas outside major flexural crack zones obtained from pull out tests (referred as Bond-Slip Model I) conducted by Lu et al. (2005) correlate well with the meso-scale finite element analysis results. For the case of interfacial behaviour of FRP to concrete in major flexural zones, Lu et al. (2007) modifies the initial Bond-Slip Model I to include the brittle response behaviour of FRP in crack zones with crack width of $15 \mathrm{~mm}$ and $20 \mathrm{~mm}$, as shown in Figure 3.3. Both bond stress-slip models (BondSlip Model I and II) are adopted in this study to capture the effect of the formation of flexural cracks and their influence on the interaction between the FRP and the concrete substrate. In this study the interface elements used to model the bond between the FRP and the concrete follows Bond-Slip Model I if the concrete does not have major flexural cracks and Bond-Slip Model II if the concrete has major flexural cracks. A major flexural crack is identified as a crack that causes a slip between the FRP and concrete substrate greater than the allowable slip limit $s_{0}$, taken as the slip corresponding to the maximum shear bond stress denoted as $\tau_{\max }$ shown in Figure 3.3 (a). In the analysis, when the link elements (spring or interface elements) between adjacent concrete elements detect crack width $w$, and the slip of the FRP to concrete interface at both sides of the flexural crack, taken equal to $\frac{w}{2}$, is greater than $s_{0}$, then IC de-bonding mechanism is considered to be initiated and the Bond-Slip Model II is adopted to represent the interface behaviour between the FRP sheet and concrete substrate material, as shown in Figure 3.3 (b). 
Once IC de-bonding of the FRP sheet occurs, the associated bond stress quickly drops to zero as shown in Figure 3.3 (b). Given that the slip at each end of the FRP and concrete interface is equal to half the initial width of the crack, the resulting crack width that signifies initiation of debonding is equal to $2 s_{0}$. Moreover if the crack width $w$ is lesser than the specified slip limit $s_{0}$, then Bond-Slip Model I is used as no major flexural cracks have opened up in the concrete element. In the present study, the bond-slip behaviour is approximated by a tri-linear bond stressslip relationship computed by the simplified Lu model (Lu et al. 2005) given by Equations [13] to [17]. The tri-linear approximation of Bond-Slip Model I is shown in Figure 3.4.

[13] $\tau_{\max }=1.5 \beta_{w} f_{t}$

[14] $s_{0}=0.0195 \beta_{w} f_{t}$

$[15] \beta_{w}=\sqrt{\frac{2.25-\frac{b_{f}}{b_{c}}}{1.25+\frac{b_{f}}{b_{c}}}}$

[16] $G_{f}=0.308 \beta_{w}^{2} \sqrt{f_{t}}$

$[17] \propto=\frac{1}{\frac{G_{f}}{\tau_{\max ^{S_{O}}}}-\frac{2}{3}}$

where $\beta_{w}$ is the FRP to concrete width factor, $f_{t}$ is the tensile strength of the concrete, and $\tau_{\max }$ is the maximum shear stress corresponding to the allowable slip limit $s_{0}$. The factors $b_{f}$ and $b_{c}$ in Equation [15] used to calculate the width modification factor $\beta_{w}$ represent the width of the FRP plate and the width of the concrete member respectively. The factor $G_{f}$ in Equation [16] represents the interfacial fracture energy, which is used in determining the factor $\alpha$ in Equation [17] that controls the declining branch of the bond-slip model for a slip greater than the allowable slip limit $s_{0}$ shown in Figure 3.3 (a). 
The bond stress-slip curve shown in Figure 3.3 (a) is expressed by Equations [18] and [19] as follows.

[18] $\tau=\left\{\tau_{\max } \sqrt{\frac{s}{s_{0}}}\right\}$ if $s \leq s_{0}$

[19] $\tau=\left\{\tau_{\max } e^{-\alpha\left(\frac{s}{s_{0}}-1\right)}\right\}$ if $s>s_{0}$

Equation [18] represents the increasing branch up to the allowable slip limit, while Equation [19] represents the post allowable slip limit steadily declining branch which denotes the initiation of de-bonding. In this study a dual de-bonding criteria is developed to monitor the crack widths of every concrete element as suggested by Cruz-Noguez et al. (2012), if the crack width exceeds the allowable slip value then the de-bonding process is initiated and the truss elements are disengaged based on the deactivation of their respective link elements that bind them to the concrete.

\subsection{Lap Splice Modelling Background}

The adverse effect from lap splices resulting in poor seismic performance can be attributed to directly or indirectly the effect of bond decay between steel and concrete at the lap splice area which can lead to degradation of stiffness, lack of ductility, depletion of energy dissipation and absorption capabilities, lower structural load bearing capacity and the occurrence of brittle shear failure at critical locations of the structure. Extensive research involving both experimental and analytical investigations of reinforced concrete structural members have been conducted on structural deficiencies of columns by Cho and Pincheira (2004), Melek et al. (2003). Cho and Pincheira (2004) investigate the modelling of lap splices in reinforced concrete columns in a 
comparison study by using different bond stress-slip relationships in modeling the response of experimentally tested columns with short lap splices carried out by Melek et al. (2003). They compare the analytical simulation results with the experiment test data. In the study, the splitting failure mode resulting from insufficient lap splice length of the reinforcing bars in reinforced concrete columns is investigated. The analysis results are shown to correlate well with the experimental data. In another study, experimental and analytical studies of reinforced concrete beams with lap splices are conducted by Harajli et al. (2004), and Harajli (2006). The studies investigate the bond-slip behaviour between steel and concrete in beams with lap splices located at mid-span of the test beams under four point loads in order to obtain information on the bond stress-slip relationships. Observations on the influence level of confinement of the lap splice by the surrounding concrete material to the failure mechanism and behaviour of the beam are presented in this study. In comparison to studies of beams and columns available in the literature, only a few experimental studies have been conducted on deficient shear wall structures with lap splices (Paterson and Mitchell 2003; Khalil and Ghobarah 2005; Layssi et al. 2012; Shaheen et al. 2013). Paterson and Mitchell (2003) investigate the behaviour of shear wall specimens with lap splices at the plastic hinge region at the base of the wall specimen or at a short distance above the plastic hinge region. The retrofit schemes investigated the addition of a concrete collar at the wall base, and the use of headed bars and carbon fibre reinforced polymer sheets. All wall specimens are slender walls with an aspect ratio (ratio of height to length $\left(\frac{h_{w}}{l_{w}}\right)$ ) greater than 2 . The experimental results show that the retrofit scheme is successful in increasing the shear strength and ductility capacities, and preventing the lap splice failure of the wall specimens. Khalil and Ghobarah (2005) conduct tests on a squat wall specimen with an aspect ratio less than 
2. The rehabilitation techniques applied on the squat wall include the usage of biaxial carbon fiber sheets to prevent shear failure and the strengthening of the end columns of the wall specimen by using anchored fibre reinforced polymers to improve the specimen's ductility. The study shows performance enhancement of the specimen in both ductility and shear strength capacities. Layssi et al. (2012) conduct experimental testing on four slender wall specimens with poor detailing designed according to old code provisions with lap splices at the plastic hinge region. The wall specimens differ only in the amount of flexural reinforcement present in the wall boundaries. Retrofit intervention in the form of uni-directional horizontal fibre reinforced polymer sheets is applied to prevent the premature failure of the lap splice and allow the steel reinforcing bars to undergo some yielding to achieve a ductility response equal to 2 .Thus with the retrofit, the nominal flexural capacity of the wall specimen is reached with an accompanied increase in the wall specimen's displacement ductility capacity. On analytical studies, Shaheen et al. (2013) conduct computer simulations of the behaviour of specimens tested in an experimental program at Carleton University. The test specimens include deficient shear wall structures designed to now obsolete old design code provisions (ACI 1968, CSA 1977). The test specimens are shear deficient and poorly detailed as in accordance to the practice of old design standards typical in the pre 1970's period. The retrofit scheme of using carbon fibre reinforced polymer sheets in both repair and strengthening applications of the deficient walls is investigated. The specimens include nine slender, intermediate and squat shear wall specimens, with some specimens having lap splices in the plastic hinge region at the base of the walls. Results obtained from the analysis of the wall specimens indicate that there is a significant increase in flexural strength, shear strength, as well as in energy dissipation capacities and an improvement in 
ductility provided by the fibre reinforced polymer retrofit system. Despite these previous studies, there are relatively few studies on the modelling of lap splice behaviour in reinforced concrete shear wall structures. In this study the development of a model that can capture lap splice behaviour in old deficient reinforced concrete shear wall elements subjected to earthquake loading is presented. The objective of this study is to develop an accurate finite element model that can adequately capture and simulate the response of lap spliced bars in seismically deficient shear wall structures by the use of a novel bond stress-slip model to represent the interaction behaviour between the reinforcing bars and the surrounding concrete medium.

\subsection{Lap Splice Behavioural Mechanisms}

The Lap splice behaviour is investigated by modelling the bond behaviour between the reinforcing steel and concrete. There are two types of bond mechanisms that govern the behavior between reinforcing steel and concrete, namely a chemical and a mechanical mechanism. The Chemical mechanism, between the reinforcing steel bars and the concrete medium, accounts for the adhesion between the two materials. The mechanical bond mechanism accounts for the friction and interlocking behaviour between the bar ribs of the lap spliced bars and between the surrounding concrete and the bar ribs of the reinforcing bars, shown in Figure 3.5. These two types of bond behaviour mechanisms result in stresses between the two elements of steel and concrete. The bond stresses holding the two elements together represent a bond strength that must be overcome if the two elements are to separate by de-bonding. When the structure is loaded by external forces, interfacial stresses occur in the interfacial zone between the reinforcing bars and the concrete (Figure 3.5). The interfacial stresses are composed of bearing, 
friction and adhesive forces that form between the deformed bar and the concrete as shown in Figure 3.6. When the interfacial stresses resulting from the loading applied to the structure exceed the bond strength, de-bonding occurs between the two elements. The bond, between concrete and the reinforcing steel due to the friction and interlocking between the bar ribs and the concrete keys, as shown in Figure 3.5 plays a major role in load transfer and is the governing factor in load resistance, increase of energy dissipation capability, and the generation of higher structural bearing capacity of the lap splice under earthquake loading (Harajli 2006). The stresses shown in Figure 3.6 are the stresses that are acting on a reinforcing bar arising from the interaction between the reinforcing bar and the surrounding concrete. Bond failure involves two separate mechanisms: (a) pullout failure; and (b) splitting failure mechanism. Both failure mechanisms are directly influenced by the level of confinement provided by the concrete to the lap spliced reinforcing bars. Other factors that influence the bond behaviour are: (a) the properties of concrete, (b) the size and geometry of the reinforcing bars, and (c) the volume of concrete surrounding the reinforcing bars which provides initial confinement to the lap splice. The transfer of forces through bond is affected by the slippage of the reinforcing bar with respect to the surrounding concrete. When slippage is initiated, the surface adhesion between the steel and concrete materials is broken. Bearing and frictional forces develop on the sliding reinforcing bars as shown in Figure 3.6. Once slippage is initiated, the frictional forces are reduced, adhesive forces are eliminated and force transfer between the reinforcing bar and concrete is carried out mainly by the bearing forces. Pullout failure mechanism occurs in well confined/confined concrete due to the pull out force exceeding the lap splice capacity derived from the bearing capacity between the rebar ribs and the surrounding concrete material. Pull out failure is affected 
by the ratio of concrete cover to bar diameter $\left(\frac{C}{d_{b}}\right)$. Whereby, if the ratio $\left(\frac{C}{d_{b}}\right)$ is large as the concrete is well confined, slippage of the reinforcing bar is initiated after the shearing off of the surrounding concrete between the reinforcing bar ribs. The end result is the pull out of the reinforcing bar from the concrete after the initial slippage of the bar, as shown in Figure 3.7 (a). On the other hand, splitting failure occurs in unconfined concrete or in confined concrete after loss of confinement, when the ratio $\left(\frac{C}{d_{b}}\right)$ is small or adjacent pairs of lap spliced reinforcing bars are closely spaced, a tensile splitting crack parallel to the steel rebars tend to develop under the radial component of the rib bearing forces, which allows the opening up of the interlocking ribs of the reinforcing rebars and results in premature bond failure (Harajli 2006). The premature bond failure in turn allows the bars to move freely away from the concrete. This leads to relative movement of the reinforcing bars away from each other, and results in a rift of the two reinforcing bars from the concrete medium. The opening up or the formation of a rift between the rebars signifies the lap spliced bars are no longer in contact with each other and the concrete medium, and thus lose all their associated load resistance capacity.

\subsection{Lap Splice Modelling Methodology}

In this study an analysis model of lap splice behaviour is developed using the finite element method. Two approaches can be followed to formulate computer analysis models of reinforced concrete structures, namely meso-scale and macro-scale modelling. These two approaches of finite element modelling can capture the behaviour mechanisms of spliced bars and their interaction with the surrounding concrete. In meso-scale modelling the elements are modelled explicitly in a very fine mesh. The mesh scale is very small in comparison to the size of the 
specimen to provide a more detailed and thorough depiction of the actual behaviour and interaction between the different components of the modelled structure. This approach mainly is suitable to analyze and monitor the formation of cracks and the propagation of those cracks at each loading stage. However the computational effort required in the analysis using such models of refined accuracy is immense. The alternative modelling approach is by using macro-scale models. In macro-scale modelling, an interface element is used to represent the bond behaviour between the steel reinforcing bars and concrete medium. Bond stress-slip models are utilized in the formulation of the interface elements to represent the bond behaviour between the reinforcing steel bars and the concrete. The finite element model in this study follows the macro-scale modelling approach in which the reinforcing bars are not modelled explicitly with their ribs but they are modelled as discrete truss elements that are bound to the concrete by the usage of a dimensionless link element to account for the bond slip behaviour between the rebars and the adjacent concrete. The link elements have the properties of the bond stress-slip model adopted to govern the behaviour between the reinforcing bars and the concrete. The component of the linkage element in the direction of the rebar axis represents the adhesive bonding force between the concrete and the reinforcing bar, whereas the linkage force component in the normal direction to the bar axis represents the radial splitting force between the bar and the concrete medium. In the formulation, the bars are in contact with the concrete through a bonded area. The finite element method is applied in this study to model old deficient shear wall and beam structural elements with lap splices at the plastic hinge region. The finite element program Vector2 is used in this study. To capture the lap splice behaviour, the bond between the spliced bars and the surrounding concrete is modelled explicitly though appropriate bond stress-slip 
relationships. Several bond stress-slip relationships have been proposed (Eligehausen et al. 1983; Filippou et al. 1983; Gan 2000; Harajli et al. 2004). These bond stress-slip models are typically derived based on observed behaviour from experimental results. Typically, the bond stress-slip models are given in the form of stress-slip curves or envelopes which are dependant on parameters that determine how much a bar slips with respect to the concrete medium as a result of the stress in the bar. The factors that play a major role in the derivation of a bond stress-slip model are: (a) concrete confinement as affected by transverse reinforcement, amount of concrete cover, and the enhancement to the confinement effect by retrofit, such as the use of fibre reinforced polymers, (b) size of the reinforcing bar and associated relative geometry of the bar, and (c) stress state of the surrounding concrete. Previous analytical studies of bond stress-slip behaviour conducted by Filippou et al. (1983) investigate the cyclic response of beam column connections including the effect of bond degradation. The analytical results correlate well with experimental observations showing that the analytical bond stress-slip model can capture the bond slip behaviour observed in experiments. In other studies, Eligehausen et al. (1983) and Harajli et al. (2004) have derived bond stress-slip models based on experimental test results obtained from monotonic and cyclic applied loading. The model proposed by Eligehausen et al. (1983) focuses on capturing the pullout failure mode in confined concrete specimens. It incorporates an analytical derived splitting failure curve in the experimentally based model. On the other hand, the model proposed by Harajli et al. (2004) can represent the splitting failure mode at different levels of confinement of the concrete medium. Other analytical based models propose modifications to experimentally derived models to better estimate and predict the bond stress-slip response between the reinforcing bars and the concrete medium. Despite insights obtained from these previous investigations, there is still no definitive bond stress-slip model to 
capture the relationship between spliced bars and the surrounding concrete in reinforced concrete shear wall structural members of different aspect ratio. In this study, the experimentally derived models obtained from beam tests are extended to model the bond behaviour in shear wall structural elements. The bond stress-slip model by Harajli et al. (2004) is adopted in the present study to model the lap splice behaviour in reinforced concrete shear wall members. The Harajli model is based on the use of a splitting failure criterion derived from observed experiment results and generalized local bond stress-slip behaviour of steel bars embedded in both confined and unconfined concrete subjected to monotonic loading. The Harajli model (2004) is derived from regression analysis of test data obtained from previous experimental studies conducted on identical specimens tested by Harajli et al. (2006). The tests conducted by Harajli et al. (2006) consists of a series of beams with lap splices located at mid-span of the test beams. Analytical results from modelling the response of columns with short lap splices using different bond stressslip models are obtained by Cho and Pincheira (2004). The bond stress-slip models used by Cho and Pincheira (2004) are the Elighausen model (1983) and variations of the splitting curve given by Harajli et al. (2004). The analytical results are compared with the experimental data compiled by Melek et al. (2003). The Harajli model is shown to have a better correlation than the Eligehausen model. The bond stress-slip model by Harajli et al. (2004) has three modelling criteria as shown in Figure 3.8. For plain concrete, the criterion neglects the confinement effect of the concrete medium. For the case of splitting failure, the criterion considers some confinement effect is provided by the concrete medium. However the confinement is considered insufficient to prevent the opening up of the tensile cracks along the lap spliced reinforcing bars. Thus this second criterion is suitable for modelling the behaviour of unconfined or lightly 
confined concrete that is likely to fail in the splitting failure mode. The last criterion is the criterion for pull out failure which represents the behaviour of well confined concrete with sufficient confinement that prevents splitting failure of the concrete, resulting in the pull out failure of the splice rebars. The parameters that influence the failure behaviour of lap splices include: (a) the level of confinement of the concrete medium, (b) the ratio of the concrete cover to bar diameter $\left(\frac{C}{d_{b}}\right)$, and (c) the size of the steel bars. The local bond stress (u) can be determined by equilibrium between the measured bar force $\left(A_{b} F_{S}\right)$ and the circumferential bond force developed along the lap splice length $\left(u \pi d_{b} L_{s}\right)$. The end result is a direct correlation between the local bond stress $(u)$ and the bar stress $\left(F_{s}\right)$ along with the bar diameter $\left(d_{b}\right)$ and an inverse correlation with the lap splice length $\left(L_{S}\right)$, as shown in Equation [20].

[20] $u=\frac{\pi d_{b}^{2} F_{s}}{4 \pi d_{b} L_{s}}=\frac{F_{s} d_{b}}{4 L_{s}}$

In Equation [20], $A_{b}$ is taken to be equal to $\frac{\pi d_{b}^{2}}{4}$, and $L_{S}$ is the lap splice length of the bar. The bar stress $F_{S}=E_{S} \varepsilon_{S}$, where $E_{S}$ is the steel modulus of elasticity and $\varepsilon_{S}$ is the steel strain directly measured from the experiment. As shown schematically in Figure 3.8, the bond stress-slip model has four distinct stages in the relationship. A steadily increasing branch starting from the origin up to the bond stress $\alpha u_{s p}$, which is the maximum splitting force reduced by a factor $\alpha$ taken to be equal to 0.7 for both plain and confined concrete. The second branch is a linearly increasing branch from $\alpha u_{s p}$ to the splitting failure force $u_{s p}$, which is calculated based on the expression shown in Equation [21] which takes into account the confinement parameter $\left(K_{c}\right)$ of the concrete, concrete cover $(C)$, bar diameter $\left(d_{b}\right)$, and compressive strength of concrete $\left(f_{c}^{\prime}\right)$. The third stage of the bond model revolves around the sharp descending branch from $u_{s p}$ to $u_{p}$ which 
characterizes the post splitting mechanism calculated according to Equation [22] that accounts for bond degradation shown as a drop in bond strength in Figure 3.8. The third stage drops to $u_{p}$ in the case of lightly confined concrete which experiences splitting failure. For the case of plain concrete without confinement, it drops to $\beta u_{s p}$. The force reduction factor $\beta$ is taken to be equal to 0.65 for unconfined concrete. The final stage of the splitting bond failure model is the stage of progressively diminishing bond strength as shown by the slowly decaying response after the bond splitting failure has occurred in both the plain as well as the lightly confined concrete.

[21] $u_{s p}=0.78\left(f_{c}^{\prime}\right)^{\frac{1}{2}}\left(\frac{C+K_{c}}{d_{b}}\right)^{\frac{2}{3}}$

[22] $u_{p}=u_{s p}\left(0.5+K_{c s}\right) \leq u_{s p}$

In Equations [21] and [22], $K_{c}$ and $K_{c s}$ are confinement parameters which influence $u_{p}$ and $u_{s p}$ and are calculated based on expressions derived by Harajli et al. (2004). The confinement parameters $K_{c}$ and $K_{c S}$, are calculated by Equations [23] and [24] for confinement provided to the concrete by steel reinforcement. Other equations are also given by Harajli et al. (2004) addressing concrete confinement by other means. Both $K_{c}$ and $K_{C S}$ are zero for plain concrete.

[23] $K_{C}=\frac{7.0 A_{t r}}{s_{t} n_{s}}$, (concrete confinement criterion: steel reinforcement)

[24] $K_{c s}=\frac{7.5 A_{t r}}{s_{t} C n_{s}},($ concrete confinement criterion: steel reinforcement $)$

Both Equations [23] and [24], account for the number of spliced bars $\left(n_{s}\right)$, area of transverse reinforcement $\left(A_{t r}\right)$, and spacing of transverse reinforcement $\left(s_{t}\right)$. The slip at which the splitting failure starts and is calculated using the expression shown in Equation [25] as follows. 
$[25] S_{s p}=S_{1} e^{3.3 \ln \left(\frac{u_{s p}}{u_{m}}\right)}+S_{0} \ln \left(\frac{u_{m}}{u_{s p}}\right)$

In Equation [25], $S_{0}$ is taken to be equal to $0.15 \mathrm{~mm}$ for unconfined concrete, $0.4 \mathrm{~mm}$ for concrete confined by transverse reinforcement, and $0.2 \mathrm{~mm}$ for concrete confined with fibre reinforced polymer sheets. $S_{1}$ in Equation [25] is related to the rib pattern of the reinforcement bar. It is associated with the first rib on the bar taken equal to $0.15 c_{0}$, where $c_{0}$ is the clear distance between the bar ribs of the reinforcing bar. In Equation [25], $\left(u_{m}\right)$ refers to the maximum bond strength reached for a fully confined specimen where the mode of failure is the pull out failure, and this is represented by the top pull out failure curve shown in Figure 3.8. For unconfined concrete the descending branch beyond splitting, is assumed to follow Equation [26] as shown below:

[26] $u=\frac{\beta u_{s p}}{\sqrt{\frac{s}{s_{s p}}}}, \mathrm{u}$ is the bond stress, and $\mathrm{s}$ is the bond slip.

The Harajli bond stress-slip relationship (Harajli et al. 2004) for the longitudinal M-20 reinforcing bars shown in Figure 2.3 in the squat wall specimen is presented in Figure 3.2. Also to validate the assumption of using the Harajli bond stress-slip relationship (Harajli et al. 2004) in modelling seismically deficient shear wall structures, further analysis on poorly confined beam and shear wall elements with lap splices at plastic hinge locations is conducted. The analysis of the Harajli beam specimen (Harajli 2006) and wall specimens experimentally tested by Paterson and Mitchell (2003) and Layssi and Mitchell (2012) are presented. The Harajli bond stress-slip relationship with plain concrete splitting failure criterion is selected to model poorly confined beam and shear wall elements with lap splices at plastic hinge locations. This assumption is made to account for the poor detailing found in old deficient shear walls. 


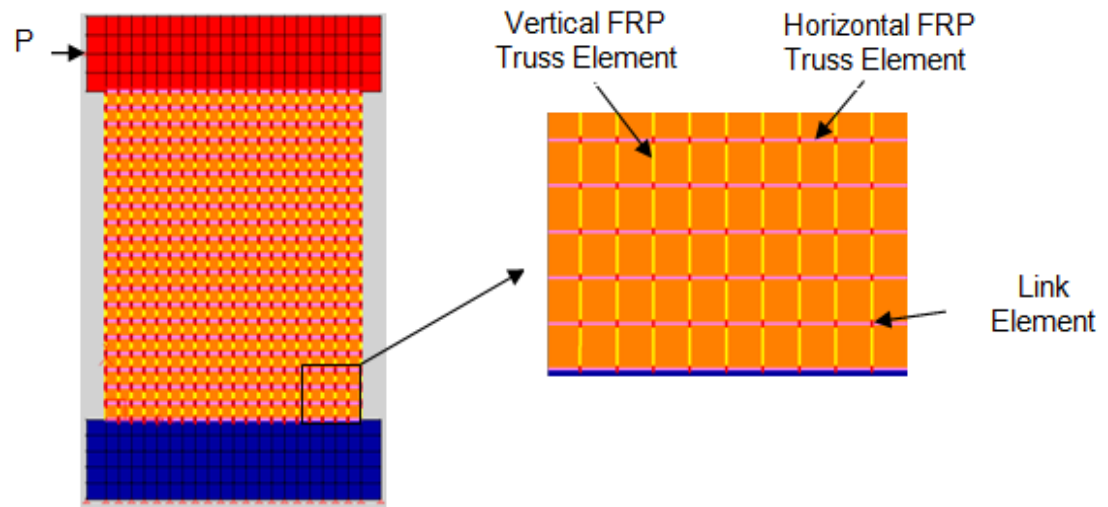

Figure 3.1: Finite element model of slender FRP wall and components (Shaheen et al. 2013).

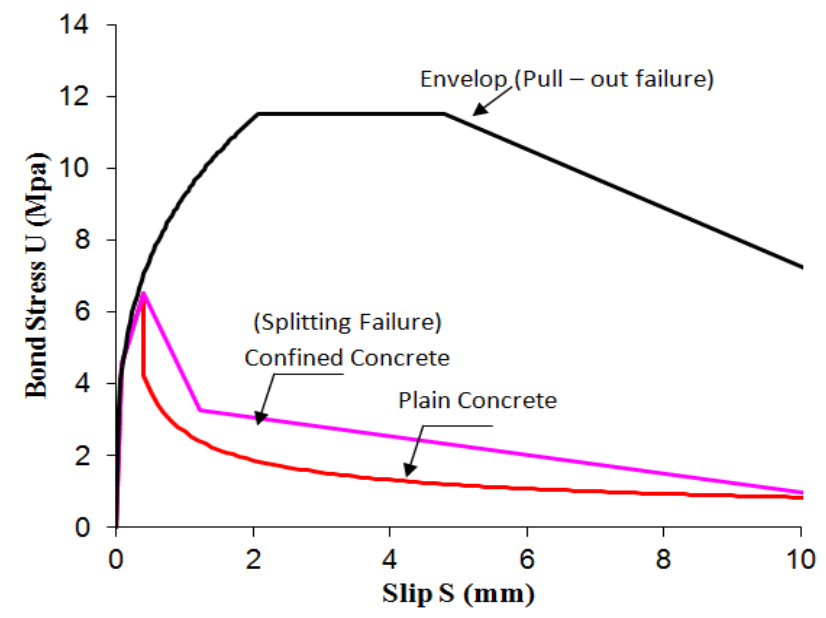

Figure 3.2: Harajli bond stress-slip relationship (Harajli et al. 2004) used to model lap spliced bars in the squat wall specimens. 


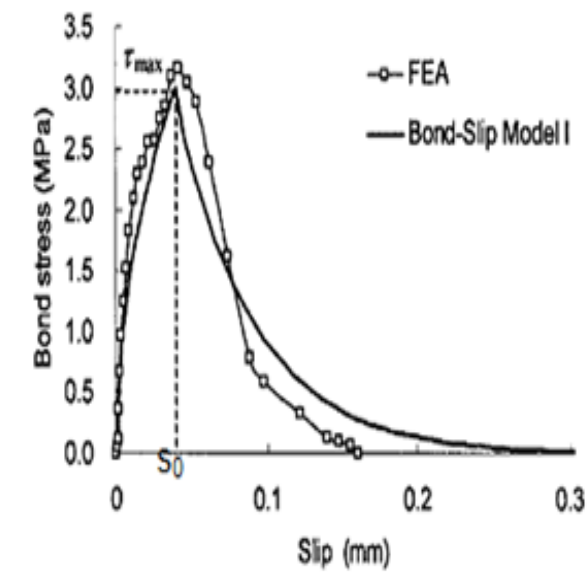

(a) Bond stress-slip behaviour outside major flexural crack zones

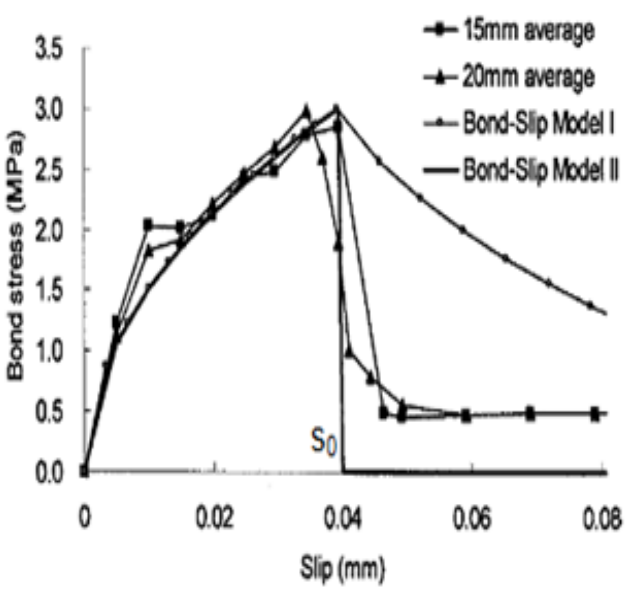

(b) Bond stress-slip behaviour inside major flexural crack zones

Figure 3.3: Bond stress-slip relationships derived from meso-scale finite element models conducted by Lu et al. (2007).

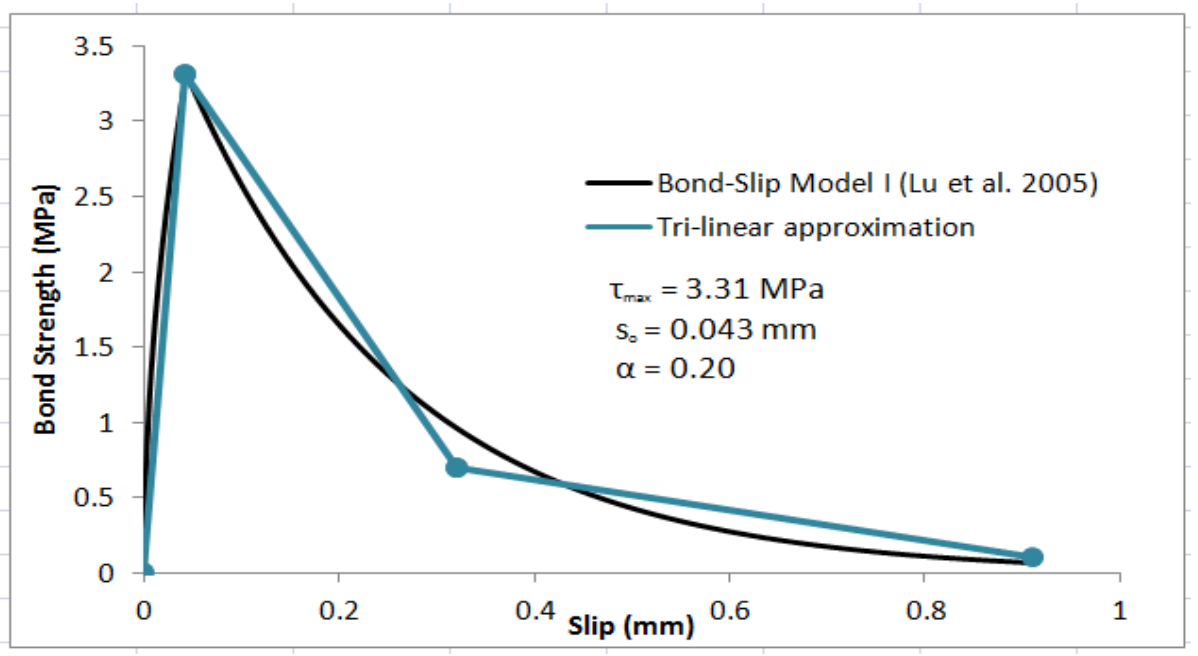

Figure 3.4: Tri-linear approximation of Bond-Slip Model I (Lu et al. 2005). 


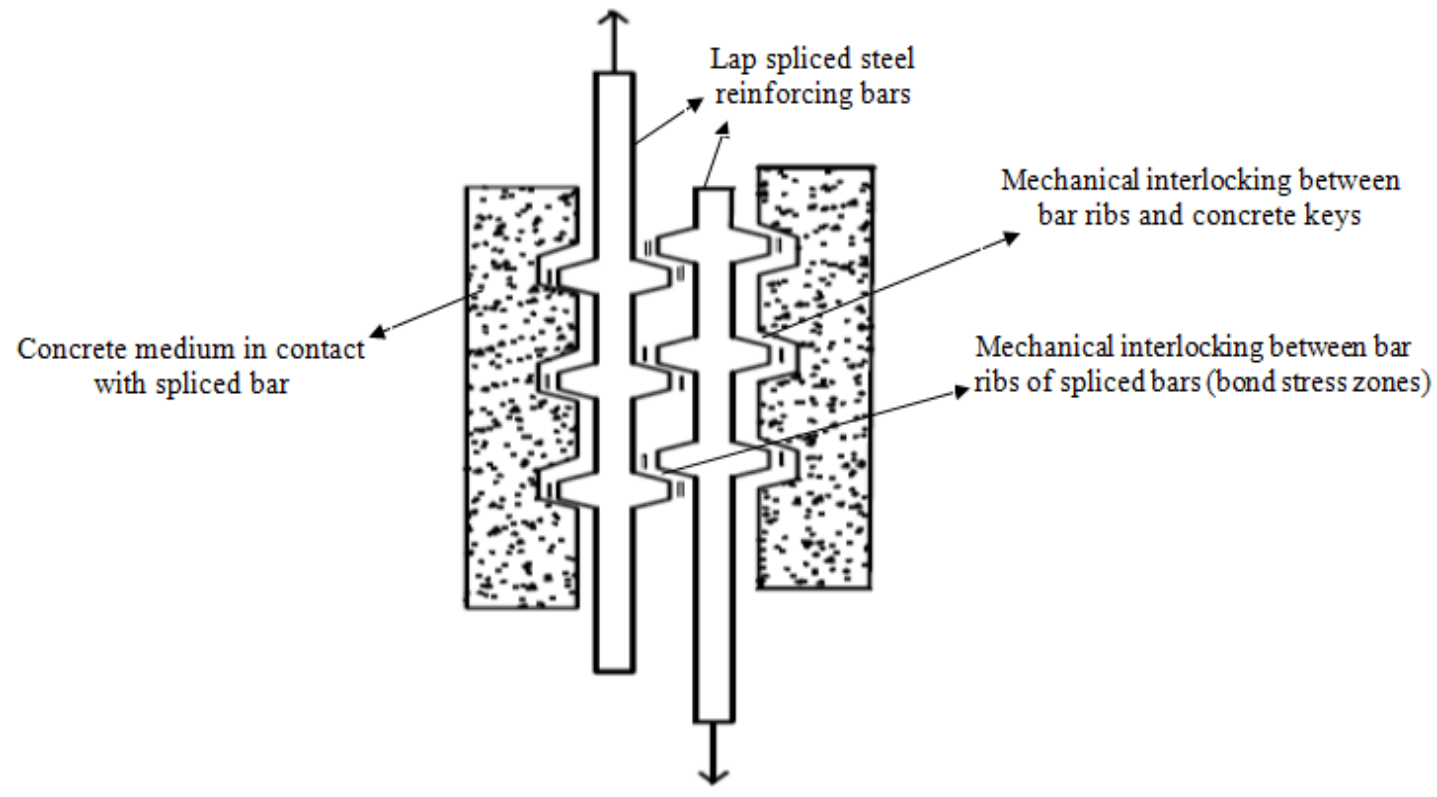

Figure 3.5: Schematic of lap splice behaviour and bond stresses zones.

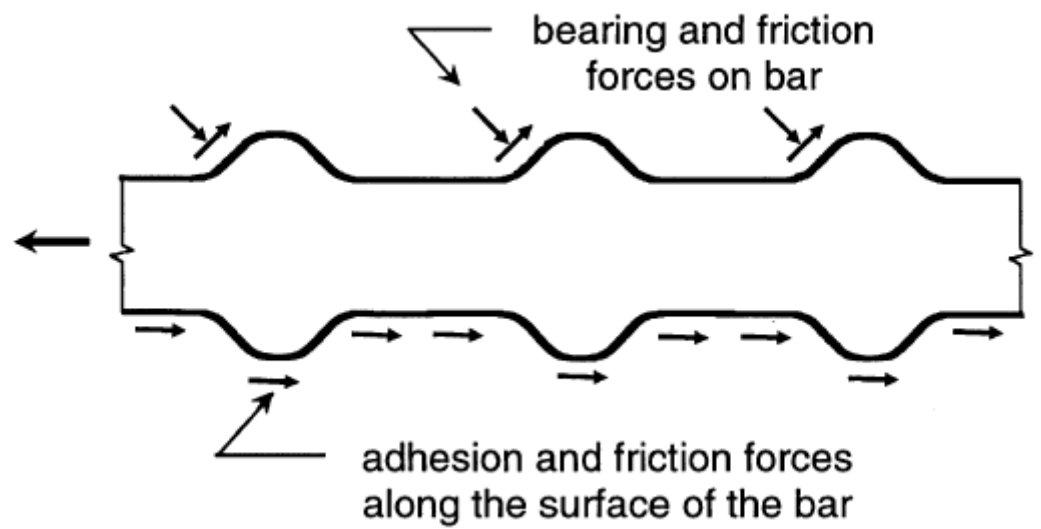

Figure 3.6: Bond stresses generated on a deformed bar (ACI 408R-03). 


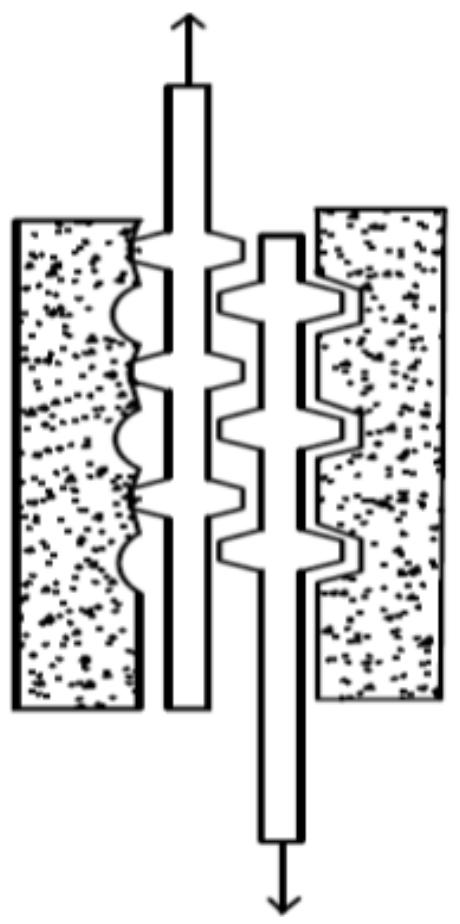

Figure 3.7 (a): Pullout Failure Mode

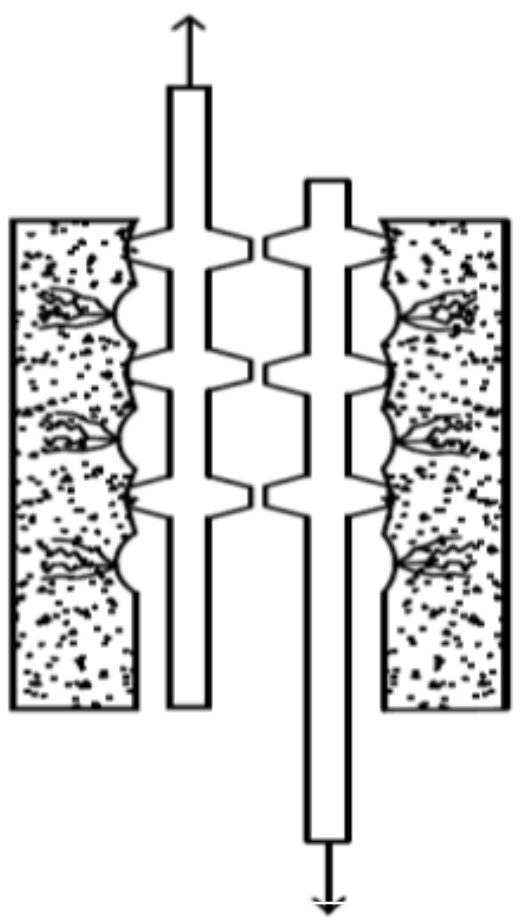

Figure 3.7 (b): Splitting Failure Mode

Figure 3.7: Lap splice behavioural mechanisms.

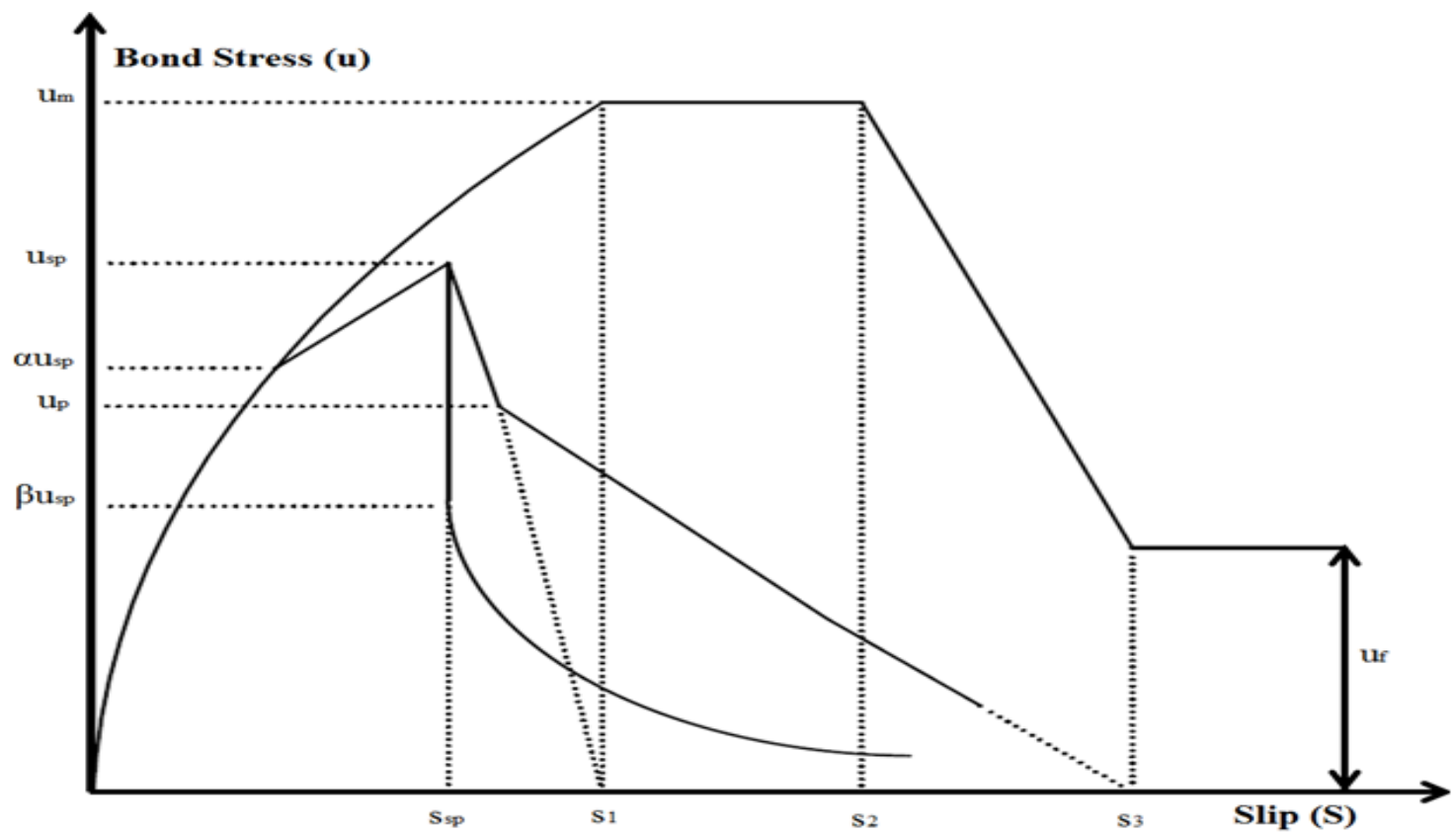

Figure 3.8: Local bond stress-slip relationship for different concrete confinement criteria (Harajli et al. 2004). 


\section{Chapter 4}

\section{Analysis of Reinforced Concrete Structures}

\subsection{Modelling of Unconfined Reinforced Concrete Beams}

Analytical modelling of a beam specimen tested by Harajli (2006) under cyclic loading is presented. The beam specimen specifications are shown in Figure 4.1. The beam specimen contains lap splice bottom bars at mid-span. The lap spliced length of the bars is equal to $5 \mathrm{~d}_{\mathrm{b}}$, where the lap splice length is short enough to simulate local bond conditions but long enough to allow a reasonable number of bars to resist the tensile force through bond (Harajli 2006). The beam specimen in the experiment has a $125 \mathrm{~mm}$ splice length for a $25 \mathrm{~mm}$ reinforcing bar. The beam specimen in this study is the control beam specimen designated as B25 control. This control specimen is a specimen with no confinement in the lap splice zone. The beam specimen consists of two continuous $20 \mathrm{~mm}$ top reinforcement bars to resist negative moment generated by the reverse cyclic loading, and two $25 \mathrm{~mm}$ lap spliced bars at the bottom of the beam (tension side). Shear reinforcement of $6 \mathrm{~mm}$ closed ties are provided in shear spans spaced at $100 \mathrm{~mm}$. The beam has two pockets of dimensions $70 \mathrm{~mm}$ x $70 \mathrm{~mm}$ for attaching instrumentation to the exposed parts of the steel bar.

\subsubsection{Modelling Approach and Material Properties}

The beam specimen is modelled by determining different sets of material properties for concrete at different parts of the beam specimens. The two ends of the beam specimen are modelled without lap splices with transverse reinforcement of $6 \mathrm{~mm}$ closed ties. The centre part of the 
beam has lap splices, as shown in Figure 4.1, in which no transverse reinforcement is present. The two exposed pockets are modelled by weak concrete of near zero strength with no transverse reinforcement as a close assumption to the open space. The lap spliced bars and the two continuous reinforcement bars at the top are modelled as discrete truss elements located on top of each other. In the case of continuous reinforcement two approaches can be used in the modelling process. These approaches are characterized in either doubling the area and using one truss element to represent the two bars, or modelling each bar separately by defining two truss elements on top of one another. Both approaches yield the same result as the program can distinguish through the interface elements which bar is linked to the concrete medium. The interaction between the spliced bars/continuous bars and the concrete medium is represented by zero length link elements. The concrete material has a compressive strength $f_{c}^{\prime}=35.8 \mathrm{MPa}$, tensile strength of $f_{t}=1.97 \mathrm{MPa}$, and negligible compressive and tensile strength for the exposed pockets. The reinforcement material properties are listed in Table 4.1.

\subsubsection{Material Models and Finite Element Simulations}

The material models used in the analysis are the Popovics concrete model (Popovics 1973) for the pre-peak response, and the Popovics/Mander (Mander et al. 1988) model for the post-peak response. Tension stiffening and softening effects are not considered. Slip distortions between the steel and concrete medium are considered by using the Vecchio-Lai slip distortion model (Vecchio and Lai 2004). The finite element model of the beam specimen is shown in Figure 4.2. The beam specimen is subjected to a displacement controlled reverse cyclic loading. The load is applied in four point bending as shown in Figure 4.2. The bond stress-slip relationship used to 
model the response of the bottom $25 \mathrm{~mm}$ lap spliced bars is shown in Figure 4.3.

\subsubsection{Finite Element Analysis and Discussion of Results}

The load-displacement relationships for the beam specimen along with its respective failure mode are presented. A comparison of the hysteresis curves of both the experimental and analytical beam specimens is presented in Figure 4.4. As shown in Figure 4.4, the analytical and experimental hysteresis curves are in good correlation with each other. The initial stiffness and the ultimate strength obtained in the analysis results correlate well with the test results, as shown in Figure 4.4. The displacement ductility and energy dissipation capacity of the analytical model is slightly higher than that of the experimental result. This increase in ductility and energy dissipation is attributed to the assumption of the material properties of the smeared $6 \mathrm{~mm}$ closed ties present in the beam specimen. Also the lap spliced bars provide the flexural strength needed at the pocket section to resist flexural cracks. However after repeated cycles of loading, flexural cracks start appearing at the notch locations in the constant moment region of the beam. The formation of these longitudinal cracks from the notch location is then accompanied by the bond splitting failure between the spliced bars and concrete, which is visible in Figure 4.4. These results have also been reported experimentally by Harajli (2006) which states that all beam specimens have encountered the bond splitting failure mechanism. The spiked lines appearing on top of the analytical curve are associated with the splitting failure of the concrete. The only short coming of the finite element analysis results is the inability of the finite element model to adequately follow the post-splitting behaviour of the concrete. 


\subsection{Modelling of Unconfined Reinforced Concrete Shear Wall I}

In this study the shear wall specimens tested by Paterson and Mitchell (2003), and Layssi and Mitchell (2012) with lap splices at the plastic hinge region have been modelled and analyzed. Paterson and Mitchell test four shear wall specimens designed according to old code provisions. All wall specimens are tested under quasi static reverse cyclic loading. The un-retrofitted specimen W1 is modelled in this study. It contains lap splices at the plastic hinge region, with a lap splice length of $550 \mathrm{~mm}$ of the inner spliced bars and a lap splice length of $900 \mathrm{~mm}$ of the outer spliced bars. The height of the W1 specimen is $3400 \mathrm{~mm}$ with a width of $1200 \mathrm{~mm}$. The specifications of wall W1 are shown in Figure 4.5. In the modelling of the wall specimen tested by Paterson and Mitchell (2003) the base of the wall specimen is assumed to be fixed. The concrete material of the wall specimen has a compressive strength $f_{c}^{\prime}=25.9 \mathrm{MPa}$, and a tensile strength $f_{t}=1.67 \mathrm{MPa}$. The steel reinforcement material properties in the concrete regions are summarized in Table 4.2. The thickness of the wall specimens is $300 \mathrm{~mm}$. The bond stress-slip relationship for both types of lap splices (No.15, 25) are shown in Figure 4.6.

\subsubsection{Material and Element Formulations}

The concrete material of the test wall is modelled as an orthotropic material with smeared rotating cracks using a model developed by Wong and Vecchio (2003). The steel reinforcement material is modelled as an elasto-plastic material with strain hardening effects. The smeared crack approach is used to model the cracking of the concrete. In the smeared crack approach an infinite number of parallel cracks with infinitely small width are considered to be evenly 
distributed or "smeared" over the element. The concrete regions are modelled using four node quadrilateral elements with the steel being smeared over the concrete region (transverse steel, No. 10 bars). The lap spliced bars (No 25 and 15) are modelled as discrete truss elements located directly on top of each other. The interaction between the spliced bars and the concrete medium is represented by zero length link elements. The material models used in the analysis are the Popovics concrete model (Popovics 1973) for the pre-peak response, and the Popovics/Mander model (Mander et al. 1988) for the post-peak response. Tension stiffening and softening effects are not considered. Slip distortions between the reinforcement trusses and the concrete medium are considered by using the Vecchio-Lai slip (Vecchio and Lai 2004) distortion model. Connection between the lap spliced bars and the concrete at the base of the wall follows the common node approach since the spliced bars have hooked ends which is treated as a form of anchorage. The finite element model of specimen W1 is shown in Figure 4.7. The wall specimen is subjected to a displacement controlled reverse cyclic unit loading up to failure. The loading is applied at the top of the wall.

\subsubsection{Finite Element Analysis and Discussion of Results}

The load-displacement relationship for wall specimen W1 is presented with a comparison against experimental data. Along with the comparison of hysteresis curves, the failure modes of the wall specimen from computer simulation are compared with the failure modes observed during the tests. The hysteresis curves are presented in Figure 4.8. As shown in Figure 4.8, there is a strong correlation between the predicted analytical results with the measured experimental response. There is a good correlation on the initial stiffness and the ultimate strength between the 
analysis and test results of the $\mathrm{W} 1$ specimen of $170 \mathrm{KN}$ in comparison with $200 \mathrm{KN}$ as seen in the experimental curve of wall specimen $\mathrm{W} 1$. The ultimate deflection reached is $14.7 \mathrm{~mm}$ which is a little higher than the $14.2 \mathrm{~mm}$ reached in the experimental curve presented in Figure 4.8. This discrepancy in strength and displacement is attributed to modelling restrictions of the finite element model of the wall. The finite element model seems not to be able to model the post splitting behaviour of the concrete. This inability to represent post failure splitting also affects the overall response which in turn affects the energy dissipation capability and overall displacement ductility of the wall specimen. Nevertheless the predicted failure mode of the W1 specimen correlates well with the failure mode of the experimental W1 wall. As shown in Figure 4.8, the flexural cracks at the top and then shear cracks that are widening at the bottom are well depicted in the finite element model. Moreover the failure occurs along the No.25 lap spliced bars as indicated by longitudinal cracks along the top and bottom of the specimen, which are visible at the wall edge. This is also reported by Paterson and Mitchell (2003). Also the yield deflection of the wall specimen as predicted analytically is $9 \mathrm{~mm}$ as compared to the reported yield deflection of $9.5 \mathrm{~mm}$ in the experiment. Thus overall the usage of the bond stress-slip relationship to model the global response of wall specimens with lap splices has proven to be close and adequate.

\subsection{Modelling of Unconfined Reinforced Concrete Shear Wall II}

In Addition to the wall specimen previously presented, this study also includes the modelling of a recent study conducted by Layssi and Mitchell (2012). The walls modelled in this study are the control wall specimens W1 and W2 with lap splices at the plastic hinge region. 
The only difference between the two wall specimens is the amount of concentrated flexural reinforcement at both ends of the wall specimens. The wall specimens look similar in layout to the previously modelled wall specimen by Paterson and Mitchell (2003). The wall specifications are shown in Figure 4.9. All of these wall specimens are slender walls with an aspect ratio (ratio of height to length) greater than 2. The wall specimens have a thickness of $150 \mathrm{~mm}$, width of $1200 \mathrm{~mm}$ and a height of $3400 \mathrm{~mm}$. The same modelling approach is applied as the one listed in section 4.2.1. The concrete material compressive strength for wall specimen $\mathrm{W} 1$ is $31.2 \mathrm{MPa}$ and the compressive strength for wall specimen W2 is $30.4 \mathrm{MPa}$. The steel material properties are detailed in Table 4.3. The bond stress-slip relationship for both types of lap splices (No.10, 20) are shown in Figure 4.10. The bond stress-slip relationships for the W2 wall specimen are very close to the stress-slip relationships presented in Figure 4.10, thus they are not presented here. The material models and the finite element models of both wall specimens are the same as discussed previously in section 4.2.1.

\subsubsection{Finite Element Analysis and Discussion of Results}

The load-displacement behaviour of the wall specimens W1 and W2 are presented with a comparison against experimental data in Figure 4.11. As shown in Figure 4.11 there is a strong correlation between the analytical and experimental results. There is a good correlation on the initial stiffness of both wall specimens between the analytical predictions and the test results. The analytical ultimate strength of the $\mathrm{W} 1$ specimen reaches $75 \mathrm{KN}$ in comparison with $95.2 \mathrm{KN}$ from the experiment, whereas the ultimate strength of the W2 specimen reaches $130 \mathrm{KN}$ while the experimental result gives $140.5 \mathrm{KN}$. 
The ultimate displacement reached by the $\mathrm{W} 1$ wall specimen is $12.5 \mathrm{~mm}$ while the experimental curve shows a displacement of $13.25 \mathrm{~mm}$. The W2 wall specimen reaches an ultimate displacement of $14.5 \mathrm{~mm}$ while the experimental curve gives around $15 \mathrm{~mm}$. On energy dissipation, the analysis results of both wall specimens are nearly the same as the test results. Hysteresis curves of both walls closely follow the experimental results. As reported by Layssi and Mitchell (2012) the failure of the wall specimen during the test is brittle as shown in Figure 4.11, whereby the side splitting failure of the $20 \mathrm{M}$ lap splices prior to yielding causes a significant drop in load capacity as characterized by the sharp decrease beyond ultimate. The analytical simulations are stopped at the moment the wall fails due to the same observations made by the authors. The discrepancy in strength is attributed to the splitting of the concrete mentioned also in the previous analysis of the Paterson and Mitchell (2003) wall specimen. The overall usage of the bond stress-slip relationship for modelling the global response of wall specimens with lap splices is proven to be adequate.

Table 4.1: Reinforcement Properties in Various Concrete Regions.

\begin{tabular}{ccccccc}
\hline $\begin{array}{c}\text { Bar Diameter } \\
\left(d_{b}\right) \text { in } \mathrm{mm}:\end{array}$ & $\begin{array}{c}\text { Yield Strength } \\
f_{y}(\mathrm{MPa}):\end{array}$ & $\begin{array}{c}\text { Ultimate Strength } \\
f_{u}(\mathrm{MPa}):\end{array}$ & $\begin{array}{c}\text { Yielding } \\
\text { Strain }\left(\varepsilon_{y}\right):\end{array}$ & $\begin{array}{c}\text { Ultimate } \\
\text { Strain }\left(\varepsilon_{u}\right):\end{array}$ & $\begin{array}{c}\text { On Set of Strain } \\
\text { Hardening } \\
\left(\varepsilon_{s h}\right):\end{array}$ & $\begin{array}{c}\text { Strain } \\
\text { Hardening } \\
\text { Modulus } \\
(\mathrm{MPa}):\end{array}$ \\
\hline 6 & $520^{*}$ & $700^{*}$ & 0.0026 & 0.105 & 0.015 & 2000 \\
\hline 20 & 510 & 700 & 0.00255 & 0.11 & 0.015 & 2000 \\
\hline 25 & 485 & 700 & 0.0025425 & 0.1225 & 0.015 & 2000 \\
\hline
\end{tabular}

Values denoted by $*$ have assumed properties due to insufficient information presented in the original paper.

Table 4.2: Reinforcement Properties in Various Concrete Regions.

\begin{tabular}{ccccccc}
\hline $\begin{array}{c}\text { Bar Diameter } \\
\left(d_{b}\right) \text { in } \mathrm{mm}:\end{array}$ & $\begin{array}{c}\text { Yield Strength } \\
f_{y} \text { (MPa): }\end{array}$ & $\begin{array}{c}\text { Ultimate Strength } \\
f_{u}(\mathrm{MPa}):\end{array}$ & $\begin{array}{c}\text { Yielding } \\
\text { Strain }\left(\varepsilon_{y}\right):\end{array}$ & $\begin{array}{c}\text { Ultimate } \\
\text { Strain }\left(\varepsilon_{u}\right):\end{array}$ & $\begin{array}{c}\text { On Set of Strain } \\
\text { Hardening } \\
\left(\varepsilon_{s h}\right):\end{array}$ & $\begin{array}{c}\text { Strain } \\
\text { Hardening } \\
\text { Modulus } \\
(\mathrm{MPa}):\end{array}$ \\
\hline 10 & 320 & 459 & 0.00223 & 0.3732 & 0.0162 & 388.485 \\
\hline 15 & 453 & 709 & 0.00199 & 0.20 & 0.00491 & 1312.2 \\
\hline 25 & 423 & 667 & 0.00216 & 0.165 & 0.00753 & 1549.5 \\
\hline
\end{tabular}


Table 4.3: Reinforcement Properties in Various Concrete Regions.

\begin{tabular}{ccccccc}
\hline $\begin{array}{c}\text { Bar Diameter } \\
\left(d_{b}\right) \text { in mm: }\end{array}$ & $\begin{array}{c}\text { Yield Strength } \\
f_{y}(\mathrm{MPa}):\end{array}$ & $\begin{array}{c}\text { Ultimate Strength } \\
f_{u}(\mathrm{MPa}):\end{array}$ & $\begin{array}{c}\text { Yielding } \\
\text { Strain }\left(\varepsilon_{y}\right):\end{array}$ & $\begin{array}{c}\text { Ultimate } \\
\text { Strain }\left(\varepsilon_{u}\right):\end{array}$ & $\begin{array}{c}\text { On Set of Strain } \\
\text { Hardening } \\
\left(\varepsilon_{\text {sh }}\right):\end{array}$ & $\begin{array}{c}\text { Strain } \\
\text { Hardening } \\
\text { Modulus } \\
(\mathrm{MPa}):\end{array}$ \\
\hline 11.3 & 470 & 727 & 0.0024 & 0.6777 & 0.0162 & 388.485 \\
\hline 19.6 & 460 & 637 & 0.0023 & 0.4718 & 0.0162 & 388.485 \\
\hline
\end{tabular}

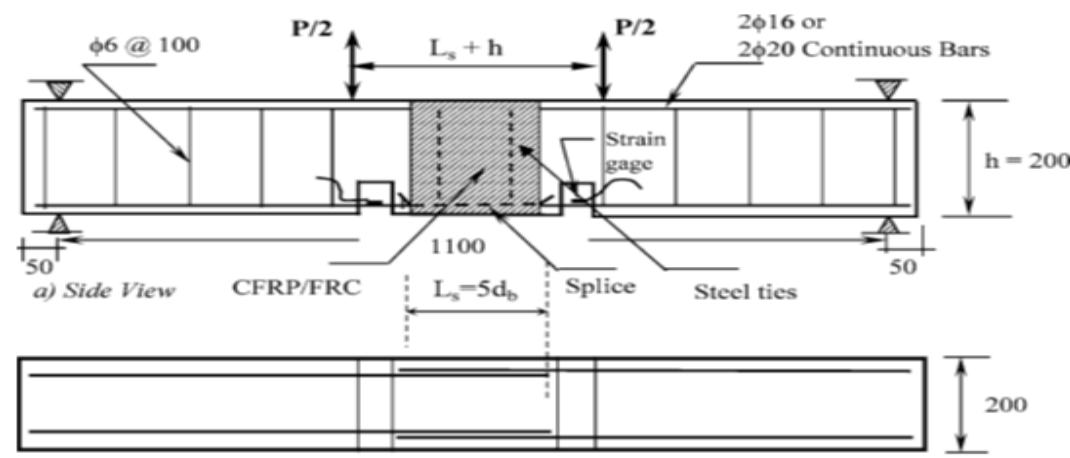

b) Bottom View (Tension Side)

Note: All dimensions are in $\mathrm{mm}$

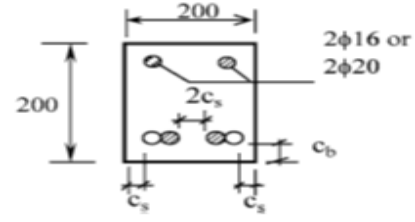

Figure 4.1: Beam specimen specifications (Harajli 2006).

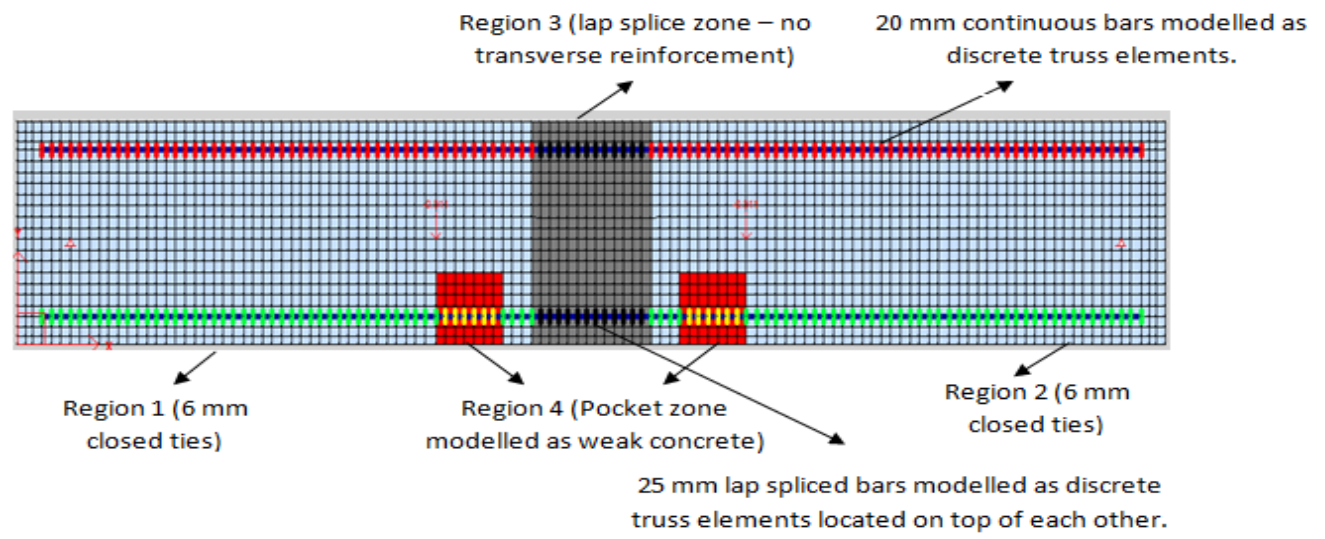

Figure 4.2: Finite element model of beam specimen. 


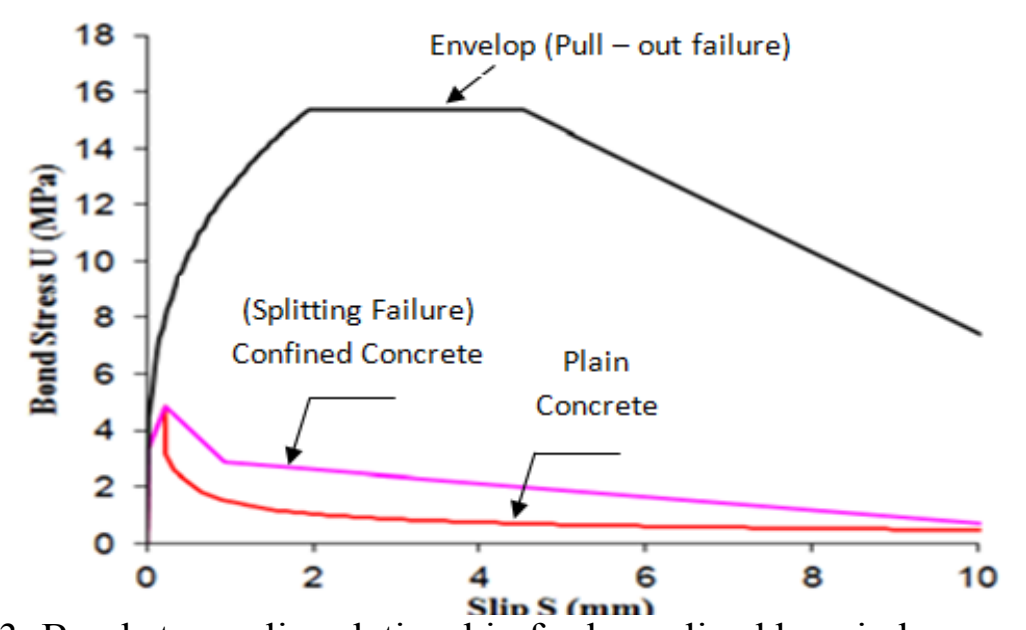

Figure 4.3: Bond stress-slip relationship for lap spliced bars in beam specimen.

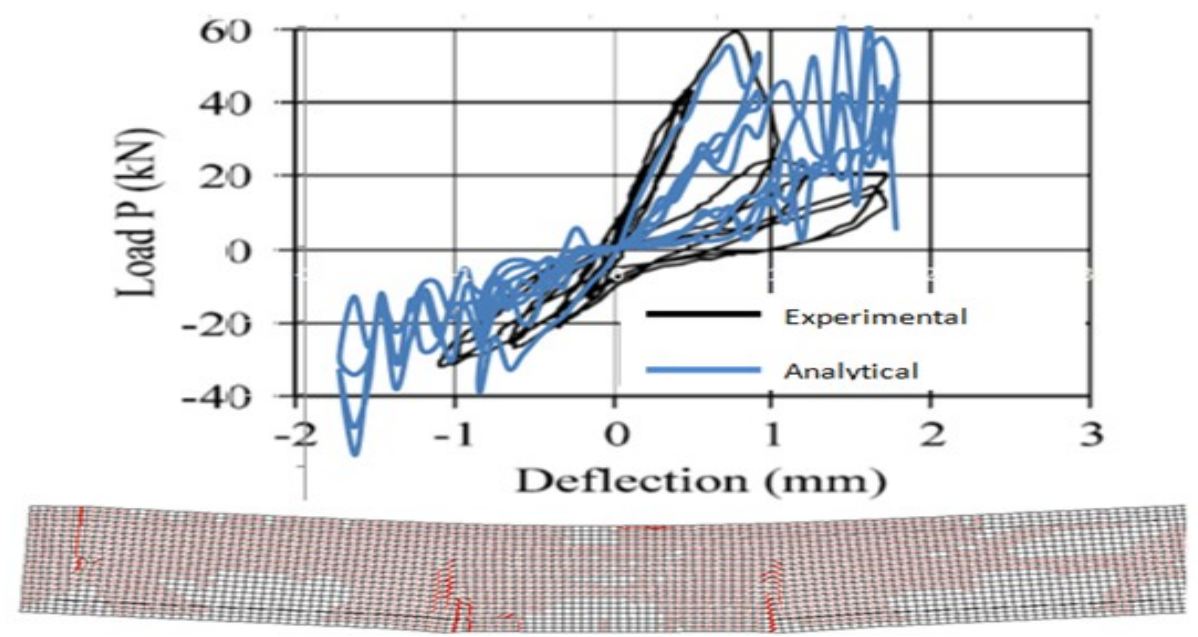

Figure 4.4: Hysteretic curve comparison of analytical modelling with original beam specimen B25 (Harajli 2006) and associated failure mode.
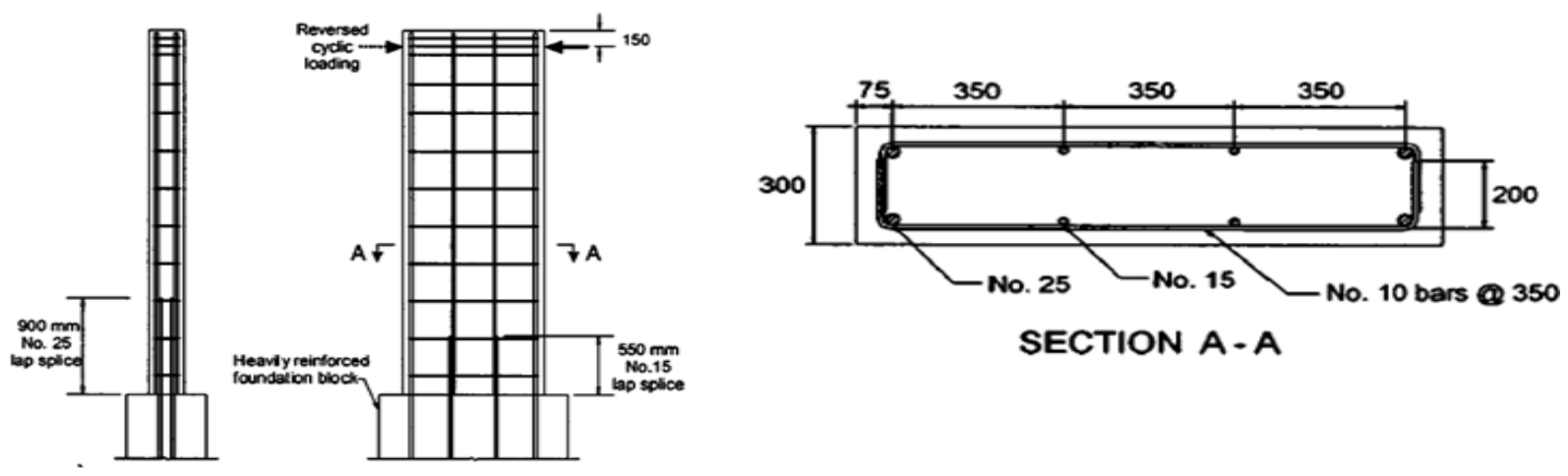

W1 wall specimen

Figure 4.5: W1 wall specimen details and lap splice locations (Paterson and Mitchell 2003). 


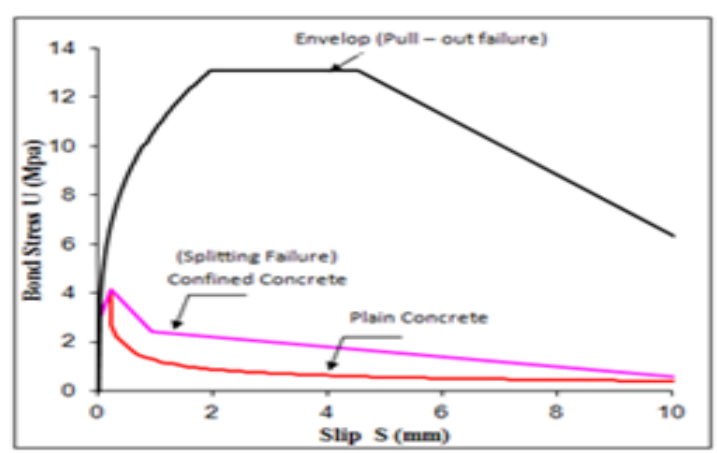

Bond stress-slip curves (No. 25 bars)

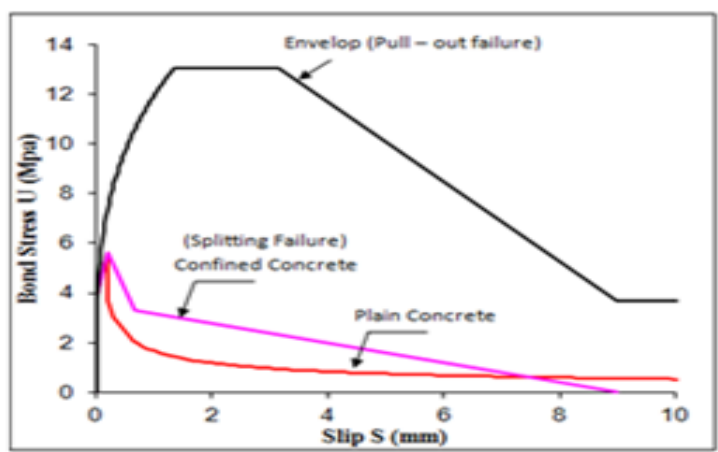

Bond stress-slip curves (No.15 bars)

Figure 4.6: Bond stress-slip curves for lap spliced bars in the Paterson and Mitchell (2003) wall specimen W1.

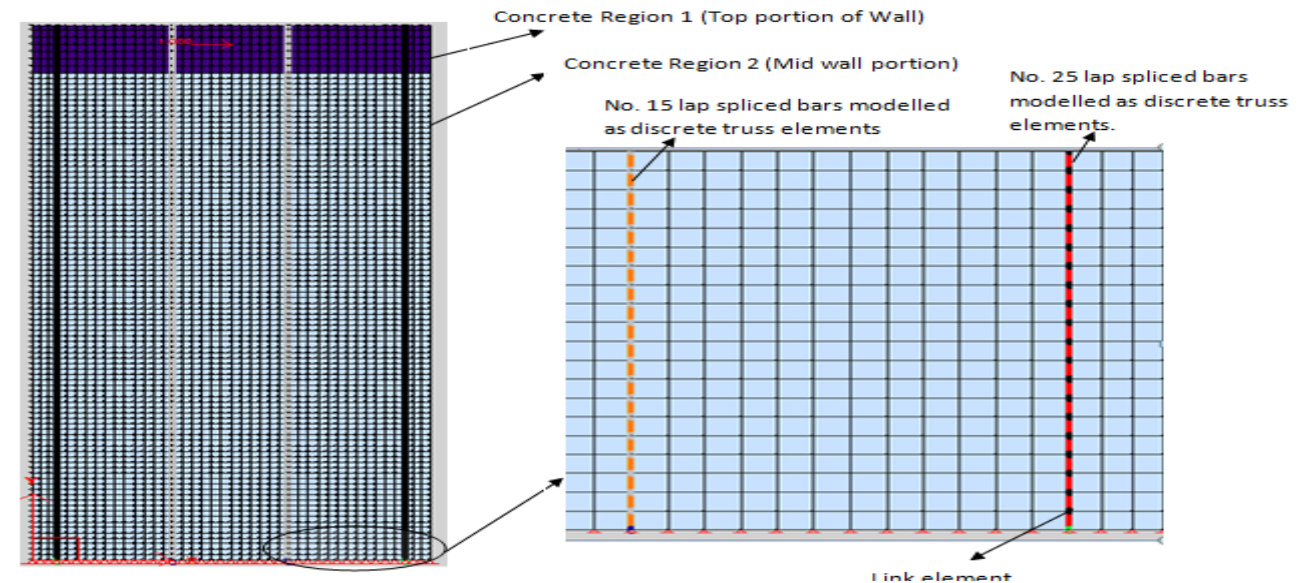

Figure 4.7: Finite element model of wall specimen W1.

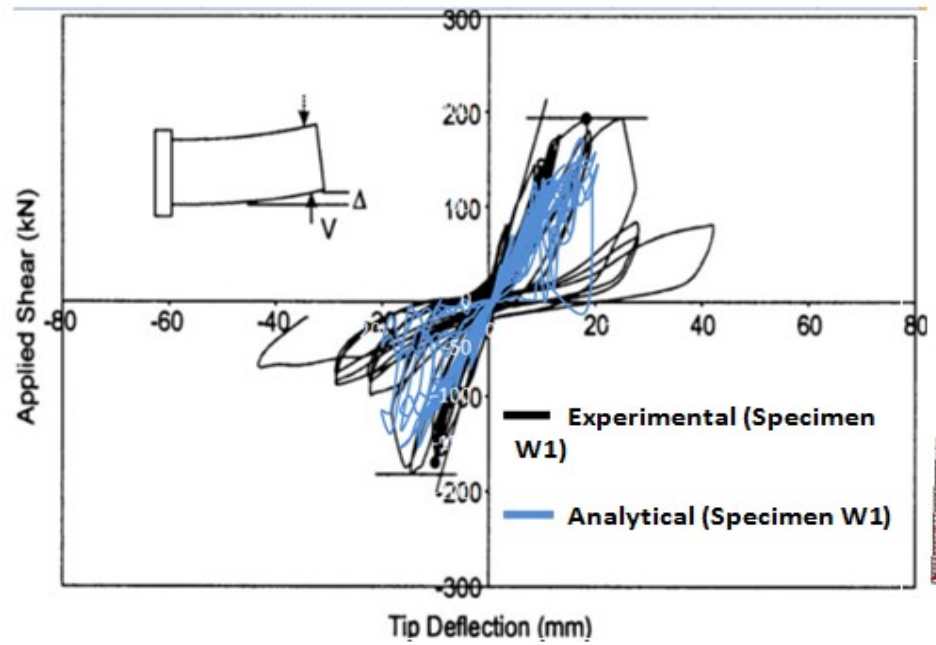

Observed mode of Failure:
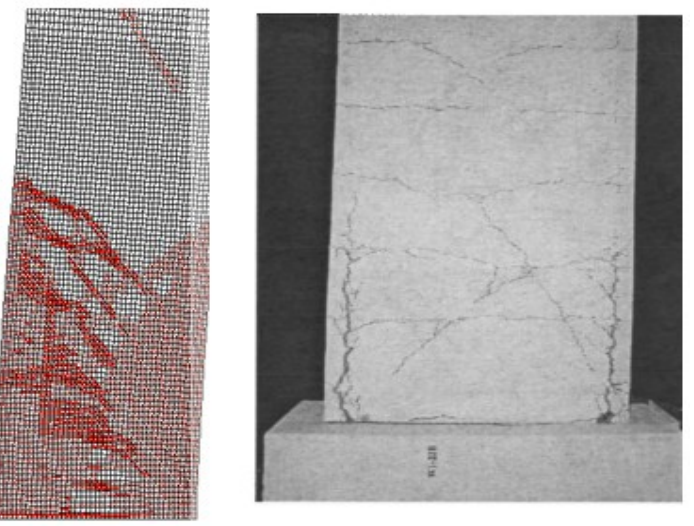

Figure 4.8: Hysteresis curve of wall specimen W1 along with failure modes and original failure mode from experiment (Paterson and Mitchell 2003). 

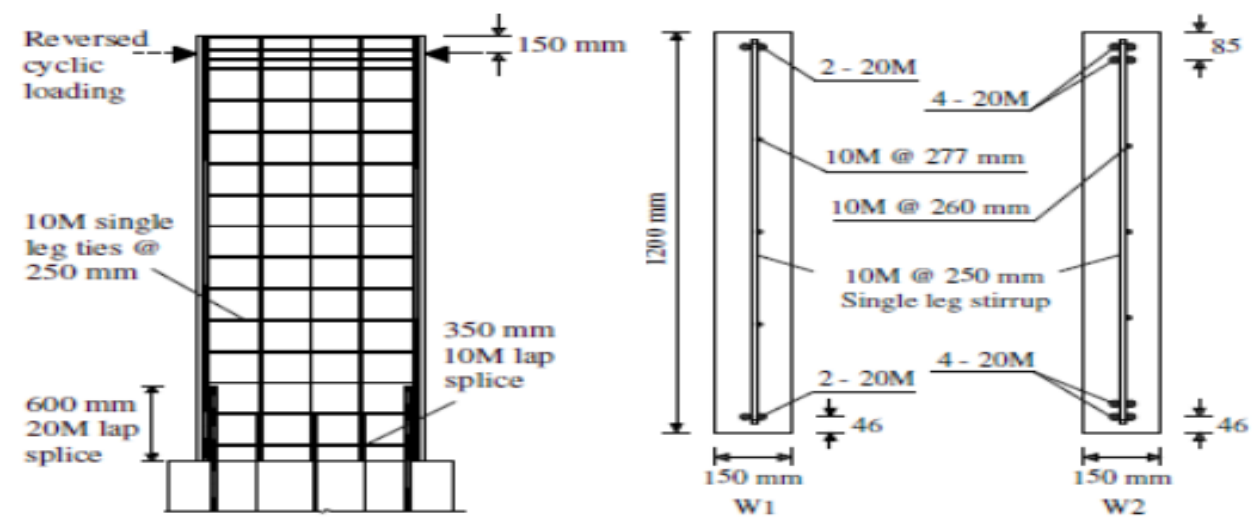

Figure 4.9: W1 and W2 wall specimen details and lap splice locations (Layssi and Mitchell 2012).

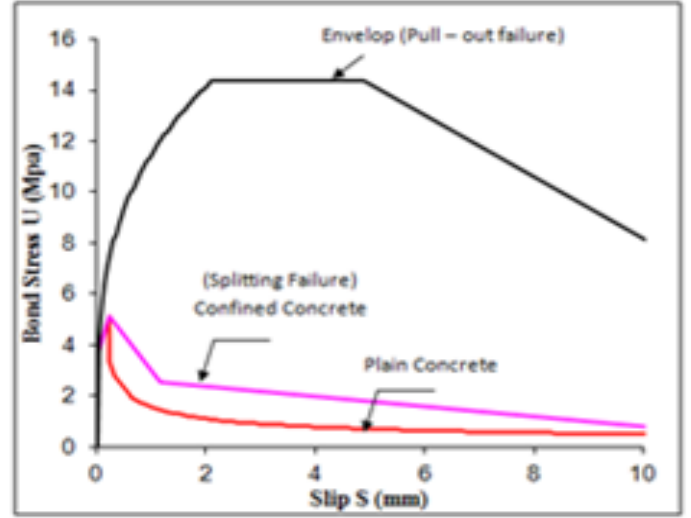

Bond stress-slip curves (No.20 bars)

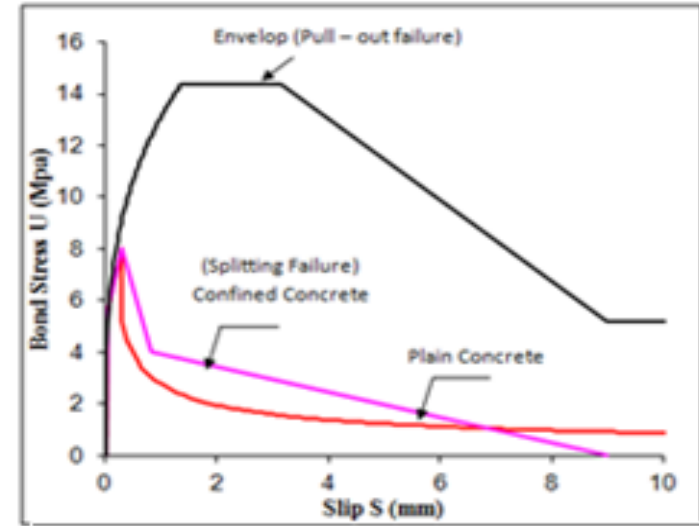

Bond stress-slip curves (No.10 bars)

Figure 4.10: Bond stress-slip curves for lap spliced bars in the W1 and W2 wall specimens in the Layssi and Mitchell (2012) study.

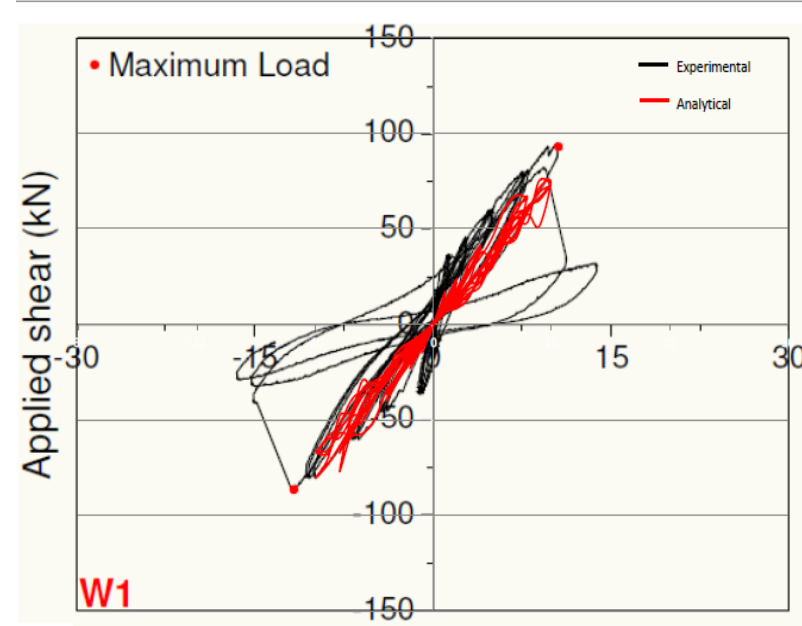

Tip Deflection (mm)

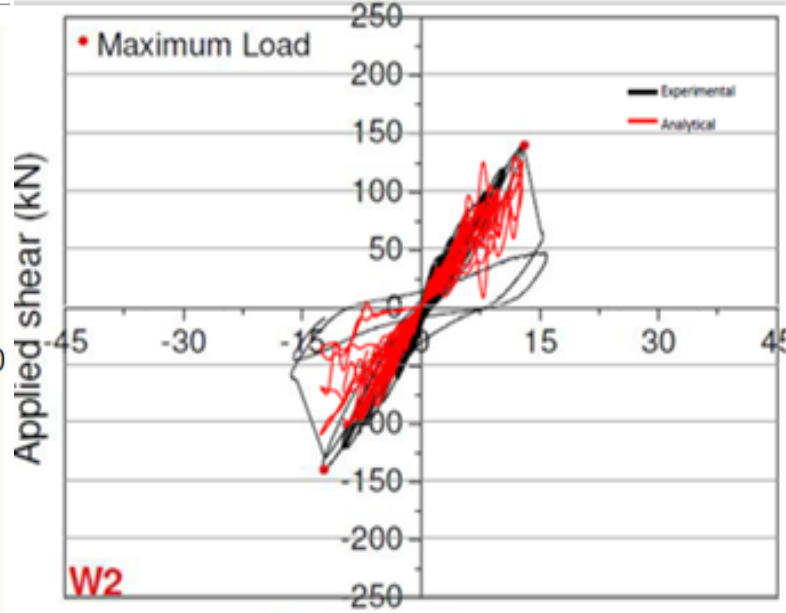

Tin Deflection $(\mathrm{mm})$

Figure 4.11: Hysteresis plots for both W1 and W2 specimens. 


\section{Chapter 5}

\section{Analysis of Seismically Deficient Reinforced Concrete Shear Walls}

\subsection{Finite Element Results and Discussions of Seismically Deficient Walls}

The wall specimens are subjected to a quasi-static reverse cyclic loading up to failure. In this section the finite element simulation results are presented. Comparisons of the analysis results from different specimens are discussed. The finite element simulations include: (a) control walls, (b) strengthened walls, (c) repaired walls. In Section 5.2, the results of the analysis conducted on variations of the slender wall specimens are discussed. In Section 5.3, the results of the intermediate wall specimens are discussed, and in Sections 5.4 and 5.5 the results of the squat wall specimens are presented.

\subsection{Slender wall specimens}

The hysteresis curves of the analyzed wall specimens are presented as comparison cases: (a) control wall versus with FRP strengthened wall, and (b) control wall versus FRP repaired wall. The failure modes are shown in Figures 5.1 and 5.2. As shown in Figures 5.1 and 5.2, the FRP repair and strengthening system has a significant impact on the seismic response of the control slender wall specimen. Significant increases in ultimate displacement capacity, energy dissipation capability, and structural load bearing capacity are observed and summarized in Tables 5.1 and 5.2. Moreover, the FRP repair and strengthening system has an important impact on the ductility behaviour of the control wall specimen as the mode of failure shifts from a brittle diagonal shear failure to a ductile failure behaviour of sliding shear at the base of the wall 
specimen after flexural yielding of the steel reinforcing bars has occurred, as shown in the crack patterns in Figures 5.1 and 5.2. The initiation of the sliding shear failure in the strengthened wall and repaired wall specimens starts by the formation of tensile cracks in concrete. The tensile cracks on the wall boundaries are followed by the crushing of the concrete at the toe of the wall specimen. As the cyclic lateral load increases, the flexural cracks at the wall edges open up wider and spread towards the wall center where they eventually meet and connect to become a continuous crack at the base. Once the connection between the cracks is achieved, the wall panel then experiences a rocking rotation about the compressive base corner of the wall due to uplift at the tension side of the wall specimen. Further loading can lead to slippage at the wall base of sliding shear failure. As the failure shifts from a brittle mannered failure mode to a ductile failure mode the energy dissipation experienced by the system is enhanced. Figure 5.11 shows the energy dissipation plots. It is observed that the energy dissipated by the slender wall specimen in repair and strengthening is much higher than the energy dissipated by the control wall which concludes that a more ductile seismic performance has been attained by both repaired and strengthened systems.

\subsection{Intermediate wall specimens}

The hysteresis curves of the analyzed wall specimens as listed in the preface of section 5.1 are presented as comparison cases: (a) control wall versus FRP strengthened, and (b) control wall versus FRP repaired wall. The failure modes are shown in Figures 5.3 and 5.4. As shown in Figures 5.3 and 5.4, the FRP repair and strengthening system has a significant impact on the seismic response of the control intermediate wall specimen. Similar observations discussed for 
the slender walls also apply here for the intermediate wall specimens. In the case of intermediate walls, enhancement to the confinement effect provided by the FRP sheets in both repair and strengthening applications is shown to be effective in alleviating some of the structural deficiencies provided by old design and construction practices as shown in the cracking pattern presented in Figures 5.3 and 5.4 and also in the energy dissipation plots shown in Figure 5.11. The application of the FRP sheets in the horizontal and the vertical directions play an important role in confining the concrete and bridging the diagonal tension cracks. This translates into a higher stiffness in case of the strengthening scheme and a high initial stiffness recovery rate for the repair scheme which enables the intermediate wall specimen to sustain higher forces as presented in Table 5.1, and also maintain a ductile response as shown in Figures 5.3 and 5.4. The failure modes defined by the cracking pattern in Figures 5.3 and 5.4, shift from a diagonal tension failure in the control wall specimen to a ductile sliding shear failure in both the repair and strengthening cases of the intermediate wall specimens. The energy dissipation observed in Figure 5.11 also shows that the repair and strengthening scheme is successful in increasing the ductility capacity of the wall specimens and plays an important role in promoting a more ductile behaviour.

\subsection{Squat wall specimens without Lap Splices}

The load-displacement relationships obtained of the cases: (a) control wall versus FRP strengthened wall, and (b) control wall versus FRP repaired wall, are presented with their respective failure modes in Figures 5.5 and 5.6. As shown in Figures 5.5 and 5.6, it is observed that the FRP repair and strengthening system has similar observations with the squat wall 
specimens as in the cases of the slender and intermediate wall specimens. The FRP reinforcing scheme is shown to have beneficial effects on the seismic behaviour of the control wall specimens. It provides sufficient confinement to alter the brittle behaviour response as observed in Figure 5.5 shown by the diagonal tension cracks in the cracking pattern simulation of the control wall, to a more ductile response as observed in Figures 5.5 and 5.6 as shown by the formation of sliding shear at the base of the wall specimen in a ductile manner. The FRP repair scheme is shown to also remedy the poor detailing of the control wall specimen and adequately repair the damaged wall specimen as shown in Figure 5.6 (b), where the onset of diagonal tension is effectively confined by the FRP sheets.

\subsection{Squat wall specimens with Lap Splices}

The investigation of the squat wall specimens with lap splices are considered in two scenarios based on the lap splice length. The first scenario is the long lap splice length scenario of $36 \mathrm{~d}_{\mathrm{b}}$. The wall with a lap splice length of $36 \mathrm{~d}_{\mathrm{b}}$ is retrofitted by the application of 4 horizontal FRP sheets per side no vertical FRP sheet added. The load-displacement relationships obtained of the

cases: (a) control wall versus FRP strengthened wall, and (b) control wall versus FRP repaired wall, are shown in Figures 5.7 and 5.8. As shown in Figures 5.7 and 5.8, the FRP improves significantly the seismic response of walls with lap splice length of $36 d_{b}$ at the plastic hinge region. While the long lap splice length contributes to the load resistance of the lap spliced reinforcing bars against slippage, the confinement effect of the FRP sheets prevents the concrete from splitting failure. For the case of the control wall shown in Figure 5.7 (a), it can be seen that the wall specimen fails in diagonal tension shear due to insufficient shear reinforcement present 
in the wall specimen. The lap spliced reinforcing bars are shown to hold together and develop some yielding until the crushing of the concrete and the propagation of the shear cracks in the analysis. In comparison with the addition of FRP in the strengthening wall, the failure mode shifts to a sliding shear failure along the lap splice length after yielding of the vertical reinforcing bars. This is due to the expansion of flexural cracks and not due to the slippage of the bars. Thus the FRP is effective in enhancing the structural bearing capacity, energy dissipation and ultimate displacement capacity of wall specimens in the case of the wall specimen with long lap spliced bars. The repair scheme yields similar results to the strengthening scheme, with only the difference in the failure mode of the formation of sliding shear failure plane at the base of the wall specimen. This suggests that the resistance of the lap spliced reinforcing bars enhanced by the addition of the FRP sheets is sufficient to resist the forces applied on the structure resulting in a sliding shear failure of the wall. It is also noted that the concrete medium is not as severely damaged as in the strengthening scheme case and the resistance provided by both the ribs of the spliced bars and the FRP sheets are effective in facilitating the sliding shear failure at the base of the wall specimen.

The second scenario considered in the investigation of shear walls with lap splice reinforcing bars is the case with short lap splice length of $21 d_{b}$. The wall with a lap splice length of $21 d_{b}$ is retrofitted by the application of 4 horizontal FRP sheets in addition to 3 vertical FRP sheets per side of the wall. The load-displacement relationships obtained of the cases: (a) control wall versus with FRP strengthened wall, and (b) control wall versus FRP repaired wall, are shown in Figures 5.9, and 5.10. As presented in Figures 5.9 and 5.10, the FRP improves significantly the seismic response of walls with lap splice length of $21 d_{b}$ at the plastic hinge region. The FRP 
sheets are shown to have the effect of enhancing the ductile response of the wall specimens. The final failure of the walls due to a brittle sliding shear behaviour at the base of the wall specimens shows that the FRP system is not effective in preventing this type of failure. In the current study presented, it is attempted to retrofit the lap splice deficiency by enhancing the confinement effect of the concrete by adding FRP sheets on the concrete medium. It is also noted that in this study the layered effect of the multiple FRP plies is not taken into account in the analysis as the multiple FRP sheets are modeled by single layer of discrete truss elements. However it has been shown by Cruz-Noguez et al. (2012) that computer simulation results still correlate well with experimental results. Moreover the repair curve as noted in Figure 5.10 and in Table 5.3 is considerably less than the strengthening curve in terms of energy dissipation. This indicates that an early brittle failure of the lap spliced bars which in turn prevent the FRP from adequately confining the damage or repairing the lap splice to improve the ductility and energy dissipation capability of the wall specimen.

\subsection{Ductility and Drift Ratio}

The ductility and drift ratio of the wall specimens that have been modelled using Vector2 are presented in Table 5.4. As expected, wall specimens with higher lateral drift ratio also have higher displacement ductility. For both strengthening and repair applications, the addition of the FRP sheets enhances the lateral drift and ductility capacities of the wall specimens. As shown in Table 5.4, the ductility of the slender wall specimens increases from 2.3 of the control wall, to 3.0 for the strengthening case and 3.3 for the repaired specimen. It is noted the repaired slender wall specimen exhibits a higher ductility and drift ratio than the strengthened wall specimen. 
As the load bearing capacity of the wall specimen drops due to cumulative damage, suffered by the wall, the contribution of the FRP sheets in resisting the load increases and eventually becomes the dominant element in resisting the total load applied on the structure. The intermediate wall specimens also exhibit similar behaviour as in the slender wall specimens. The ductility of the intermediate wall specimens increases from 1.6 of the control wall to 1.9 for the strengthening case and 2.0 for the repaired specimen with the corresponding lateral drift increasing slightly from $0.71 \%$ to $0.82 \%$ to $0.88 \%$, respectively. The same observations are found in regards to the squat wall specimens in which the increases in ductility and lateral drift indicate a shift from the original brittle behaviour to a more ductile behaviour. The ductility rises gradually from 1.4 of the control wall to 2.0 for the strengthening case and 2.2 for the repaired wall as shown in Table 5.4. In the squat wall specimen with the long lap splice case it is shown that the lap splices have a slightly lower ductility equal to 1.2 than that of the control squat wall without lap splices of 1.4. The FRP in both strengthening and repair cases helps to shift the brittle response to a more ductile response behaviour. The lap splice length with larger number of ribs engage with the concrete keys and each other during loading resulting in, increases of the resistance capacity of the wall specimen. and allows the wall specimen to keep carrying load. The ductility reached by the repaired squat wall specimen with the long lap splice clearly shows that the FRP repair scheme is effective in making the lap splice connection hold as the repaired wall specimens ductility reaches the same value of 2.2 as that of the repaired squat wall specimen without lap splices. For the short lap splice case, all wall specimen have lap splice failure resulting in a ductility ratio of less than 1 which denotes the response when lap splice fails relative to the yield response of the squat wall without lap splices. It is noted that the 
strengthening case exhibits a higher drift and ductility than the repaired case due to the fact that the lap spliced bars fail early on in the analysis resulting in the inability of the FRP repair procedure in confining the damage allowing the wall specimen to maintain load bearing capacity. The experimental slender wall results are presented in Table 5.5. It is shown that the drift ratio and the ductility of the experimentally tested slender wall specimen are in good correlation with the analytical results presented in Table 5.4.

\subsection{Energy Dissipation}

Energy dissipation plots are presented to show the accumulated amount of energy dissipation of the wall specimens observed in the analysis. Figure 5.11 shows the accumulated energy disipation for the wall specimens. As presented in Figure 5.11, the FRP reinforcing scheme facilitates a considerable increase in the energy dissipation capability of each wall specimen. The results are summarized in Tables 5.1, 5.2, and 5.3. Table 5.3 shows that the FRP reinforced walls with the strengthening scheme have on average $9.5 \%$ higher stiffness, $18.0 \%$ higher strength, $51.2 \%$ higher ultimate displacement, and a $680 \%$ higher energy dissipation capability than walls with no FRP reinforcement. FRP reinforced walls with the repair scheme have in average 20.3\% higher strength, 55.9\% higher ultimate displacement, $371.4 \%$ higher energy dissipation capability than walls with no FRP reinforcement. Also as noted in Table 5.2, the yielding stiffness of the FRP following repair of the damaged walls is less than that of the control wall specimens because in the analysis of the repaired wall the diagonal tension cracks in the control walls are not considered to have been adequately repaired sealed with epoxy such that the 
repaired wall only has the addition of the FRP sheets. This assumption is considered here to simulate the case when the concrete cracks are not properly repaired such that the wall can regain a substantial part of the initial stiffness loss due to damage. In this case, the FRP sheets serve to provide the baseline information of the ability of the FRP system in recovering the initial stiffness of damaged wall specimens. According to the results obtained from Table 5.2, the FRP repair scheme recovered $88 \%$ of the yielding stiffness in the slender wall specimen, $82 \%$ in the intermediate wall, $86 \%$ in the squat wall specimen without lap splices, $68 \%$ in the squat wall specimen with $36 d_{b}$ lap splice, and $70 \%$ stiffness recovery in the squat wall specimen with $21 d_{b}$ lap splice. Thus, on average the FRP repair system has a 79\% stiffness recovery capacity. Previous studies conducted by Lombard et al. (1999); and Hiotakis (2004) reported increases in stiffness (28\%) and (40\%) for slender walls with the same amount of vertical FRP reinforcement. However, in those studies the steel longitudinal reinforcement ratio is $0.8 \%$, while the longitudinal ratio used in this study is $3 \%$. Thus, the contribution of the vertical FRP material is more significant in the walls tested by Lombard et al. (1999) and Hiotakis (2004). Tables 5.2 and 5.3, clearly show the benefits of an FRP reinforcing system consisting of vertical and horizontal FRP sheets used simultaneously. Premature shear failure is prevented by enhancing the shear strength of the wall specimens (with the FRP sheets applied in the horizontal direction), allowing the wall specimens to reach their ultimate flexural capacities. The flexural strength and yielding stiffness are also increased by the use of vertical sheets of FRP material. In terms of energy dissipation the FRP reinforced walls exhibited an average of $680 \%$ increase utilizing the strenghening scheme and $371.4 \%$ using the repair scheme which translates to a significantly better seismic performance of FRP-reinforced wall specimens. 


\subsection{Comparison with experimental results}

In this section the analytical results of the slender wall specimen are compared with the experimental results. In Figures 5.12, 5.13 and 5.14, the hysteresis curves of the control, strengthened, and the repaired slender wall specimen are presented and compared with the analytical results. The average material properties obtained from concrete cylinder and steel coupon tests include a concrete strength of $23.04 \mathrm{MPa}$ and a yielding stress of $414.76 \mathrm{MPa}$ and an ultimate stress of $597 \mathrm{MPa}$ for the reinforcing steel bars. These measured material properties are used in the computer models to generate the computer simulation presented in this section. From the control wall comparison shown in Figure 5.12, it is shown that the analytical results have the same initial stiffness of $46.5 \mathrm{KN} / \mathrm{mm}$ as the tested slender control wall. The computer model also shows the same failure mechanism of diagonal tension shear failure as observed in the test wall. The computer results follow the same pattern as the experimental results during responses in the elastic range and at low ductility level. The yield displacement reached in the computer simulation of the control slender wall is $6.84 \mathrm{~mm}$ while the measured yield displacement in the push direction is $5.8 \mathrm{~mm}$ and in the pull direction is $4.19 \mathrm{~mm}$. The average experimental yield displacement is $5.0 \mathrm{~mm}$. The ultimate peak load attained in the computer model is $444.5 \mathrm{KN}$, while the ultimate load reached in the experimental test is $346.12 \mathrm{KN}$. The ductility level for the computer simulation is 2.3 , while the observed ductility in the push direction is 1.93 and in the pull direction is 1.38 . The average ductility level in the experimental test is equal to 1.70. As shown in Figure 5.12, there is a discrepency in the peak strength between the prediction by the computer model with the test results. 
This discrepency together with the unsymmetric test results observed in the push and pull directions can be attributed to some factors in the loading sequences experienced during the testing process of the control wall. During the test, the wall specimen was observed to have slid upon loading before the problem was rectified. Further, there was an interruption to the test sequence due to stoppage of hydraulic testing equipment. The test results may be affected as a result of these interruptions leading to discrepencies observed between the computer simulations and the test data. For the case of the strengthened slender wall shown in Figure 5.13, it is noted that the analytical results are in good agreement with the experimental results. The yielding stiffness in the strengthened experimental wall is slightly higher than that of its analytical counterpart and is equal to $87.7 \mathrm{KN} / \mathrm{mm}$, while the analytical model has a stiffness of 72 $\mathrm{KN} / \mathrm{mm}$. The ultimate strength predicted by the computer model is $540 \mathrm{KN}$ and is very close to the experimental result of $595 \mathrm{KN}$. The ultimate predicted displacement in the computer simultations is $20.6 \mathrm{~mm}$ while the observed maximum displacement in the experiment in the pull direction is $22.4 \mathrm{~mm}$ and in the push direction is $12.7 \mathrm{~mm}$ with an average ultimate displacement in the test of $18.0 \mathrm{~mm}$. The tested strengthened wall specimen shows a close level of ductility of 3.3 in the pull direction compared to 3.18 in the push direction. The average ductility of the test is 3.2. The ductility predicted by the computer model of the strengthened wall is 3.0. The observed failure modes are flexural cracking of the concrete and then yielding of the steel reinforcing bars at the two edges of the wall, followed by de-bonding of the CFRP sheets from the concrete substrate and fracture tear of the CFRP sheet at the base of the wall edges. As the lateral applied load increases, the area of the FRP de-bonding spreads towards the center part of the wall. Finally, soon after the FRP sheets are de-bonded entirely at the base of the wall with the 
spreading of the de-bonded regions meeting in the interior part of the wall base, the wall specimen experiences the ultimate failure mode of sliding shear failure which is the same failure mode predicted by the computer simulation. The transition of the failure mode from a brittle diagonal tension shear failure mechanism in the control wall to a ductile behaviour as characterized by the ultimate failure of sliding shear at the base of the strengthened slender wall. This transition to ductile behaviour demonstrates the effectiveness of the FRP strengthening scheme in enhancing the seismic behaviour of the deficient control wall specimen. The FRP sheets reach their ultimate fracture strength as the lateral load resistance is entirely shifted to the FRP sheets after the yielding and buckling of the reinforcing bars and the crushing of the concrete. The FRP strengthening scheme is effective in mitigating the brittle behaviour of diagonal tension failure of the deficient wall to a ductile behaviour. For the case of the repaired slender wall presented in Figure 5.14 the predicted behaviour by the computer model correlates well initially during the re-test of the repaired wall. The computer simulation results follow the experimental hysteresis behaviour closely. One possible reason for the discrepancy between the computer simulation results and the test data is that in the computer model, the wall specimen is simulated to suffer only damage corresponding to the onset of diagonal tension failure of the original wall. In the actual test, the wall specimen suffers a more severe level of damage of diagonal tension corresponding to a near complete loss of lateral load resistance. The computer simulated repaired wall specimen reaches an ultimate strength of $542.2 \mathrm{KN}$, as compared to an ultimate strength of $656.50 \mathrm{KN}$ in the experimental test. On the initial stiffness, the experimental test result gives $103.625 \mathrm{KN} / \mathrm{mm}$ while the predicted initial stiffness in the computer simulation is $48.96 \mathrm{KN} / \mathrm{mm}$. 
This apparent higher stiffness in the tested wall specimen is attributed to the repair process with the cracks in the damaged wall specimen repaired and sealed by epoxy injections. The application of the FRP sheets applied on top of the epoxy injection repaired wall increases the stiffness of the actual wall specimen which is not accounted in the simulation. Also the confinement effect of layered FRP sheets is not taken into account in the analytical model which contributes to the increase in initial stiffness in the test specimen.On the experiment, the repaired wall specimen achieves a high level of displacement ductility of 3.0 in the push direction and 3.5 in the pull direction. The displacement ductility predicted by the computer model is 3.3 . The high displacement ductility level observed in the test signifies that the FRP sheets continue to carry load until the development of its maximum tensile strength. Overall the curves as shown in Figure 5.14 follow each other closely indicating that although there are differences in the repair process of the actual wall from the computer simulation, are shown, the prediction of the behaviour of the repaired wall by the computer generated model gives reasonable agreements with the experimentally obtained results.

Table 5.1: Finite element analysis results for Control vs. Strengthened with FRP.

\begin{tabular}{|c|c|c|c|c|c|c|c|c|}
\hline Wall type: & $\begin{array}{c}\text { Yielding } \\
\text { stiffness, } \\
\text { Ky } \\
\text { No FRP } \\
(\mathrm{KN} / \mathrm{mm})\end{array}$ & $\begin{array}{c}\text { Yielding } \\
\text { stiffness, } \\
\text { Ky } \\
\text { with FRP } \\
(\mathrm{KN} / \mathrm{mm})\end{array}$ & $\begin{array}{l}\text { Ultimate } \\
\text { strength, } \\
\text { Pu } \\
\text { No FRP } \\
\text { (KN) }\end{array}$ & $\begin{array}{l}\text { Ultimate } \\
\text { strength, } \\
\text { Pu } \\
\text { with FRP } \\
\text { (KN) }\end{array}$ & $\begin{array}{c}\text { Ultimate } \\
\text { displacement, } \\
\Delta \mathrm{u} \\
\text { No FRP } \\
(\mathrm{mm})\end{array}$ & $\begin{array}{c}\text { Ultimate } \\
\text { displacement, } \\
\Delta \mathrm{u} \\
\text { with FRP } \\
(\mathrm{mm})\end{array}$ & $\begin{array}{l}\text { Energy } \\
\text { Dissipation } \\
\text { No FRP } \\
(\mathrm{KN} / \mathrm{mm})\end{array}$ & $\begin{array}{c}\text { Energy } \\
\text { Dissipation } \\
\text { with FRP } \\
(\mathrm{KN} / \mathrm{mm})\end{array}$ \\
\hline Slender wall & 55.79 & 63.71 & 444.50 & 539.60 & 17.81 & 22.83 & 31943.52 & 134054.00 \\
\hline $\begin{array}{c}\text { Intermediate } \\
\text { wall }\end{array}$ & 155.79 & 170.17 & 987.40 & 1223.40 & 13.78 & 17.71 & 34325.87 & 159064.50 \\
\hline $\begin{array}{c}\text { Squat wall-2 } \\
\text { without lap } \\
\text { splice }\end{array}$ & 306.64 & 342.29 & 1884.10 & 2192.70 & 10.81 & 16.17 & 14894.94 & 90614.78 \\
\hline $\begin{array}{c}\text { Squat wall } 2 \\
\text { with } 36 \mathrm{db} \text { lap } \\
\text { splice }\end{array}$ & 294.68 & 306.19 & 1317.40 & 1469.90 & 8.70 & 14.68 & 14964.12 & 45926.22 \\
\hline $\begin{array}{l}\text { Squat wall } 2 \\
\text { with } 21 \mathrm{db} \text { lap } \\
\text { splice }\end{array}$ & 284.00 & 308.71 & 902.70 & 1044.20 & 4.84 & 8.77 & 633.69 & 13345.61 \\
\hline
\end{tabular}


Table 5.2: Finite element analysis results for Control vs. Repair with FRP.

\begin{tabular}{|c|c|c|c|c|c|c|c|c|}
\hline Wall type: & $\begin{array}{c}\text { Yielding } \\
\text { stiffness, } \\
\text { Ky } \\
\text { No FRP } \\
\text { (KN/mm) }\end{array}$ & $\begin{array}{c}\text { Yielding } \\
\text { stiffness, } \\
\text { Ky } \\
\text { with FRP } \\
\text { (KN/mm) }\end{array}$ & $\begin{array}{c}\text { Ultimate } \\
\text { strength, } \\
\text { Pu } \\
\text { No FRP } \\
\text { (KN) }\end{array}$ & $\begin{array}{c}\text { Ultimate } \\
\text { strength, } \\
\text { Pu } \\
\text { with FRP } \\
\text { (KN) }\end{array}$ & $\begin{array}{c}\text { Ultimate } \\
\text { displacement, } \\
\Delta \mathrm{u} \\
\text { No FRP } \\
(\mathrm{mm})\end{array}$ & $\begin{array}{c}\text { Ultimate } \\
\text { displacement, } \\
\Delta \mathrm{u} \\
\text { with FRP } \\
(\mathrm{mm})\end{array}$ & $\begin{array}{l}\text { Energy } \\
\text { Dissipation } \\
\text { No FRP } \\
(\mathrm{KN} / \mathrm{mm})\end{array}$ & $\begin{array}{l}\text { Energy } \\
\text { Dissipation } \\
\text { with FRP } \\
(\mathrm{KN} / \mathrm{mm})\end{array}$ \\
\hline Slender wall & 55.79 & 49.75 & 444.50 & 542.20 & 17.81 & 23.81 & 31943.52 & 156513.30 \\
\hline $\begin{array}{c}\text { Intermediate } \\
\text { wall }\end{array}$ & 155.79 & 131.16 & 987.40 & 1232.90 & 13.78 & 17.74 & 34325.87 & 161747.40 \\
\hline $\begin{array}{c}\text { Squat wall-2 } \\
\text { without lap } \\
\text { splice }\end{array}$ & 306.64 & 268.87 & 1884.10 & 2221.80 & 10.81 & 18.19 & 14894.94 & 115872.70 \\
\hline $\begin{array}{l}\text { Squat wall } 2 \\
\text { with } 36 \mathrm{db} \text { lap } \\
\text { splice }\end{array}$ & 294.68 & 224.05 & 1317.40 & 1487.70 & 8.70 & 14.51 & 14964.12 & 49190.00 \\
\hline $\begin{array}{c}\text { Squat wall } 2 \\
\text { with } 21 \mathrm{db} \text { lap } \\
\text { splice }\end{array}$ & 284.00 & 219.52 & 902.70 & 1116.40 & 4.84 & 8.77 & 633.69 & 1827.78 \\
\hline
\end{tabular}

Table 5.3: Comparison between FRP Reinforced / Unreinforced Specimens

\begin{tabular}{|c|c|c|c|c|c|c|c|}
\hline Wall type: & $\begin{array}{l}\% \text { increase } \\
\text { in } \mathrm{Ky}\end{array}$ & $\begin{array}{c}\% \text { increase in } \\
\mathrm{Pu} \\
\text { (strengthened) }\end{array}$ & $\begin{array}{c}\% \text { increase } \\
\text { in Pu } \\
\text { (Repair) }\end{array}$ & $\begin{array}{c}\% \text { increase in } \\
\Delta u \\
\text { (strengthened) }\end{array}$ & $\begin{array}{c}\% \text { increase in } \\
\Delta \mathrm{u} \\
\text { (Repair) }\end{array}$ & $\begin{array}{l}\% \text { increase in } \\
\text { Energy } \\
\text { Dissipation } \\
\text { Capacity } \\
\text { (strengthened) }\end{array}$ & $\begin{array}{c}\% \text { increase in } \\
\text { Energy } \\
\text { Dissipation } \\
\text { Capacity } \\
\text { (Repair) }\end{array}$ \\
\hline Slender wall & $14.20 \%$ & $21.39 \%$ & $21.98 \%$ & $28.20 \%$ & $33.69 \%$ & $320 \%$ & $390 \%$ \\
\hline $\begin{array}{l}\text { Intermediate } \\
\text { wall }\end{array}$ & $9.23 \%$ & $23.90 \%$ & $24.86 \%$ & $28.57 \%$ & $28.74 \%$ & $363 \%$ & $372 \%$ \\
\hline $\begin{array}{c}\text { Squat wall-2 } \\
\text { without lap } \\
\text { splice }\end{array}$ & $11.63 \%$ & $16.40 \%$ & $17.92 \%$ & $49.61 \%$ & $68.27 \%$ & $508 \%$ & $678 \%$ \\
\hline $\begin{array}{c}\text { Squat wall } 2 \\
\text { with } 36 \mathrm{db} \text { lap } \\
\text { splice }\end{array}$ & $3.90 \%$ & $11.58 \%$ & $12.93 \%$ & $68.72 \%$ & $66.78 \%$ & $207 \%$ & $229 \%$ \\
\hline $\begin{array}{c}\text { Squat wall } 2 \\
\text { with } 21 \mathrm{db} \text { lap } \\
\text { splice }\end{array}$ & $8.70 \%$ & $15.68 \%$ & $23.67 \%$ & $81.00 \%$ & $82.00 \%$ & $2000 \%$ & $188 \%$ \\
\hline
\end{tabular}

Table 5.4: Drift Ratio and Ductility

\begin{tabular}{|c|c|c|c|c|}
\hline Wall Type & Aspect Ratio & Wall State & Drift Ratio (\%) & Ductility \\
\hline \multirow{3}{*}{ Slender } & \multirow{3}{*}{1.2} & Control & $0.87 \%$ & 2.3 \\
\hline & & Strengthened & $1.15 \%$ & 3.0 \\
\hline & & Repaired & $1.26 \%$ & 3.3 \\
\hline \multirow{3}{*}{ Intermediate } & \multirow{3}{*}{0.85} & Control & $0.71 \%$ & 1.6 \\
\hline & & Strengthened & $0.82 \%$ & 1.9 \\
\hline & & Repaired & $0.88 \%$ & 2.0 \\
\hline \multirow{3}{*}{ Squat } & \multirow{3}{*}{0.65} & Control & $0.48 \%$ & 1.4 \\
\hline & & Strengthened & $0.75 \%$ & 2.0 \\
\hline & & Repaired & $0.80 \%$ & 2.2 \\
\hline \multirow{3}{*}{ Squat with $36 d_{b}$ lap splice } & \multirow{3}{*}{0.65} & Control & $0.43 \%$ & 1.2 \\
\hline & & Strengthened & $0.53 \%$ & 1.4 \\
\hline & & Repaired & $0.81 \%$ & 2.2 \\
\hline \multirow{3}{*}{ Squat with $21 \mathrm{~d}_{\text {b lap splice }}$} & \multirow{3}{*}{0.65} & Control & $0.22 \%$ & $0.4 *$ \\
\hline & & Strengthened & $0.49 \%$ & $0.8 *$ \\
\hline & & Repaired & $0.33 \%$ & $0.6 *$ \\
\hline
\end{tabular}

Table 5.5: Experimental Slender Wall Results

\begin{tabular}{|c|c|c|c|c|c|c|}
\hline \multirow[t]{2}{*}{ Wall Type } & \multirow[t]{2}{*}{ Aspect Ratio } & \multirow[t]{2}{*}{ Wall State } & \multicolumn{2}{|c|}{ Drift Ratio (\%) } & \multicolumn{2}{|c|}{ Ductility } \\
\hline & & & Push & Pull & Push & Pull \\
\hline \multirow{3}{*}{ Slender } & & Control & $0.62 \%$ & $0.32 \%$ & 1.93 & 1.38 \\
\hline & 1.2 & Strengthened & $0.72 \%$ & $1.25 \%$ & 3.18 & 3.3 \\
\hline & & Repaired & $0.70 \%$ & $0.78 \%$ & 3.0 & 3.5 \\
\hline
\end{tabular}




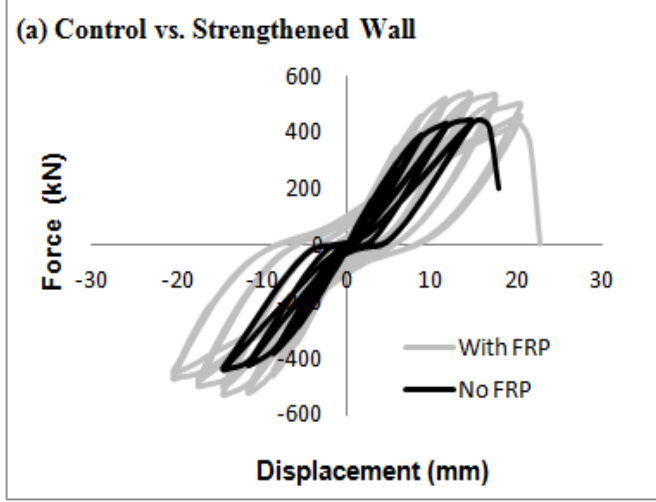

Failure Modes: Control vs. Strengthened

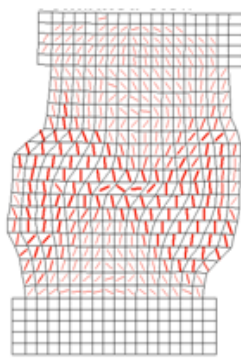

(a) Control Diagonal Tension Shear

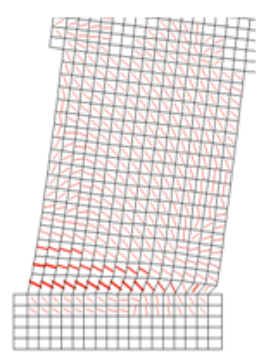

(b) Strengthened Sliding Shear

Figure 5.1: Hysteresis curve for slender wall specimen (scenario (a)).

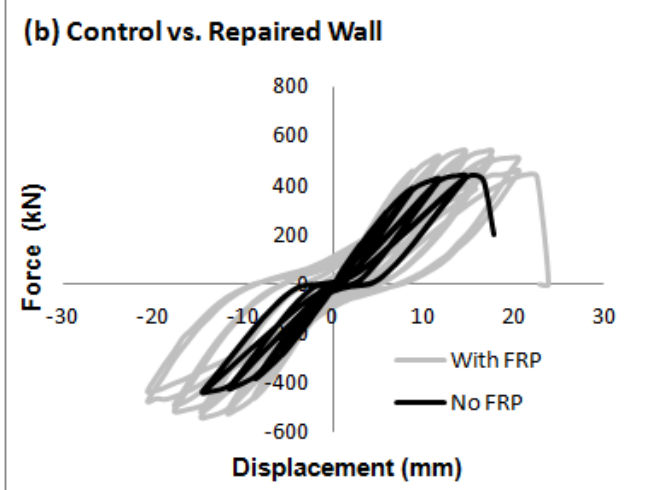

Failure Modes: Repair procedure

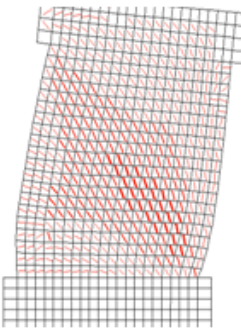

(a) Pre-Repair Onset of Diagonal Tension Shear

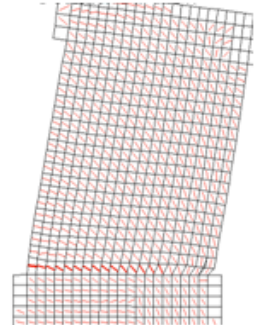

(b) Post-Repair Sliding Shear

Figure 5.2: Hysteresis curve for slender wall specimen (scenario (b)).

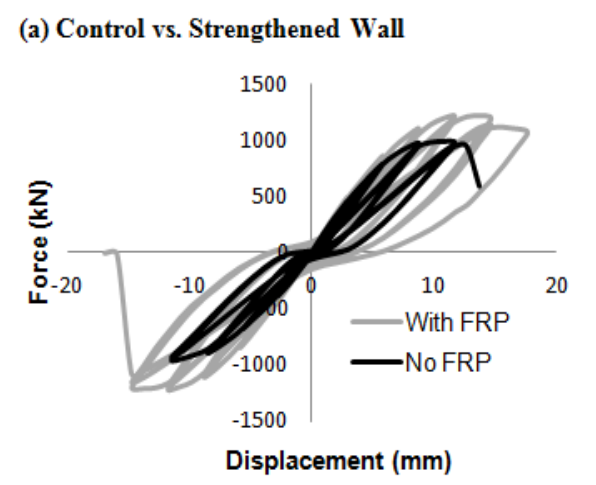

Failure Modes: Control vs. Strengthened

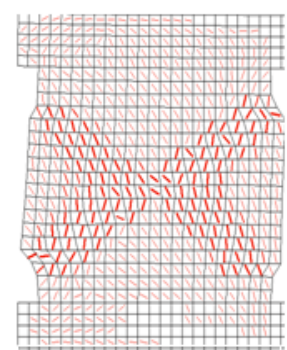

(a) Control

Diagonal Tension

Shear

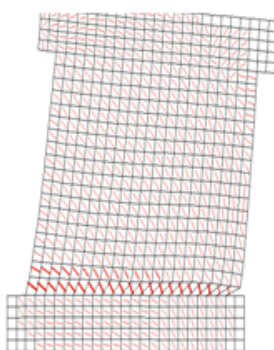

(b) Strengthened Sliding Shear

Figure 5.3: Hysteresis curve for intermediate wall specimen (scenario (a)). 


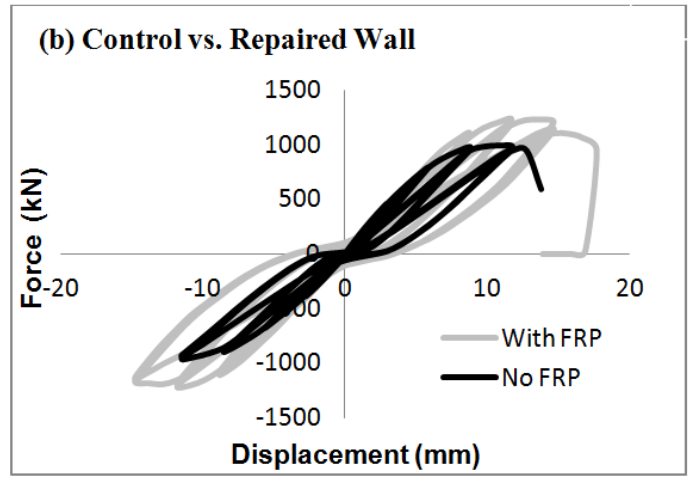

Failure Modes: Repair procedure

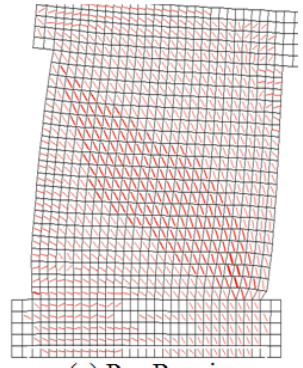

(a) Pre-Repair Onset of Diagonal Tension

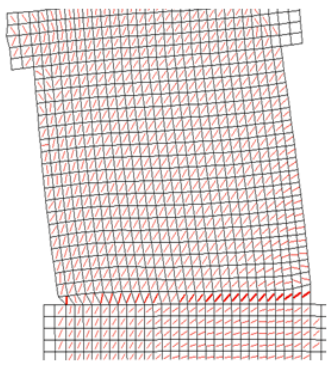

(b) Post-Repair Sliding Shear

Figure 5.4: Hysteresis curve for intermediate wall specimen (scenario (b)).

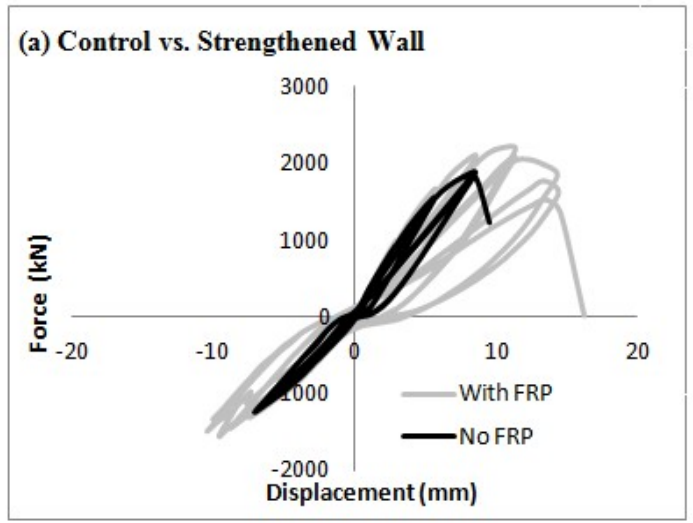

Failure Modes: Control vs. Strengthened

Figure 5.5: Hysteresis curve for squat wall specimen (scenario (a)).

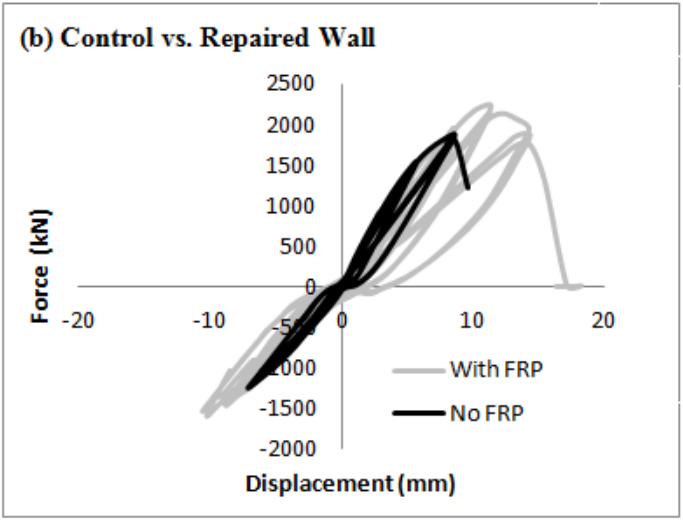

Failure Modes: Repair procedure

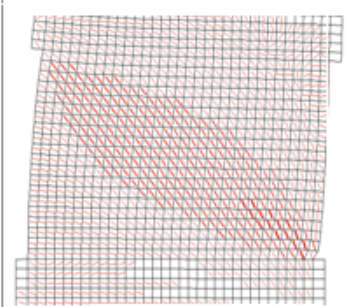

(a) Pre-Repair

Onset of

Diagonal Tension

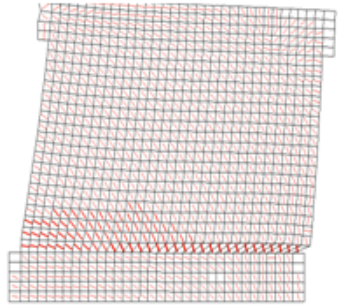

(b) Post-Repair Sliding Shear

Figure 5.6: Hysteresis curve for squat wall specimen (scenario (b)). 

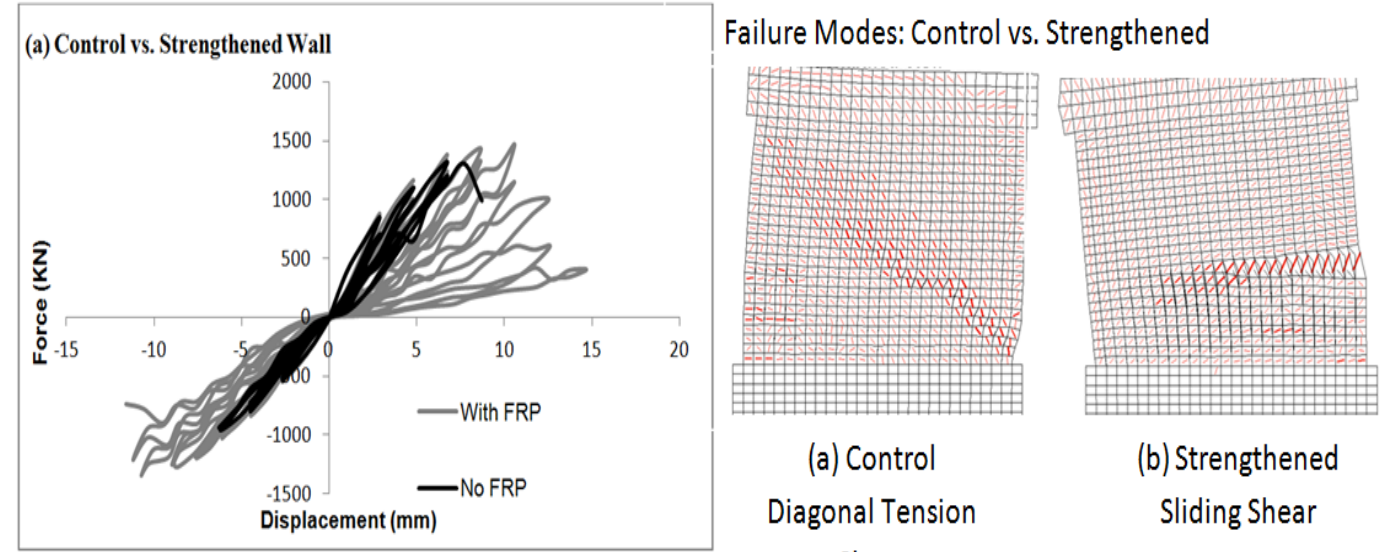
(a) Control
Diagonal Tension
Shear
(b) Strengthened
Sliding Shear

Figure 5.7: Hysteresis curve for squat wall specimen with $36 d_{b}$ lap splice length (scenario (a)).
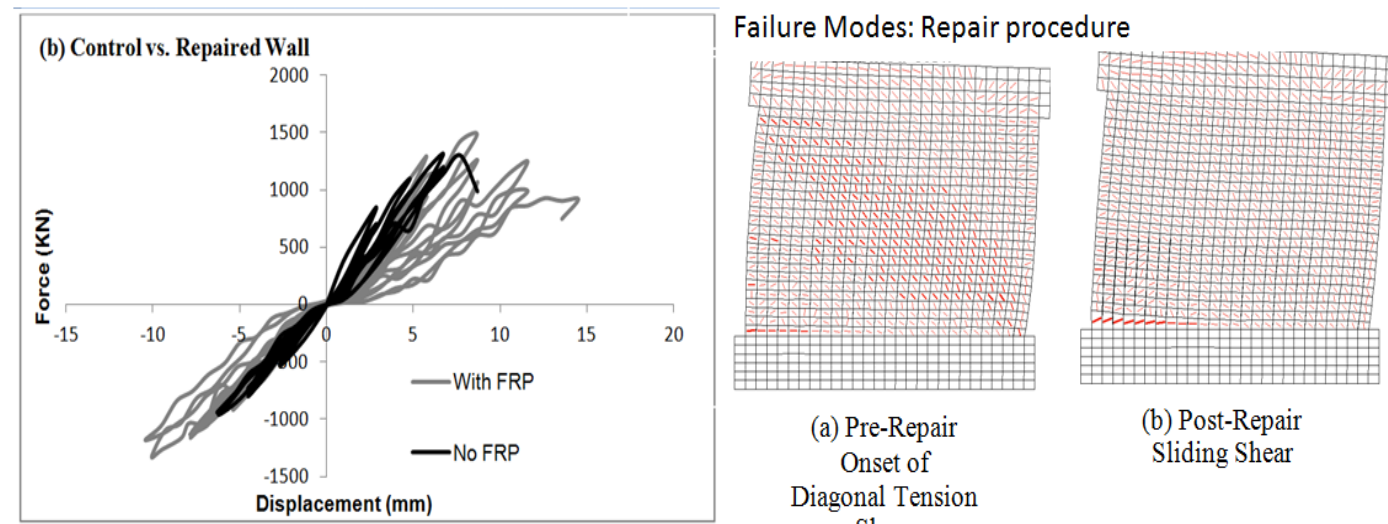
(a) Pre-Repair
Onset of
(b) Post-Repair
Sliding Shear

Diagonal Tension

Shear

Figure 5.8: Hysteresis curve for squat wall specimen with $36 \mathrm{~d}_{\mathrm{b}}$ lap splice length (scenario (b)).

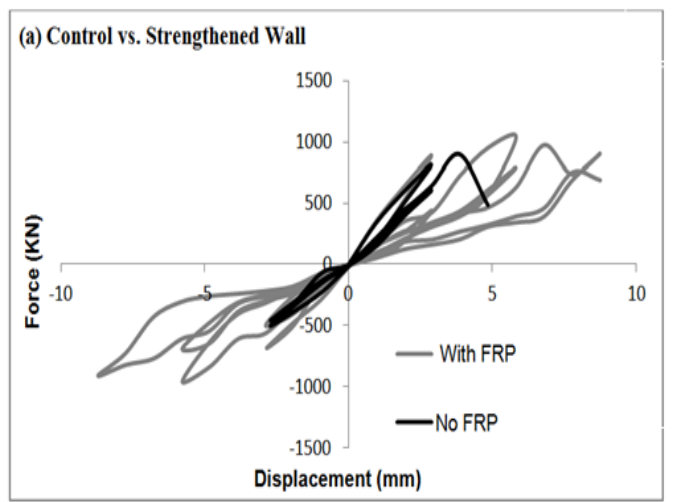

Failure Modes: Control vs. Strengthened

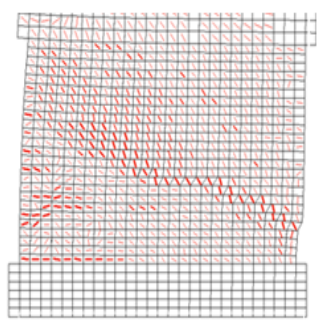

(a) Control

Diagonal Tension

Shear

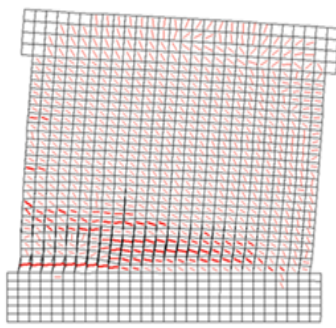

(b) Strengthened Sliding Shear

Figure 5.9: Hysteresis curve for squat wall specimen with $21 \mathrm{~d}_{\mathrm{b}}$ lap splice length (scenario (a)). 

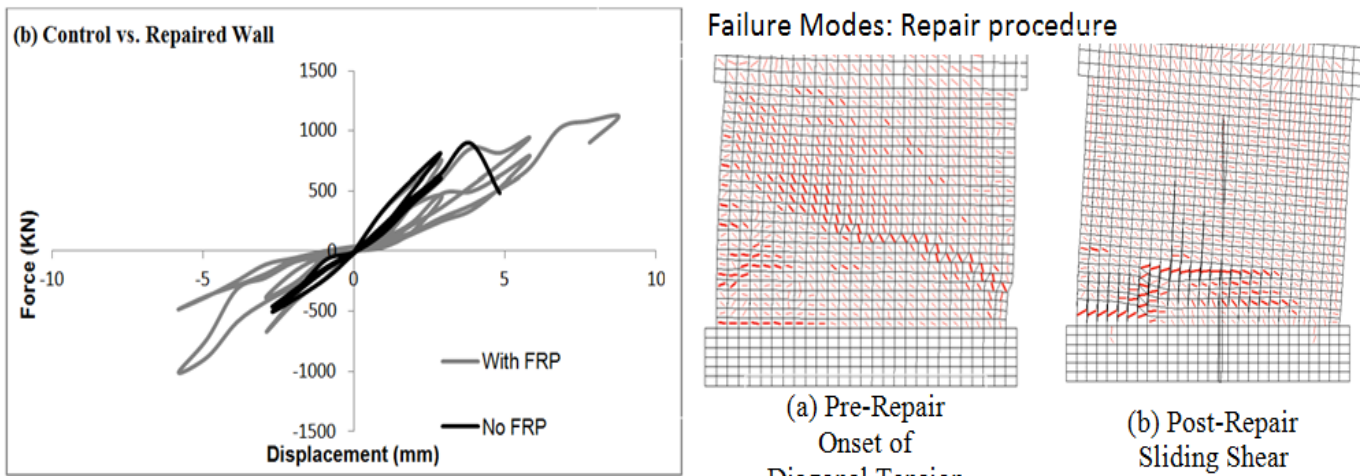
(a) Pre-Repair
Onset of
Diagonal Tension

\begin{abstract}
(b) Post-Repair Sliding Shear
\end{abstract}

Shear

Figure 5.10: Hysteresis curve for squat wall specimen with $21 d_{b}$ lap splice length (scenario (b)).
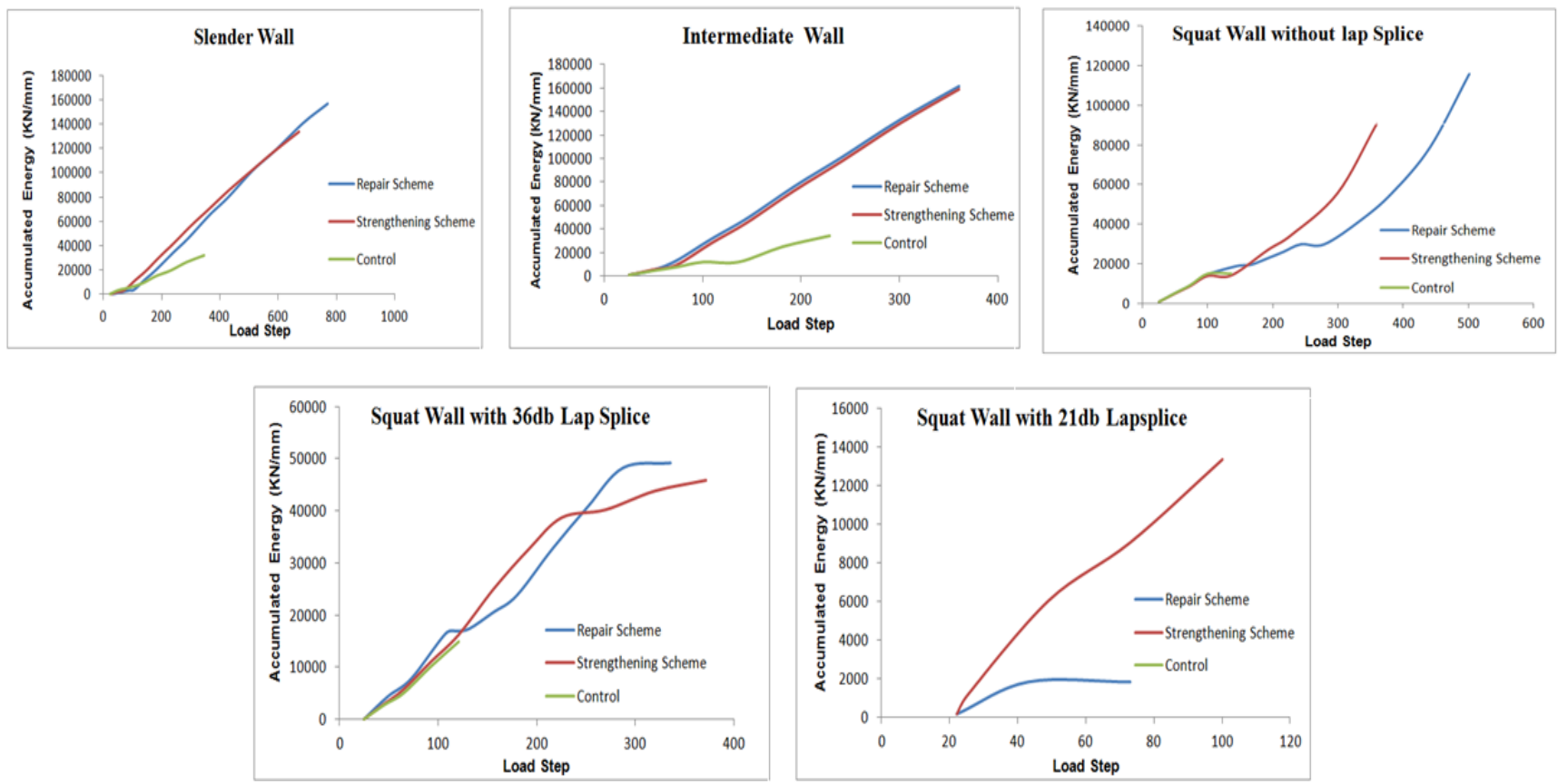

Figure 5.11: Energy dissipation curves for (Slender, Intermediate and Squat wall speciemns) with and without FRP. 


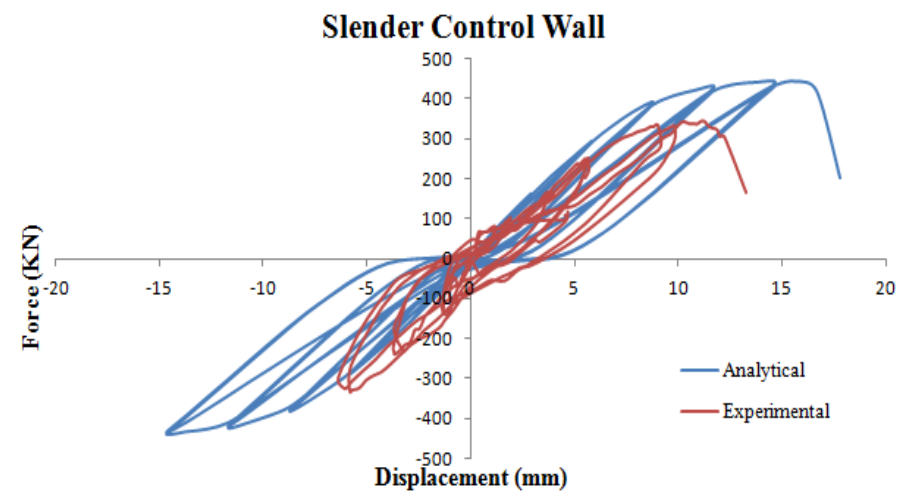

Figure 5.12: Comparison between analytical and experimental control slender wall specimens

Slender Strengthened Wall

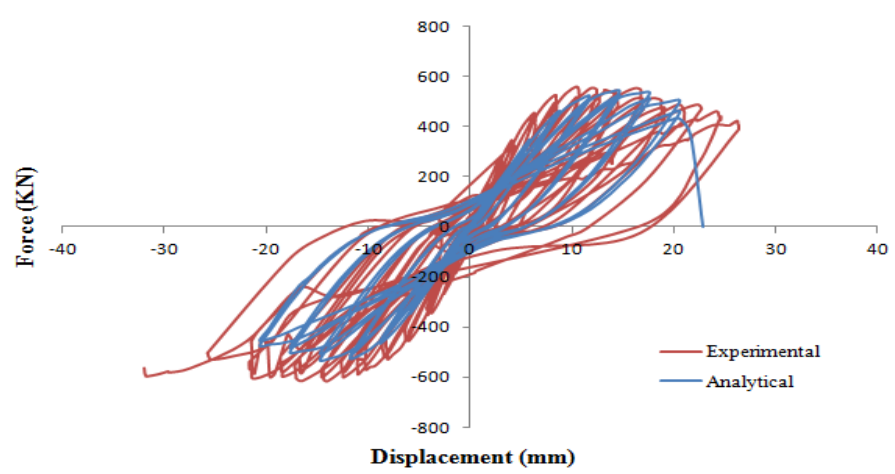

Figure 5.13: Comparison between analytical and experimental strengthened slender wall specimens

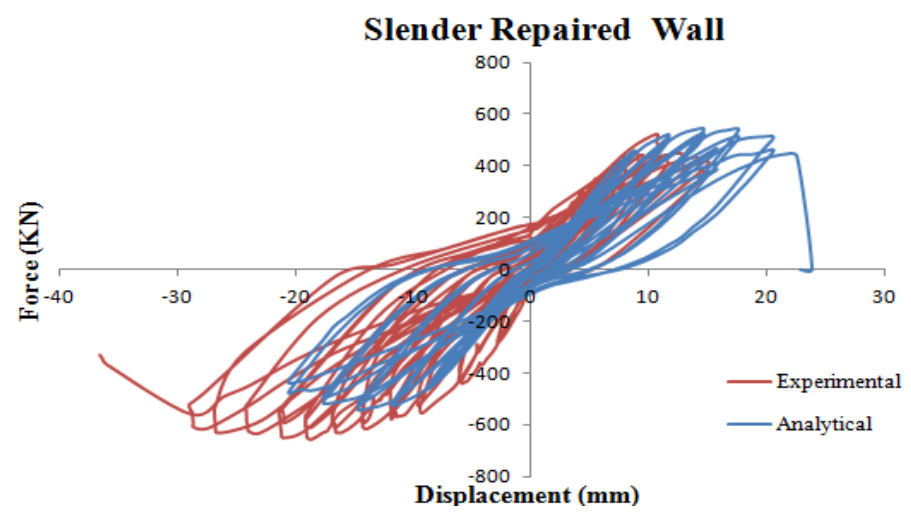

Figure 5.14: Comparison between analytical and experimental repaired slender wall specimens 


\section{Chapter 6}

\section{Summary and Conclusions}

\subsection{Conclusions and Recommendations}

This paper presents the finite element analysis of nine reinforced shear wall specimens designed according to old design specifications (ACI 1968, CSA 1977), and also includes analytical finite element models of deficient beam and shear wall structural elements. Macro-scale models are used to investigate lap splice behaviour in reinforced concrete shear walls and beams. The modelling methodology follows the usage of bond stress-slip relationships to relate lap splice behaviour to the surrounding concrete medium. Novel modelling techniques are introduced to model beam and wall specimens with lap spliced bars using the finite element program Vector2. Numerical results obtained from the analytical modelling show a good correlation with experimental data for both the load-displacement responses and for the overall failure mechanism. The conclusions that can be drawn from this study are the following:

- Finite element simulations show that the FRP system prevents brittle shear failure in the walls under study and enhances the seismic response thus facilitating a more ductile behaviour of the walls in comparison to their original state.

- FRP system is shown to increase the strength, stiffness, energy dissipation capability and ultimate displacements of the wall specimens.

- Retrofit of lap splice deficiency in reinforced concrete shear walls by the confinement effect of FRP retrofit scheme is shown to be effective. 
- The Harajli bond stress-slip model yielded close approximate results to various experimental data obtained from various studies in the literature.

- The usage of bond stress-slip relationships in numerical modelling of shear wall structures is validated and can be utilized in investigating future studies 


\section{List of References}

[1] ACI 318 (1968), "Building Code Requirements for Structural Concrete", American Concrete Institute, Detroit, Michigan, USA.

[2] ACI 318 (2005), "Building Code Requirements for Structural Concrete", American Concrete Institute, Farmington Hills, Michigan, USA.

[3] Antoniades, K. K, Salonikios, T. N., and Kappos, A. J. (2003). Cyclic tests on seismically damaged reinforced concrete walls strengthened using fiber-reinforcedpolymer reinforcement. ACIStructura] Journal 10(Á4), 510-518.

[4] Antoniades, K., Salonikios, T., and Kappos, A. (2003). "Cyclic Tests on Seismically Damaged Reinforced Concrete Walls Strengthened Using Fiber-Reinforced Polymer Reinforcement." ACI Struct. J. (100)4, 510-518.

[5] ACI 408R-03, "Bond and Development of Straight Reinforcing Bars in Tension", American Concrete Institute, Farmington Hills, Michigan, USA.

[6] CSA (1977), "Code for the Design of Concrete Structures for Buildings", CAN3-A23.3M77, Canadian Standard Association, Rexdale, Ontario, Canada.

[7] CSA A23.3 (2004), "Design of Concrete Structures", Canadian Standards Association, Rexdale, Ontario, Canada.

[8] Cruz-Noguez, C., Lau, D. T. and Sherwood, E. (2012), “Analytical modeling of reinforced concrete shear walls with externally-bonded CFRP reinforcement.", 6th International Conference on Advanced Composite Materials in Bridges and Structures, ACMBS-VI, Kingston, Ontario, Canada, May 22-25 2012 
[9] Cruz-Noguez, C., Lau, D. T., Sherwood, E., Lombard, J., Hiotakis, S. and Foo, Simon (2012), "Repair and strengthening of RC shear walls using externally-bonded FRP sheets.", 6th International Conference on Advanced Composite Materials in Bridges and Structures, ACMBS-VI, Kingston, Ontario, Canada, 2012.

[10] Cortés Puentes, L. (2009), "Nonlinear Modelling and Analysis of Repaired and Retrofitted Shear Walls." Master's thesis, Department of Civil and Environmental Engineering, University of Ottawa.

[11] Cho, J.Y. and Pinchiera, J. (2004), "Nonlinear Modelling of RC Columns with Short Lap splices",13th World Conference on Earthquake Enginerring, Vancouver, British Columbia, Canada, August 2004.

[12] Elnady, M. (2008), "Seismic Rehabilitation of RC Structural Walls." Phd Dissertation, Department of Civil and Environmental Engineering, McMaster University.

[13] Eligehausen R, Popov EP, Bertero VV (1983), "Local bond stress-slip relationships of deformed bars under generalized excitations, Rep. UCB/EERC-83/23." Univ of Calif Berkeley, 162 pp.

[14] Filippou FC, Popov EP, Bertero VV (1983), "Effects of bonddeterioration on hysteretic behavior of reinforced concrete joints." Rep. UCB/EERC-83/19, Univ. of Calif., Berkeley, 184 pp.

[15] Fiorato, A. E., Oesterle, R. G., and Corley, W. G. (1983). Behavior of earthquake resistant structural walls before and after repair. ACIJournal, 80(5), 403-413.

[16] Gan, Y., (2000), "Bond Stress and Slip Modeling in Nonlinear Finite Element Analysis of Reinforced Concrete Structures", M.A.Sc Thesis, University of Toronto, 251 pp. 
[17] Harajli M. H., Hamad B. S., Rteil A. (2004) "Effect of confinement on bond strength between steel bars and concrete." ACI Structural Journal 101(5): September-October, pp. 595-603.

[18] Harajli, M. H., (2006), "Effect of confinement using steel, FRC, or FRP on the bond stressslip response of steel bars under cyclic loading." Materials and Structures., 39, 621-634.

[19] Hiotakis, S. (2004). "Repair and Strengthening of Reinforced Concrete Shear Walls for Earthquake Resistance Using Externally Bonded Carbon Fibre Sheets and a Novel Anchor System." Master's thesis, Department of Civil and Environmental Engineering, Carleton University.

[20] Khalil, A. and Ghobarah, A. (2005). "Behaviour of Rehabilitated Structural Walls." J. of Earthquake Eng., (9)3, 371-391

[21] Lombard, J. (1999), "Seismic strengthening and repair of reinforced concrete shear walls using externally-bonded carbon fibre tow sheets", Master's thesis, Department of Civil and Environmental Engineering, Carleton University.

[22] Lombard, J., Lau, D., Humar, J., Foo, S. and Cheung, M. (2000), "Seismic strengthening and repair of reinforced concrete shear walls", Proceedings of 12th World Conference on Earthquake Eng., (CD-ROM), paper No. 2032.

[23] Layssi, H. and Mitchell, D. (2012), "Experiments on Seismic Retrofit and Repair of Reinforced Concrete Shear Walls",Proceedings of the $6^{\text {th }}$ International Conference on FRP Composites in Civil Engineering (CICE), June 13-15, 2012, Rome, Italy.

[24] Lu, X. Z., Teng, J. G., Ye, L. P., and Jiang, J. J. (2005). "Bond-slip models for FRP sheets/plates bonded to concrete." Eng. Struct., 27(6), 920-937. 
[25] Lu, X. Z., Teng, J. G., Ye, L. P., and Jiang, J. J. (2005). "Meso-scale finite-element model for FRP sheets/plates externally bonded to concrete.” Eng. Struct., 27(6), 564-575.

[26] Lu, X. Z., Teng, J. G., Ye, L. P., and Jiang, J. J. (2007). "Intermediate crack debonding in FRP-strengthened RC beams: FE analysis and strength model.” J. of Comp. for Constr., ASCE, (11)2, 161-174.

[27] Li, Z. J., Balendra, T., Tan, K. H., and Kong, K. H. (2005). "Finite element modeling of cyclic behavior of shear wall structure retrofitted using GFRP." Proceedings of $7^{\text {th }}$ International Symposium on Fibre-Reinforced Composite Reinforcement for Concrete Structures-FRPRCS-7, SP-230 Vol 1 (499-514). Kansas City, MO, USA:American Concrete Institution.

[28] Layssi, H. and Mitchell, D. (2012), "Experiments on Seismic Retrofit and Repair of Reinforced Concrete Shear Walls", Proceedings of the $6^{\text {th }}$ International Conference on FRP Composites in Civil Engineering (CICE), June 13-15, 2012, Rome, Italy.

[29] Meier, U., Deuring, M., Meier, H, and Schwengler, G. (1992), "Strengthening of Structures with CFRP Laminates: Research and Applications in Switzerland", Proceedings of the 1st International Conference on Advanced Composite Material in Bridges and Structures, Sherbrooke, Quebec, 243-251.

[30] Mander, J.B., Priestley, M.J.N., and Park, R. (1988), "Theoretical Stress-Strain Model for Confined Concrete", ASCE Journal of Structural Engineering, Vol. 114, No. 8, pp. 1804-1826.

[31] Melek, M., Wallace, J. W., and Conte, J. P. (2003), "Experimental Assessment of Columns with Short Lap Splices Subjected to Cyclic Load," PEER Report 2003/04, University of California, Berkeley. 
[32] Oesterle, R. G., Fiorato, A. E., Johal, L. S., Carpenter, J. E., Russell, H. G., and Corley, W. G. (1976). Earthquake-resistant structural walls - tests of isolated walls(Report to National Science Foundation). Skokie, IL, USA: Portland CementAssociation Engineering.

[33] Palermo, D., and Vecchio, F. J. (2002). "Behavior of three-dimensional reinforced concrete shear walls.”, ACI Structural Journal, 99(1), 81-89.

[34] Paterson, J. and Mitchell, D. (2003), "Seismic Retrofit of Shear Walls with Headed Bars and Carbon Fiber Wrap", Journal of Structural Engineering, ASCE, Vol. 129, No. 5, pp. 606614.

[35] Popovics, S. (1973), "A Numerical Approach to the Complete Stress-Strain Curve of Concrete", Cement and Concrete Research, Vol. 3, No.5, pp. 583-599.

[36] Sato, (2003). "Mechanical characteristics of the retrofitted members." Technical Rep. of the JCI Technical Committee on Retrofit Technology, 62-78.

[37] Shaheen, I. K., Cruz-Noguez, C .A., and Lau, D.T. (2013), "Seismic Retrofit of R.C. Shear Walls with Externally Bonded FRP Tow-Sheets", $3^{\text {rd }}$ Speciality Conference on Disaster Prevention and Mitigation, CSCE 2013, Montreal, Quebec, Canada, May $29^{\text {th }}-$ June $1^{\text {st }}$ 2013.

[38] Teng, J. G., Smith, S. T., Yao, J., and Chen, J. F. (2003). "Intermediate crack-induced debonding in RC beams and slabs.” Constr. Build.Mater., 17(6-7), 447-462.

[39] Wiradinata, S. (1985), "Behavior of Squat Shear Walls Subjected to Load Reversal", Master's thesis, University of Toronto, Toronto, Ontario.

[40] Vecchio, F. J., and Bucci, F. (1999), “Analysis of repaired reinforced concrete structures”, Journal of Structural Engineering, 123(6), 644-652. 
[41] Vecchio, F. J., and Lai, D. (2004), "Crack Shear-Slip in Reinforced Concrete Elements", Journal of Advanced Concrete Technology, Vol. 2, No. 3, pp.289-300.

[42] Wong, P. S., and Vecchio, F. J. (2002). VecTor2 and FormWorks user's manual (Publication No. 2002-02). Toronto, ON, Canada: University of Toronto, Department of Civil Engineering.

[43] Wong, S. Y., and Vecchio, F. J. (2003), "Towards modeling of reinforced concrete members with externally bonded fiber-reinforced polymer composites", ACI Struct. J., 100(1), 47-55. 
